\title{
REGULAÇÃO EMOCIONAL PELA ATENÇÃO: UM ESTUDO DE NEUROIMAGEM POR RESSONÂNCIA MAGNÉTICA FUNCIONAL
}

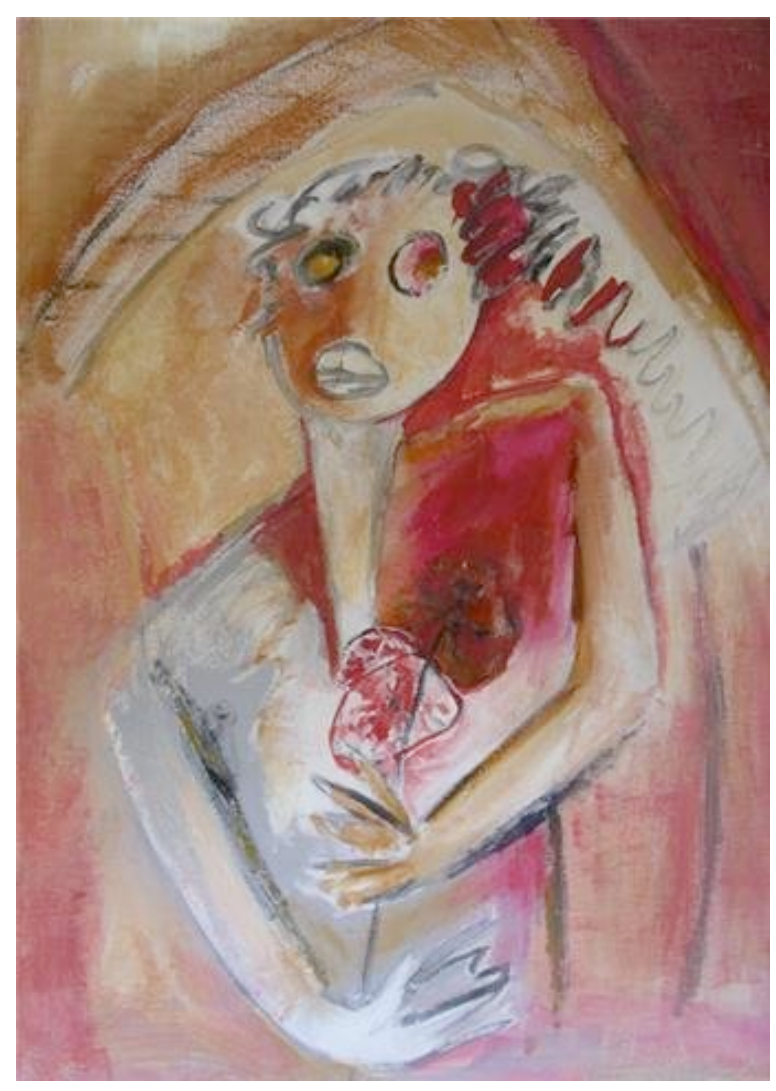

Tiago Arruda Sanchez

UNIVERSIDADE DE SÃO PAULO

Ribeirão Preto 


\section{UNIVERSIDADE DE SÃO PAULO}

REgulaÇão EMOCiONAL PELA ATENÇÃo: UM ESTUdO DE NEUROIMAgEM POR RESSONÂNCIA MAGNÉTICA FUNCIONAL

Tiago Arruda Sanchez

Tese Apresentada ao Departamento de Física e Matemática - FFCLRP, da Universidade de São Paulo, para a Obtenção do Título de Doutor em Ciências, Área: Física Aplicada à Medicina e Biologia.

Orientador: Prof. Dr. Dráulio Barros de Araújo

Ribeirão Preto 
Dedico este trabalho, com amor, à minha mãe Aparecida Arruda Sanchez. 

"Nesta idade de agora//Tempos mais tardios de outro$\mathrm{ra} / /$ Sou tanto quanto olhos, aos poucos, o que visei

Sou aos trancos e barrancos o caminho //Não títulos ou riquezas guardadas//Mais! A vida plena de sabedoria cultivada

Ouvidoria do saber de agora a cada instante//Tanto que palpita, palpita...//E continua o opinar verdejante

Ânsias nossas,//Ânsia da idade minha//Que tinha, ou trinta, na tinta.

Ânsias científicas,//Profissionais e Morais aos homens//Humanas, espirituais e existenciais às minhas

Desfio em análise //pio em silencio//...e Sôa ouvidos..." 



\section{Agradecimentos}

Aproveito aqui para registrar a minha gratidão a todos que, de alguma maneira, contribuíram para a minha formação humana e profissional e, consequentemente, para a gratificante conclusão deste trabalho de doutoramento.

Especialmente, agradeço a minha mãe, Aparecida Arruda Sanchez, e aos meus pai e avó (em memória), Valdemir Sanchez Morais e Lázara de Mattos Soares Arruda, pela criação e amor. Também, sou grato a todos os meus irmãos, por contribuírem para que a nossa criação se tornasse um ato alegre, responsável e, principalmente, amigável. Obrigado Tati, Rô, Di e Lipe!

Agradeço ao Prof. Draulio Barros de Araujo pela orientação e o exemplo, especialmente, pela oportunidade e pela confiança.

Sou grato, também, pela confiança e colaboração, da profas. Leticia de Oliveira e Mirtes Fortes. Agradeço, ainda, àqueles que também colaboraram neste trabalho, dentre eles, Izabela, Fátima, Mateus e Eliane Volchan do grupo de neurofisiologia do Rio; a Sandra da ressonância do HCRP; a Rita do centro de imagens do HCRP; o Élcio, o Eldereiz, o Aziani, o Serginho e a Nilza do DFM; todos os solidários voluntários que participaram dessa pesquisa; e, por fim, meus queridos amigos da USP de Ribeirão e do LabNec em Niterói.

Agradeço à minha bela e querida Isabela, pelo amor, apoio e dedicação na época que mais precisei.

Dentre todas as outras pessoas especiais que contribuíram e me deram apoio durante a realização deste doutorado, fico feliz por ter tido ótimos parceiros para as horas mais difíceis, os amigos do laboratório Neuroimago: Márcio, Fabiana, Kelley, Bruno, Khallil, Gisene, Carlos Estombelo, Hellen, Paula, Carlo... E obrigado a todos amigos da pós-graduação!

Sou grato ao querido Sérgio Mascarenhas, que me incentivou a procurar, até encontrar, uma colocação profissional de acordo com as minhas inspirações, numa física aplicada ao social, à medicina, à biologia e à psicologia, o que contribuiu para a beleza do meu trabalho.

E agradeço, também, a todos os ótimos professores que me educaram e foram exemplos para a minha formação humana. Gratidão especial à Ivanilda Higa, José Inácio Vasconcellos, Nelson Canzian e Kleber Daum Machado. 
Minha devoção a toda a "moçada" do pólo aquático, pela força "monster" e momentos de descontração: Guarú, 2 Gui's, 3 M’Ares, Callil, João, Andrew, Confete, Cicinho, Piru, Kléston, Beiço, e todos mais. Abraço, também, aos amigos do Café com Jung, da Rainha do Céu, do Orion, do Surf e a todos aqueles amigos que já passaram pela minha vida e que, eventualmente, ainda irão passar. Sou grato pela companhia e exemplo.

Por fim, gostaria de agradecer ao apoio financeiro fornecido pela CAPES e ao apoio institucional dado pelas instituições públicas de pesquisa, em especial, à Universidade de São Paulo, os quais fomentam a ciência, base imprescindível para o desenvolvimento do país. 


\section{ÍNDICE}

INTRODUÇÃO

EFEITO DA EMOÇ̃̃O SOBRE A ATENÇÃO............................................................................................. 1

RECURSOS DE PROCESSAMENTO DA ATENÇÃO.............................................................................. 2

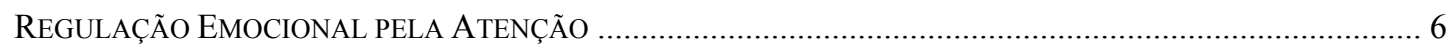

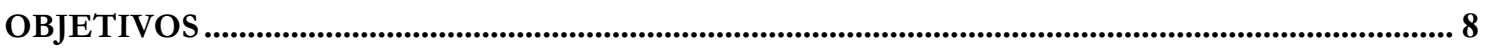

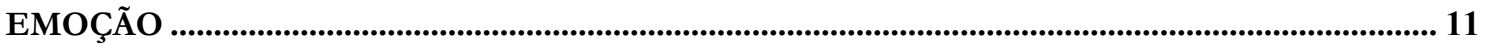

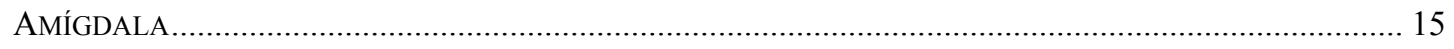

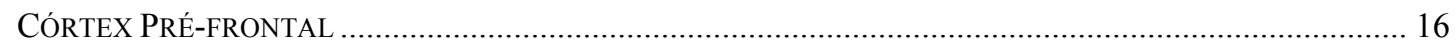

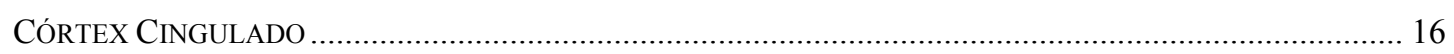

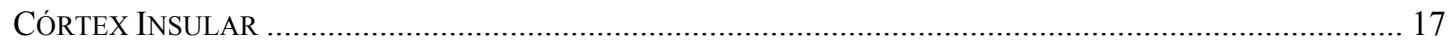

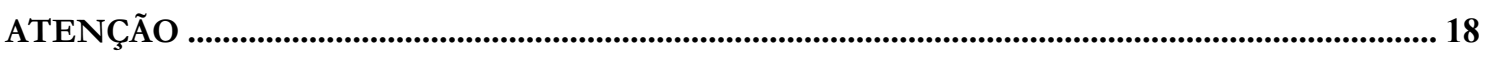

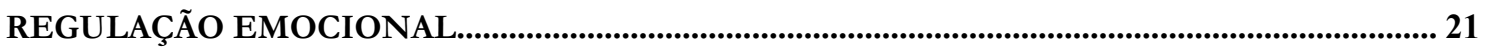

REGULAÇÃO DAS EMOÇÕES: DIFERENÇAS INDIVIDUAIS .................................................................... 25

RESSONÂNCIA MAGNÉTICA FUNCIONAL ..................................................................................... 27

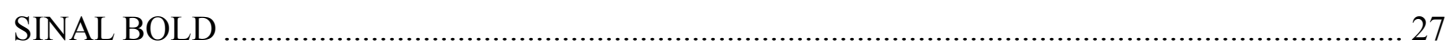

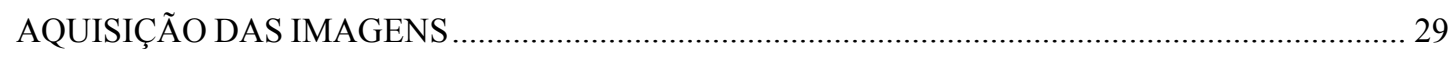

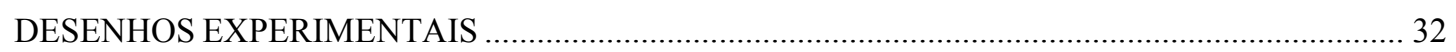

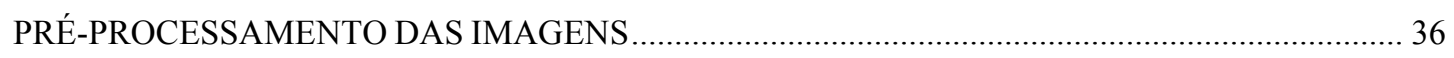

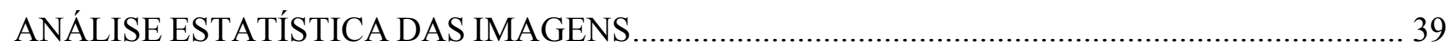

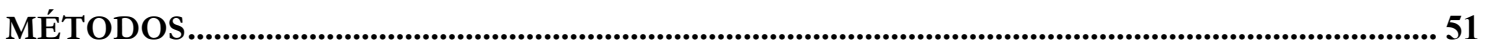

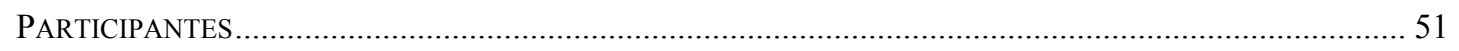

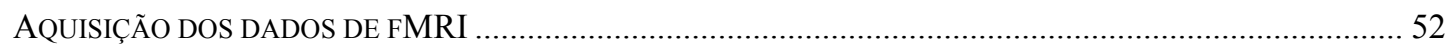

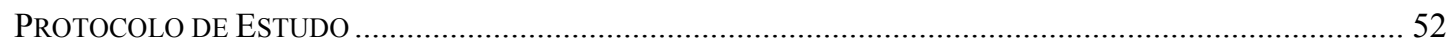

FMRI VOXEL-A-VOXEL DE CÉREBRO INTEIRO ………………....................................................... 57

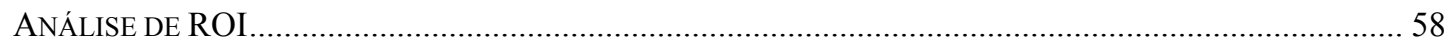




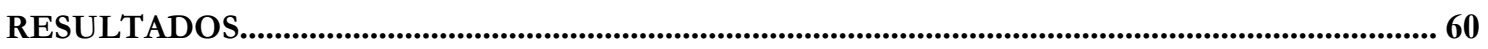

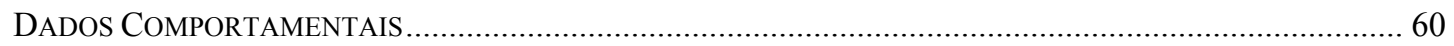

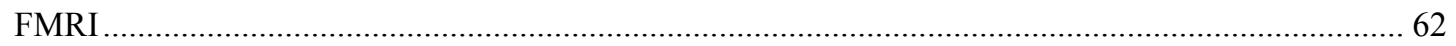

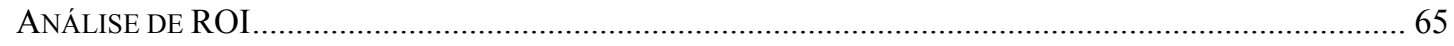

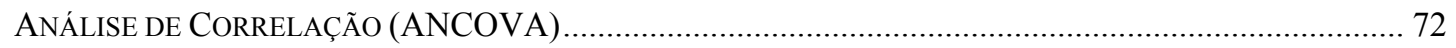

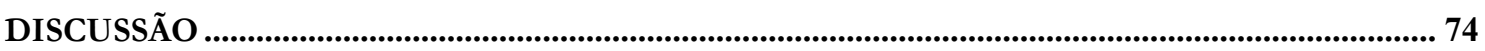

PROCESSAMENTO EMOCIONAL E DEMANDA DE ATENÇÃO............................................................... 75

EFEITO DA ATENÇÃO SOBRE O PROCESSAMENTO EMOCIONAL ……...................................................... 77

UMA HIPÓTESE ALTERNATIVA PARA A REGULAÇÃO PELA ATENÇÃO POR UM PROCESSO INIBITÓRIO .......81

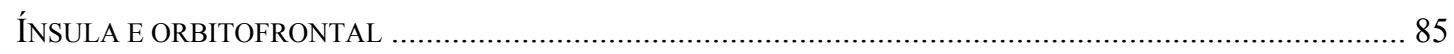

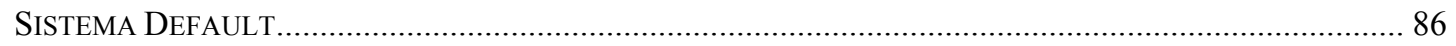

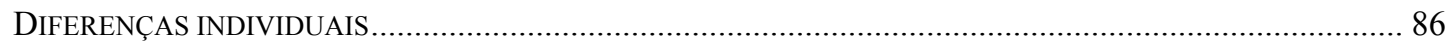

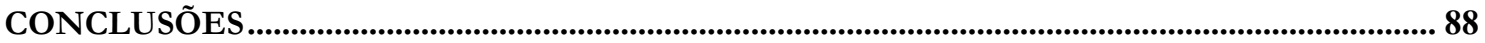

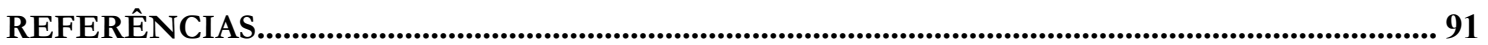




\section{RESUMO}

Apesar das evidências a favor da automaticidade no processamento de estímulos aversivos, especialmente na amígdala, a sua resposta parece ser dependente da disponibilidade de recursos atentivos. Dessa forma, a atenção pode atuar como um mecanismo de regulação emocional, importante para a compreensão de uma série de distúrbios psiquiátricos em que este mecanismo está prejudicado. Nesse estudo, investigamos o processo do regulação emocional pela atenção sob uma condição de grande demanda atentiva e com estímulos altamente aversivos. Imagens funcionais por ressonância magnética foram adquiridas de 22 voluntários saudáveis enquanto figuras emocionais (IAPS - International Afective Picture System), neutras e aversivas (corpos mutilados) eram apresentadas enquanto eles realizavam três tarefas diferentes, em que a atenção era manipulada. As imagens foram apresentadas no centro do campo visual, enquanto apareciam duas barras, uma de cada lado da figura. As três tarefas atentivas correspondiam a reconhecer: (1) a valência emocional da figura, (2) a semelhança na orientação das duas barras com diferenças de $0^{\circ}$ ou $90^{\circ}$ (tarefa fácil) e (3) a semelhança das mesmas com diferença de $0^{\circ}$ ou apenas $6^{\circ}$ (tarefa muito difícil). Nas análises de regiões de interesse (ROIs) observamos um padrão de regulação emocional, com dimuição da amplitude do sinal BOLD estimado, nas regiões da amígdala, ínsula anterior, cíngulo posterior e córtex pré-frontal medial, ventrolateral e orbitofrontal na tarefa fácil. Já na tarefa difícil, esse comportamento se manteve, com excessão do sinal da ínsula e do orbitofrontal, que voltou a subir, talvez, por um efeito de estresse. Verificamos uma maior amplitude do sinal BOLD na região dos córtices pré-frontal dorsolateral, parietal superior e área motora suplementar quando a atenção foi alocada para as tarefas de barras, supostamente, por um efeito da demanda maior de atenção. Nestes resultados, todo um conjunto de estruturas envolvidas no processamento emocional foi regulado pela manipulação da atenção nas tarefas. Também observamos uma correlação entre o traço de afeto positivo dos sujeitos e a estimativa do sinal BOLD da amígdala sob a regulação emocional. Estas evidências indicam que, mesmo para estímulos extremamente negativos, a disponibilidade de recursos de atenção e, talvez, mecanismos inibitório de controle cognitivos sobre a amígdala sejam fatores condicionantes da resposta emocional.

Palavras-chave: Neuroimagem Funcional, fMRI, Análise de ROI, Regulação Emocional, Atenção. 


\begin{abstract}
Because of the biological significance of emotional stimuli, their processing is considered largely automatic. However, there are also evidences that processing of emotional stimuli requires some level of attention. Higher attention demands in a task may limit emotional processing which can be interpreted as an emotion regulation strategy. Our experiments utilized highly demanding attention task while also highly aversive and arousing visual stimuli comprising mutilated bodies is presented. The experiment employed a single task, which consisted of determining whether two peripheral bars were like oriented or not, such to evaluate further brain mechanisms involved in emotion regulation by functional magnetic resonance imaging (fMRI). Our results revealed that task-irrelevant unpleasant images slowed reaction time during the performance of the main easy task, but not at highly demanding one which is suggesting of emotion suppression. Such modulatory effect was also revealed by ROI analysis showing that many brain regions, including regions of amygdala, anterior insula, posterior cingulate, and medial, ventrolateral and orbitofrontal prefrontal cortex have their processing of emotional visual stimuli reduced by attentional manipulations while there were BOLD signal increases in dorsolateral prefrontal and superior parietal cortex respective to attention demand. These results suggest that attentional manipulations that more fully consume attentional resources in order to demonstrate that the processing of emotional stimuli is limited.
\end{abstract}

Key words: Functional Neuroimaging, fMRI, ROI analysis, Emotion Regulation, Atention. 


\section{INTRODUÇÃO}

Interações recíprocas entre emoção, atenção e cognição tem, potencialmente, importantes implicações na compreensão dos transtornos psiquiátricos. Vários transtornos mentais, tais como o de ansiedade, podem ser parcialmente explicados por uma facilidade em engajar ou uma dificuldade em desengajar a atenção em situações emocionalmente negativas (Fox et al., 2001). Ainda, alguns transtornos mentais, incluindo ansiedade, fobia, transtorno de estresse pós-traumático, desordens obsessivo-compulsivas e depressão podem ser caracterizadas pela persistência de emoções negativas, em que a incapacidade de regular as emoções parece influenciar o desenvolvimento e manutenção destas doenças (Campbell-Sills et al, 2006; Taylor, 2007). Dessa forma, a interação entre os processos emocionais e atentivoscognitivos, assim como seus substratos neurais, constituem um atual desafio para a neurociência do comportamento e para a compreensão de transtornos psiquiátricos.

\section{EFEITO DA EMOÇÃO SOBRE A ATENÇÃO}

Estudos comportamentais mostram que existe uma captura preferencial da atenção pelas figuras emocionais de alta ativação (arousal, do inglês). Alguns estudos usam o estímulo emocional como alvo da atenção durante uma tarefa (Williams et al., 1996), enquanto outros usam o estímulo emocional como fator distrativo, irrelevante para a execução da tarefa alvo (Bishop et al., 2004). Apesar da detecção de sinais de ameaça ser facilitada quando a ameaça é irrelevante para um objetivo corrente, como no engajamento dos sujeitos em tarefas direcionadas, o sinal de ameaça serve como um distrator emocional e resulta em um efeito de interferência que compromete a performance dos sujeitos nas tarefas (Compton, 2003). Estímulos irrelevantes nas tarefas podem demonstrar um aspecto do processamento emocional que são particularmente importantes para a medida da atenção, relacionados ao efeito da interferência emocional. Nesses estudos, os estímulos devem ser ignorados porque eles não geram qualquer informação necessária à tarefa, porém eles podem requerer um recrutamento de recursos atentivos (Meinhardt and Pekrun, 2003; Mogg et al., 2000; Schupp et al., 2003). 
Em geral, quando as figuras emocionais são irrelevantes para a tarefa principal, observa-se que as latências no tempo de resposta são maiores para figuras emocionais em comparação às neutras, e, dentre as figuras emocionais, figuras negativas determinaram maiores latências em comparação às positivas. A hipótese é de que essas figuras são classificadas como mais interessantes e são observadas por períodos mais longos, além de serem melhor lembradas do que figuras neutras (Tipples e Sharma, 2000; Hartikinen et al., 2000). Schimmack e Derryberry (2005) propuseram que, de fato, a ativação emocional (arousal) seria o fator chave para explicar a capacidade de uma figura emocional engajar a atenção.

\section{RECURSOS DE PROCESSAMENTO DA ATENÇÃO}

Diversos trabalhos têm sugerido a existência de uma capacidade limitada de recursos de processamento da atenção (Lavie, 1995; Lavie et al., 2003; Lavie \& De Fockert, 2003; Lavie et al., 2004; Pinsk et al., 2004; Beck \& Lavie, 2005; Jenkins et al., 2005; Lavie, 2005; Maxwell et al., 2005; Pessoa et al., 2002a; Pessoa et al., 2005). Lavie (1995) propôs que a capacidade perceptiva é limitada, mas que a percepção ocorre automaticamente dentro desses limites. Em seus experimentos, Lavie e colaboradores demonstraram que a capacidade de uma tarefa relevante de exaurir recursos de processamento determinaria se estímulos irrelevantes, ou distrativos, seriam percebidos ou não. Dentro dessa perspectiva, se uma tarefaalvo possui uma baixa demanda de processamento, a atenção inevitavelmente se estende ao processamento de distrativos irrelevantes (Lavie \& Tsal, 1994; Lavie, 1995; Lavie et al., 2003; Lavie \& De Fockert, 2003, Beck \& Lavie, 2005; Lavie, 2005).

Rees e colaboradores (1997) testaram a percepção de estímulos visuais dinâmicos irrelevantes durante a realização de uma tarefa, utilizando fMRI e o tempo de reação como medida comportamental. Voluntários visualizavam uma tela sobre a qual palavras eram apresentadas no centro, e pontos brancos em movimento apareciam na periferia. Os participantes eram instruídos a atender às palavras e a ignorar os pontos durante todo o teste. $\mathrm{Na}$ condição de baixa demanda de atenção, a tarefa era apertar uma tecla caso a palavra aparecesse em letra maiúscula, e na condição de alta demanda, a tarefa era apertar uma tecla caso a palavra fosse dissílaba. A percepção do movimento foi avaliada comparando as condições em que os pontos se moviam, àquela em que eles permaneciam estáticos. Os resultados mostraram que sob condições de baixa demanda, os pontos em movimento produziam 
maior ativação da área V5 em comparação aos pontos estáticos, sugerindo que houve a percepção do movimento. Entretanto, sob condições de alta demanda, não houve aumento da atividade em V5 associada aos estímulos em movimento. Tais achados indicaram que sob condições de alta demanda os estímulos distrativos não foram processados, ou seja, a capacidade do indivíduo em ignorar um estímulo irrelevante foi determinada pela manipulação da demanda da tarefa.

A hipótese de que os estímulos não atendidos sejam menos processados reforça a importância da atenção para a percepção. De fato, evidências convergentes mostraram que a percepção de estímulos fora do foco atentivo pode ser atenuada ou mesmo eliminada sob certas circunstâncias (Lavie, 1995; Joseph et al., 1997; Rees et al., 1997; Simons \& Levin, 1997; Rensink et al., 1997; Mack \& Rock, 1998; Rensink, 2002; Pessoa et al, 2002a e 2002b). Estudos recentes mostraram que quando indivíduos têm sua atenção focalizada em um dado objeto ou evento relevante, falham em detectar a presença de outros estímulos mesmo que sejam salientes (Simons \& Chabris, 1999; Simons, 2000). Tal fenômeno, conhecido como cegueira atentiva (inattentional blindness, do inglês), pode ser interpretado com base na teoria da Lavie (Lavie \& Tsal, 1994; Lavie, 1995; Rees et al., 1997), em que a percepção de um estímulo pode não ocorrer em função do esgotamento de recursos na tarefa principal, impedindo o seu processamento.

Entretanto, alguns pesquisadores propuseram que uma exceção para o papel da atenção na percepção seja o processamento de estímulos emocionais, para os quais tem sido relatada a ocorrência de um processamento automático, independente da alocação voluntária da atenção (e.g. Vuilleumier et al., 2001; Vuilleumier, 2005; Anderson et al., 2003). Vuilleumier e colaboradores (2001) testaram os efeitos da atenção e da valência emocional sobre o processamento de faces utilizando fMRI. Eles manipularam o foco da atenção entre estímulos atendidos e não atendidos para verificar se o processamento de faces com expressão de medo poderia ocorrer mesmo quando a atenção dos sujeitos estivesse direcionada para uma tarefa de alta demanda de atenção. Os resultados mostraram que as respostas do giro fusiforme para faces eram fortemente manipuladas pela atenção espacial, ou seja, a ativação era maior quando as faces eram o alvo da tarefa. Entretanto, a resposta da amígdala esquerda para expressões de medo não foi afetada pela manipulação espacial da atenção, corroborando a hipótese de que seja uma estrutura cuja atividade independe do foco de atenção. 
Descobertas similares foram encontradas pela manipulação da atenção em estímulos sobrepostos, enquanto o foco espacial da atenção era mantido constante (Anderson et al., 2003). No estudo de Anderson e colaboradores (2003), as respostas da amígdala foram às mesmas para faces de medo, em condições atendidas ou não. A relevância biológica para tal processamento diferenciado seria explicada pela necessidade da detecção rápida de estímulos potencialmente perigosos (LeDoux, 1996).

Neste sentido, resultados de neuroimagem funcional têm mostrado que estímulos emocionais poderiam ativar regiões cerebrais automaticamente, independente do foco da atenção. Voluntários normais exibem respostas involuntárias rápidas para estímulos emocionais, principalmente quando eles estão relacionados ao perigo ou à ameaça, como faces expressando medo ou figuras aversivas (e.g. Lang et al., 1998; Morris et al., 1998; Whalen et al., 1998, Globisch et al., 1999; Öhman et al., 2001). Dessa forma, estímulos emocionais seriam sempre processados, mesmo que isso ocorra de maneira mais rápida e rudimentar por meio de vias neurais que não necessariamente envolvam o córtex cerebral e sistemas cognitivos de alta ordem (Öhman et al., 2001).

Morris e colaboradores (1998) mostraram que a amígdala tem a capacidade de ser ativada sem a necessidade de ocorrer a percepção consciente dos estímulos emocionais. Eles utilizaram a tomografia por emissão de pósitrons (Positron Emission Tomography - PET) enquanto os voluntários visualizavam faces com expressão de raiva que haviam sido associadas a um som desagradável, por condicionamento aversivo. Em metade dos testes, as faces de raiva eram mascaradas, ou seja, após 40 milisegundos, elas eram substituídas por uma outra face neutra, de modo que a percepção explícita das primeiras era impedida. Eles concluiram que existiria um processamento diferenciado dos estímulos emocionalmente relevantes, mesmo sem haver consciência dos mesmos.

Embora haja evidências para a hipótese de que o processamento de estímulos emocionais não necessita da alocação voluntária da atenção, outra linha de trabalhos questiona essa abordagem e sugere que o processamento neural dos mesmos requeira algum grau de atenção (Pessoa et al., 2002a, b; Pessoa, 2005; Pessoa et al., 2005). Assim, atualmente, duas frentes principais de discussão estão sendo estabelecidas a respeito da automaticidade no processamento da amígdala. Uma delas estabelece a idéia de que o processamento emocional, dado pela amígdala, é independente da viabilidade de recursos de processamento (Dolan e Vuilleumier, 2003), mesmo em resposta a estímulos não-atendidos (Vuilleumier et al., 2001; Williams et al., 2005), ou em resposta a um estímulo apresentado enquanto o sujeito 
está fora do seu estado de consciência (Morris et al., 1999; Pessoa et al., 2006) ou, ainda, em estudos de lesões cerebrais (Dolan e Vuilleumier, 2003; Pegna et al., 2004 apud Mitchell et al., 2007). Outra idéia propõe que o processamento de estímulos emocionais, tanto quanto estímulos neutros, requerem a viabilidade de recursos atentivos (Pessoa et al., 2002, 2005). Esta proposta recai sobre um modelo de atenção que supõe uma competição pela representação neural (Desimore e Duncan, 1995) e da teoria de demanda perceptual, que propõe a possibilidade de estímulos distratores irrelevantes poderem ser processados minimamente em cada tipo de tarefa (Lavie, 1995). Então, de acordo com Pessoa e colaboradores (2002, 2005), as expressões emocionais não estão imunes aos efeitos da atenção e devem também competir pela representação neural e, dessa forma, a atividade da amígdala deve ser suprimida se uma demanda suficiente de processamento neural for estabelecida sobre a atenção em uma tarefa cognitiva.

Pessoa e colaboradores (2002a) utilizaram fMRI para comparar a diferença da ativação neural entre faces neutras, alegres e com expressão de medo, e verificar como essas respostas eram moduladas pela atenção. Os voluntários fixavam seus olhos em faces que apareciam centralmente durante todo o experimento, as quais poderiam ser atendidas ou não. No bloco de "faces atendidas", os voluntários deveriam julgar o gênero das faces apresentadas, enquanto que no bloco de "faces não-atendidas" deveriam julgar a orientação de barras (igual/diferente) que apareciam perifericamente. Nos resultados, houve maior ativação da amígdala para as faces emocionais somente quando as faces eram o alvo de atenção, indicando que a ativação dessa estrutura para estímulos emocionais não deve ser automática, mas requer algum grau de atenção.

De forma mais simples, outros pesquisadores avaliaram o efeito da quantidade de atenção dispensada para estímulos emocionais pelo julgamento feito pelos participantes sobre as características emocionais ou perceptuais dos estímulos. Eles mostraram que na ativação da amígdala era menor quando os participantes precisavam avaliar as características emocionais de cenas aversivas, pois deviam prestavam mais atenção a elas, em comparação à visualização passiva destas (Taylor et al., 2003).

Posteriormente, Pessoa e colaboradores (2005) manipularam a demanda de atenção variando o nível de dificuldade na tarefa. Isso permitiu a comparação de respostas geradas por faces emocionais não atendidas enquanto a carga atencional na tarefa era modulada. O estudo também levou em consideração que a diminuição de respostas para estímulos emocionais não atendidos possa refletir a supressão ativa da amígdala durante a execução de 
tarefas não-emocionais demandantes (modulação cognitiva). Para avaliar tal modulação, os sujeitos realizavam uma tarefa central sem as faces emocionais. Pelos resultados, houve modulação na ativação da amígdala pelo foco de atenção: respostas mais robustas foram observadas quando as faces eram atendidas (tarefa de julgamento de gênero) em comparação à condição em que as faces eram não-atendidas (tarefa central de comparação da orientação entre barras). Criticamente, um efeito de valência foi observado na amígdala direita somente durante a condição de baixa demanda atentiva, mas não em tarefas de média e alta dificuldade. Adicionalmente à realização de uma tarefa não emocional, difícil por si só, associou-se à diminuição da atividade da amígdala, o que demonstra a importância da modulação cognitiva na atividade da amígdala. Em resumo, esse estudo mostrou que tanto a disponibilidade de recursos de atenção quanto a modulação cognitiva influenciam o processamento de faces emocionais não atendidas na amígdala (Pessoa et al., 2005).

Um trabalho similar, com dados comportamentais de tempo de reação, mostrou a importância da disponibilidade de recursos de atenção no processamento de estímulos emocionais. Erthal e colaboradores (2005) mostraram que a interferência promovida pelas figuras negativas sobre a tarefa de julgamento de barras só deixou de existir quando a tarefa a ser realizada tinha um nível de dificuldade "muito difícil", exigindo, portanto, um maior nível de engajamento da atenção em comparação às outras tarefas (Erthal et al., 2005). Os voluntários realizavam um teste de discriminação de orientação entre duas barras apresentadas na periferia do campo visual (julgamento igual ou diferente). $O$ grau de dificuldade da tarefa dependia da diferença de orientação entre as barras, com menores diferenças de angulação na situação mais difícil. Simultaneamente, uma foto distrativa era apresentada entre as barras. As fotos eram de pessoas (neutras) e de corpos mutilados (negativas). Nesse estudo, a interpretação é de que durante o desempenho da tarefa "muito difícil" não haveria recursos cerebrais disponíveis para o processamento efetivo do distrativo emocional, pelo fato dos mesmos estarem devotados para o desempenho de uma tarefa com alto grau de dificuldade.

\section{REGULAÇÃO EMOCIONAL PELA ATENÇÃO}

As evidências citadas anteriormente, de que é possível diminuir o impacto de um evento emocional pela diminuição da atenção devotada a ele, também podem ser interpretadas 
como um mecanismo de regulação emocional. Existem várias estratégias de regulação emocional propostas na literatura científica, uma delas diz respeito à diminuição da alocação da atenção para os estímulos emocionais (Ochsner \& Gross, 2005). Nesse sentido, o mecanismo de regulação da emoção pela atenção pressupõe que o fato de prestar menos atenção aos estímulos emocionais, ou às suas características específicas, modula o processamento nos sistemas neurais de avaliação emocional, envolvendo estruturas como a amígdala (Ochsner \& Gross, 2005; Pessoa et al., 2002b; Pessoa et al., 2005).

A diminuição de recursos de atenção para o processamento de um estímulo emocional também pode ser vista como uma estratégia de distração cognitiva. Embora a distração cognitiva seja um mecanismo amplamente utilizado no cotidiano, essa abordagem tem sido pouco estudada no contexto de experimentos envolvendo regulação da emoção. Recentemente, Erk e colaboradores (2006) investigaram o efeito da distração cognitiva durante a espera de eventos negativos (Erk et al., 2006). Essa idéia é embasada por estudos que mostraram que durante a antecipação de um evento negativo, existe a ativação da amígdala e córtex pré-frontal medial. A idéia central desses estudos é a de que a ativação de regiões associadas ao processamento emocional durante a antecipação do estímulo seria atenuada pelo aumento da demanda cognitiva da tarefa distrativa nesse período. Os resultados demonstraram que a distração cognitiva diminui a ativação cerebral associada à expectativa de um estímulo negativo na parte rostral anterior do córtex pré-frontal medial e na amígdala. Durante a antecipação, ambas as regiões apresentaram uma diminuição da atividade durante a tarefa de alta demanda, quando comparada com a de baixa demanda, estando de acordo com os achados de que o aumento da atenção em uma tarefa possa atenuar a ativação da amígdala (Pessoa et al., 2005).

Esta tese de doutorado foi elaborada para que pudesse abordar os diversos aspectos teóricos e experimentais das técnicas utilizadas em nossa pesquisa. Dessa forma, nas seções destinadas à fundamentação teórica, redigimos um capítulo para cada um dos tópicos téoricos abordados na tese, de emoção, atenção e regulação da emoção, assim como a descrição da técnicas de ressonânica magnética funcional. Posteriormente, as últimas 3 seções dessa tese foram destinadas à descrição dos métodos experimentais, aos resultados, discussões e, por fim, às conclusões da nossa pesquisa. 


\section{OBJETIVOS}

O objetivo mais geral desta tese era investigar de que forma os mecanismos de regulação da emoção influenciam o processamento afetivo, tanto do ponto de vista comportamental quanto neurofisiológico. Estávamos interessados em compreender melhor como o efeito de estímulos emocionais podem ser modificados por meio de uma estratégia de regulação emocional específica, baseada na redução de recursos de atenção para o processamento de estímulos emocionais (distração cognitiva) através da realização de uma tarefa de atenção de alta demanda.

Neste trabalho fizemos uma adaptação de protocolos já utilizados anteriormente (Pessoa et al., 2005; Erthal et al., 2005), de forma a observar as modulações neurais implicadas na regulação emocional pela atenção fazendo uso de estímulos emocionais de maior ativação (arousal) e uma tarefas que aumentassem ainda mais a demanda atentiva.

Investigamos o efeito do processamento atentivo sobre as emoções, comparando a modulação da atividade neural sobre o reconhecimento de figuras aversivas (mutilados) e durante a realização, concomitante, de tarefas (estímulos) cognitivas com diferenças de alocação e demanda da atenção. A hipótese inicial era de que as respostas da amígdala seriam moduladas pela demanda de atenção durante as tarefas e, também, queríamos verificar se um comportamento similar ocorreria em outras regiões cerebrais associadas ao processamento emocional. Ainda, esperávamos observar uma modulação de sinal BOLD em regiões associadas às demanda de atenção, como o córtex pré-frontal dorsolateral e parietal superior, maior à medida que a dificuldade na tarefa aumentasse. Já em uma análise de correlação dos dados de fMRI com outros dados dos voluntários, como a pontuação em escalas psicométricas, gostaríamos de avaliamos o quanto uma modulação da atividade da amígdala na condição de regulação emocional pela tarefa de atenção poderia ser explicada por essas características individuais. 


\section{OBJETIVOS ESPECÍFICOS}

- Investigar a influência de estímulos afetivos sobre o comportamento (tarefa de tempo de reação manual) em condições de regulação emocional.

- Mapear os circuitos neurais associados ao processamento afetivo em condições de regulação emocional, através da técnica de ressonância magnética funcional (fMRI).

- Investigar, por ressonância magnética funcional (fMRI) utilizando análises de ROI, os efeitos da regulação emocional pela atenção sobre o processamento cerebral de estímulos afetivos.

- Também observar, nas análises de ROI (fMRI), os valores do sinal BOLD estimado associados ao processamento atentivo.

- Correlacionar os valores estimados para o sinal BOLD em condições que representem a regulação emocional com os traços individuais dos voluntários, como os obtidos através de escalas psicométricas (PANAS, idate-T e questionário de mutilados-MQ), o desempenho comportamental nas tarefas (tempo de reação e taxa de erro) e o gênero de cada um. 



\section{FUNDAMENTAÇÃo TEÓRICA}

\section{CAPÍtULO 1}

\section{EMOÇÃO}

Apesar de terem características subjetivas e não determinísticas, as emoções e as sensações corporais associadas a elas também possuem padrões de mudanças motoras viscerais e somáticas estereotipadas que são de grande interesse científico. As emoções imprimem não somente "cor" à nossa percepção de mundo, mas, também, influenciam nossa vida social e a sobrevivência de uma forma geral. Além disso, muitos transtornos psiquiátricos envolvem alterações dos estados afetivos, que podem ser relacionados à dificuldade em lidar e controlar as emoções (Taylor et al., 2007; Thayer et al., 2000).

As mudanças comportamentais e fisiológicas associadas aos diversos tipos de emoções são fundamentais para a adaptação e a sobrevivência de todos os animais. Darwin já havia esboçado uma sistematização das principais mudanças corporais e faciais associadas às expressões emocionais em sua obra: "A expressão das emoções nos homens e nos animais" (Darwin, 2000). Mais recentemente, Paul Ekman mostrou que, de forma geral, pessoas de diferentes culturas e civilizações reconhecem facilmente algumas expressões faciais umas das outras (Ekman, 1999a). Assim, ele estabeleceu a idéia de que existem expressões emocionais básicas ou universais (Ekman, 1999b). Além disso, as mudanças fisiológicas durante a experiência emocional são tão diversas quanto as expressões corporais associadas a elas. Durante um processo emocional, podemos considerar que o conjunto de todas as respostas fisiológicas operam coordenadamente, como nas mudanças observadas nos sistemas nervoso e endócrino. Em neurofisiologia, as mudanças que descrevem o fenômeno emocional são estudadas, especialmente, no sistema nervoso central e periférico (somático e autonômico). 
Levando-se em conta a perspectiva evolutiva, as emoções evoluíram de respostas reflexas simples às mais complexas e variadas para facilitar a adaptação ao ambiente, como aquelas encontradas nos humanos. Em organismos muito primitivos, o comportamento emocional pode ser caracterizado por dois tipos básicos de respostas: a aproximação direta à estímulos apetitivos e a esquiva de estímulos nociceptivos. Dependendo da saliência do estímulo e do estado motivacional que este desencadeia, o esforço corporal aumenta ou diminui em intensidade para resultar em um comportamento de aproximação ou de esquiva. Estas duas características motivacionais do comportamento podem ser representadas por parâmetros de valência afetiva (positiva/negativa) e de intensidade de ativação (arousal, do inglês), os quais são definidos em um espaço hipotético bidimensional (Schneirla, 1966).

Em humanos, admite-se que esses dois comportamentos motivacionais (apetitivo e defensivo/aversivo) estariam associados à atividade cerebral e autonômica que variariam de acordo com a intensidade da ativação (arousal) (Lang, 2008). Ainda que nos humanos o comportamento emocional frequentemente seja mais criativo e menos previsível, muitas das respostas reflexas simples ainda fazem parte do repertório de respostas e, por meio do seu estudo, é possível compreender as bases neurofisiológicas e comportamentais desencadeadas por estímulos mais complexos.

De acordo com Lang e colaboradores (1995, 1997), o nível de ativação (arousal) dos sistemas motivacionais em humanos poderia ser avaliado pelas alterações corporais considerando-se os três sistemas modulados pelas emoções: (i) a linguagem expressiva e avaliativa; (ii) mudanças fisiológicas mediadas pelo sistema somático e autonômico; e (iii) as seqüelas comportamentais, tais como padrões motores de esquiva/aproximação ou benefícios/déficits de desempenho em uma tarefa. Entretanto, apesar de todos esses parâmetros serem valiosos para a avaliação das respostas emocionais, seu padrão específico varia de acordo com o contexto e a tarefa.

A abordagem neurofisiológica em estudos sobre as emoções tem uma longa história com o emprego de animais como modelo experimental que, pouco a pouco, foi incrementada com observações em humanos com lesões cerebrais, medidas eletrofisiológicas e estudos de neuroimagem funcional. Nessa história, muitos modelos já foram propostos, baseados nas evidências científicas encontradas na época. Dentre eles, citamos os principais, de James-Lange, Cannon, Papez, Bard, Mclean, LeDoux e Damasio. 
Paul Broca, em 1877, descreveu o "grande lobo límbico" ao estudar a anatomia comparada dos sulcos e giros dos cérebros de mamíferos. Ele descreveu o lobo límbico como sendo constituído pelos giros do cíngulo e parahipocampal, e a "fissura límbica" como sendo constituída pelos sulcos atualmente denominados sulco do cíngulo, sulco subparietal e sulco colateral. A adoção do termo límbico surgiu em função do seu significado do latim de "limbus" (margem, em torno de, orla, anel), uma vez que essas estruturas, presentes em todos os mamíferos, se situam em torno do topo do tronco encefálico.

Posteriormente, em 1937, James Papez foi o primeiro a propor o sistema límbico como sendo um sistema que participaria do controle das emoções, o que levou a um grande avanço na psicofisiologia da emoção. Ele propôs um circuito básico das emoções, conhecido como circuito de Papez, constituído pelo giro do cíngulo, giro parahipocampal, hipocampo, fornix, corpo mamilar, e núcleos anteriores do tálamo. Esta proposta veio a ser ampliada por Paul MacLean em 1949, quando ele propôs o conceito de cérebro visceral. MacLean defendia a idéia de que o cérebro visceral, constituído pelo rinencéfalo (estruturas e áreas olfatórias e paraolfatórias, giro do cíngulo, giro parahipocampal e hipocampo), fosse comum a todos os mamíferos e responsável pela regulação das funções básicas de ingestão de alimentos e água, alem da reprodução. Inicialmente, MacLean, assim como Papez, não reconheceu a contribuição prévia de Broca. Mas, em suas publicações subseqüentes, adotou o termo proposto pelo autor francês e criou o conceito de sistema límbico. Desde então, muitas outras pesquisas contribuíram para o aperfeiçoamento neuroanatômico e fisiológico do sistema límbico.

Apesar de terem surgido várias teorias acerca do sistema límbico, houve um consenso entre diversos autores de que o sistema límbico possui como estruturas principais os giros corticais, os núcleos de substância cinzenta e tratos de substância branca dispostos nas superfícies mediais de ambos os hemisférios e em torno do terceiro ventrículo que se relacionam, principalmente, com as emoções, a memória e, pela participação do hipotálamo, com a manutenção da homeostase.

Nas últimas duas décadas, surgiu uma grande quantidade de dados experimentais sobre vários aspectos da neurociência das emoções. Com isso, os modelos anatômicos e fisiológicos têm sido modificados e se tornado cada vez mais complexos. Atualmente, dentre os modelos neurais das emoções, é comum classificar as emoções em negativas e positivas. As emoções negativas, especialmente, estão baseadas em um modelo associado ao medo e são estudadas, em geral, na amígdala (Ledoux, 2000). 
$\mathrm{Na}$ linha de trabalho em que os estudos de Joseph Ledoux e colaboradores se destacam, sugere-se que a amígdala seja uma estrutura fundamental para a interação entre a entrada de estímulo sensorial e a emissão de respostas de medo. Na maioria destes estudos, testam-se as respostas condicionadas ao medo, principalmente, em ratos (Ledoux, 2000). Embora a amígdala possua várias subdivisões, aparentemente apenas duas são necessárias para o condicionamento de medo. Os estímulos ambientais chegam até o núcleo lateral da amígdala através do córtex e do tálamo. Por sua vez, o núcleo lateral ativa o núcleo central que desencadeia a expressão da resposta de medo. A existência de diferentes vias de projeções aferentes da amígdala sugere a existência de duas rotas de ativação da amígdala: a via rápida de projeção direta do tálamo e a via lenta, composta pela projeção do tálamo para o cortex e deste para a amígdala. A via rápida propicia à amígdala detectar estímulos ameaçadores rapidamente, ao contrário do processamento mais elaborado realizado pelo córtex. Dessa forma, a rota de processamento rápido confere uma vantagem biológica importante para o comportamento defensivo.

O córtex pré-frontal, em especial a região ventro-medial devido a sua conexão com a amígdala, possibilita associações entre experiências prévias e a expectativa do desencadeamento de eventos futuros de natureza emocional. O córtex pré-frontal ventro-medial é parte de um sistema executivo cerebral no qual o processamento de planos e a seleção de ações são viabilizados. Damásio e colaboradores criaram a hipótese do marcador somático na tentativa de explicar a tomada de decisão a partir de antecipações emocionais que, na maioria das vezes, podem ser inconscientes (Damásio, 1996). Nos últimos anos, eles desenvolveram esse modelo que, de certa forma, resgata a teoria de William James e Carl Lange sobre a importância das respostas corporais para as sensações emocionais. Estes pesquisadores enfatizam que as emoções, ao contrário do senso comum, não só não atrapalham as nossas decisões como, também, são fundamentais para que elas sejam ponderadas adequadamente. Conforme essa hipótese, antes da tomada de decisão, somos capazes de simular uma situação futura e, nesse processo, teríamos reações somáticas (corporais) que sinalizariam ao cérebro o nosso possível estado corporal naquela situação. Esse estado corporal seria construído com base em experiências anteriores, em situações análogas àquelas e que simularíamos mentalmente a cada momento.

Os trabalhos de Damásio e colegas, além de promover a hipótese do marcador somático, corroboram outros estudos que evidenciam a importância de algumas regiões corticais préfrontais em várias funções em que o processamento emocional está implicado, como na 
regulação das emoções (Thayer, 2000; Oschner \& Gross, 2005; Taylor, 2007), no comportamento afetivo e social (Damásio, 1996), na personalidade (Davidson, 2001), além de funções cognitivas como, por exemplo, a atenção (Ohman, 2001).

Em resumo, muitas estruturas cerebrais têm sido adicionadas ao sistema límbico clássico como possíveis mediadoras do processamento emocional, incluindo a amígdala e várias regiões corticais. A seguir, serão apresentadas algumas das estruturas de maior interesse para esta tese.

\section{$A M I ́ G D A L A$}

O complexo nuclear amigdalóide, ou simplesmente amígdala, é uma estrutura cerebral fundamental para a integração de informações sensoriais às respostas emocionais, compotamentais e fisiológicas, especialmente para estímulos que sinalizam ameaça. Assim como o próprio nome diz, ela é uma estrutura complexa, composta por vários núcleos distintos, localizada no pólo do lobo temporal e medialmente abaixo do córtex. Em geral, os núcleos são dividos em três agrupamentos: basolateral, córticomedial e central. As vias aferentes da amígdala têm origens diversas, entre elas o neocórtex, o giro parahipocampal e o córtex cingulado. Os sinais dos sistemas sensoriais, exceto o olfatório, são enviados para a amígdala pelo complexo basolateral. A conexão da amígdala com o hipotálamo é feita por dois grandes feixes, que são a estria terminal e a via amigdalofugal ventral (Ribas, 2007).

Lesões no lobo temporal tem sido associadas às mudanças drásticas no comportamento emocional. Experimentos envolvendo a remoção bilateral do lobo temporal de macacos e, posteriormente, com lesões seletivas bilaterais da amígdala descrevem sintomas como: falha no reconhecimento visual de objetos (agnosia visual), diminuição da reatividade emocional (animais sem medo e menos agressivos), aumento do comportamento exploratório, e mudanças na dieta.

Também, a amígdala é necessária para o desenvolvimento de resposta defensiva condicionada, já que uma lesão da amígdala impede o condicionamento (LeDoux, 2000). Conforme mencionado anteriormente, LeDoux propôs a existência de duas vias de ativação da amígdala: uma rápida, de projeção direta do tálamo (subcortical), e outra lenta, composta pela projeção do tálamo para o córtex e deste para a amígdala (LeDoux, 2000). Estudos em hu- 
manos, principalmente portadores de lesão na amígdala, revelam indícios fisiológicos similares aos ocorridos em animais. O condicionamento do medo é comprometido em pacientes com lesão bilateral da amígdala (Damasio, 1996). Nos estudos por neuroimagem funcional é possível verificar respostas da amígdala associadas ao estabelecimento do condicionamento de medo, mesmo se o estímulo for subliminar (processados inconscientemente) (Morris, 1999).

Ainda, pacientes com lesões na amígdala não conseguem apresentar aumento da atenção sob a influência de estímulos emocionais (Anderson e Phelps, 2001). Isto parece ser reflexo da interação da amígdala com áreas de representação sensorial. Então, a amígdala parece estar envolvida em um mecanismo capaz de salientar as representações sensoriais de relevância emocional, o que repercute no impacto destas representações sobre a orientação da atenção.

\section{CÓRTEX PRÉ-FRONTAL}

O cortex pré-frontal é a porção anterior do lobo frontal e é definido anatomicamente por estar localizado à frente do córtex motor e pré-motor no lobo frontal e pelo fato de receber projeções do tálamo dorsomedial. Apesar da grande extensão anatômica e functional do córtex pré-frontal, de forma geral, ele tem sido sempre relacionado a processos cognitivos complexos e que dão suporte à regulação da emoção, memória, atenção e toda capacidade de planejamento de ações mentais ou corporais, assim como a previsão das suas consequências. Em relação às regiões pré-frontais mais relacionadas ao processamento emocional, há maiores evidências da participação do cortex órbitofrontal e do córtex pré-frontal ventromedial, especialmente por terem conexões diretas com a amígdala. Entretanto, outras regiões pré-frontais também são citadas em trabalhos com estimulação emocional, como os córtices pré-frontais medial e ventrolateral.

\section{CÓRTEX CINGULADO}

A porção anterior do giro do cíngulo tem sido associada a tarefas cognitivas ou emocionais e durante estimulação dolorosa. A hipótese mais aceita é a de que essa região cerebral tenha 
uma participação importante na detecção de conflitos. Tanto dor física decorrente de lesão corporal, quanto um sofrimento social ou, ainda, conflitos cognitivos, parecem compartilhar os mesmos recursos cerebrais. Esse sistema de detecção, estaria envolvido na seleção de informações ambientais que possam por em risco a sobrevivência, como em casos de danos físicos ou sociais, e pelo recrutamento da atenção e de recursos corporais para minimizar o perigo.

\section{CÓRTEX INSULAR}

O córtex insular, comumente chamado de ínsula, está localizado no fundo e nas margens do sulco lateral do cérebro e tem função central na interocepção. Nesse sentido, a ínsula participa do recrutamento da atenção sobre os estados corporais internos e, consequentemente, da elaboração da sensação dos estados emocionais subjetivos. A ínsula parece codificar sensações corporais como sensações viscerais e musculares (por exemplo:,fome, sede, dor, atividade vasomotora e temperatura). A porção anterior da ínsula, participa da mediação do conhecimento explícito da representação visceral que um estímulo emocional pode provocar e parece ter participação na elaboração neural da sensação de si mesmo ( self) (Damásio, 1996).

Redes neurais envolvendo a ínsula e o cíngulo anterior parecem possibilitar a formação de representações subjetivas de sentimentos relativos a nós mesmos ( self) e, também, fundamentar a nossa capacidade de avaliar a importância emocional de determinado estímulo, extendendo a avaliação às outras circunstâncias e prevendo consequências a si mesmo e a outras pessoas. Tais mecanismos também dão suporte à nossa capacidade de empatia emocional, que deve ter se especializado evolutivamente a partir de mecanismos mais simples de representação de nossos estados corporais internos e emocionais subjetivos. 


\section{CAPÍtulo 2}

\section{ATENÇÃo}

Uma definição de atenção vastamente considerada na literatura é a proposta por William James (James, 1890) que, em suas palavras, descreve: "It (the attention) is the taking possession by the mind, in clear and vivid form, of one out of what seems several simultaneously possible objects or trains of thought. Focalization, concentration of consciousness are of its essence. It implies withdrawal from some things in order to deal effectively with others."

Outra teoria da atenção é a teoria do filtro, proposta por Broadbent. Segundo o autor, a atenção agiria selecionando, ou filtrando, as informações que chegam ao indivíduo, pela retenção de alguns elementos e deixando passar outros. Ainda hoje, a teoria do filtro é utilizada para explicar como se dá a seleção de um dado estímulo em meio a uma enorme quantidade de informação do ambiente, a cada instante.

A atenção pode ser vista como um estado orgânico que afeta a receptividade geral para as entradas sensoriais. Assim, é possível selecionar uma posição do espaço, uma característica física, ou uma forma. O item selecionado tem, então, maior probabilidade de afetar a consciência, memória ou comportamento do que outros itens apresentados simultaneamente (Posner, 1980; Posner \& Petersen, 1990). Um outro sentido para atenção envolve a seleção de alguma informação para tratamento especial (Desimone \& Duncan, 1995). De acordo com essas definições, o direcionamento da atenção visual para um determinado objeto ou local produz melhor capacidade de processamento e de análise do mesmo e, por outro lado, implica em detrimento dessa capacidade para outros objetos e locais do campo visual.

Uma metáfora bastante utilizada na literatura para definir atenção sugere que esta possa ser considerada como um holofote varrendo o espaço. As regiões iluminadas pelo holofote teriam um nível de processamento mais elaborado do que as regiões que se encontram fora da área iluminada. Segundo essa visão, a atenção permitiria que uma determinada informação atingisse um nível elevado de processamento e ao mesmo tempo evitaria que outras informações, para as quais não se presta atenção, atingissem o mesmo nível de processamento. 
Trabalhos clássicos demonstraram que prestar atenção a um local do espaço diminui o tempo necessário para perceber e responder a um estímulo visual. Esse princípio está de acordo com as idéias mais recentes de atenção, segundo as quais a atenção facilitaria, de maneira mais rápida e acurada, a percepção de objetos que aparecem na cena visual. Além disso, Slotnick e colaboradores demonstraram que, além de facilitar o processamento dos itens atendidos, ocorre inibição ativa dos itens não-atendidos no campo visual. Esses autores, utilizando a técnica de Ressonância Magnética Funcional (Functional Magnetic Resonance Imaging - fMRI), monitoraram a atividade neural nos córtices estriado e extraestriado e observaram que havia uma inibição em regiões visuais que representam partes do campo visual para as quais a atenção não era alocada (Slotnick et al., 2003).

Como vimos, a modulação do processamento das entradas sensoriais é realizada por mecanismos atentivos. Basicamente, a atenção é necessária para a representação explícita de um estímulo e a discriminação de eventos sensórios (Posner \& Petersen, 1990). Entretanto, existe evidência de que um certo grau de processamento, pré-atentivo, pode existir independente da atenção ou da percepção consciente do estímulo, o que deve servir para guiar a atenção, preferencialmente, para outros eventos salientes (Merikle, 2001). 



\section{CAPÍTULO 3}

\section{REGULAÇÃO EMOCIONAL}

A regulação das emoções pode ser entendida como o processo pelo qual os indivíduos conseguem modular suas emoções (Gross, 1998). Assim, a regulação emocional inclui todas as processos explícitos ou implícitos para manter, aumentar, ou diminuir um ou mais componentes da resposta emocional. (Gross, 1998; Gross, 2002; John \& Gross, 2004; Ochsner \& Gross, 2005). Essa habilidade influencia diretamente o comportamento e a expressão da emoção, o que é fundamental para a interação social (Lopes et al., 2005). Então, podemos imaginar que a capacidade cognitiva de auto-regular as emoções pode ter sido fundamental para a evolução das características sociais da espécie humana, sobre os quais os sistemas sociais estão construídos (Porges, 1997; Gross, 2002; Lopes, 2005).

A forma como os indivíduos regulam suas emoções afeta seus relacionamentos e o seu bem-estar. A habilidade de regular emoções tem um papel importante não somente no desenvolvimento de relações sociais, mas também, na promoção da saúde mental (Gross \& Munoz, 1995). Por exemplo, alguns transtornos mentais podem ser caracterizadas pela persistência de emoções negativas, em que a incapacidade de regular as emoções parece influenciar o desenvolvimento e manutenção das mesmas (Campbell-Sills et al, 2006; Taylor, 2007).

Lazarus e colaboradores foram os primeiros a estudar os efeitos da cognição na experiência e regulação das emoções (Lazarus \& Alfert, 1964; Lazarus et al., 1965). No estudo de 1965, Lazarus e colaboradores observaram que a manipulação do tipo de avaliação cognitiva feita sobre um filme poderia alterar as medidas fisiológicas evocadas pelo conteúdo emocional presente no filme. Os resultados mostraram que o grupo controle apresentou os valores de freqüência cardíaca e condutância de pele mais altos, indicativos de uma resposta emocional maior, do que o grupo de sujeitos que eram orientados a "intelectualizar" o conteúdo emocional, enfatizando a importância de informações verbais na habilidade de reduzir respostas a estressores (Lazarus et al., 1965).

Dentre os principais estudos para explicar o processo de geração da emoção e os mecanismos de regulação subjacentes, Gross e colaboradores desenvolveram um modelo baseado 
em diferentes estratégias de regulação conforme o momento em que elas surgem durante os processos de geração da emoção (Gross, 1998; Gross, 2002). Neste modelo, as emoções teriam início com a avaliação de pistas emocionais de origem interna ou externa. Quando avaliadas, as pistas disparariam um conjunto de respostas emocionais que envolveriam sistemas fisiológicos, comportamentais e de sensações subjetivas. Uma vez determinadas as tendências às respostas emocionais, estas poderiam ser moduladas de várias maneiras. A modulação daria a forma final à resposta emocional manifestada. Então, pelo modelo de Gross, as estratégias de regulação da emoção poderiam ser distinguidas conforme o momento em que elas surgem durante os processos de geração da emoção, de duas formas principais: antecedente ou focada na resposta.

Segundo Gross e colaboradores, a regulação antecedente consiste em modificar a própria situação em que um estímulo emocional poderia surgir ou, então, mudar a maneira pela qual o evento é avaliado, alterando seu impacto antes do estabelecimento das respostas emocionais. A regulação antecedente consiste em estratégias como: a seleção da situação, a modificação da situação, a modificação cognitiva e a alocação da atenção (Gross, 2002). Já a regulação focalizada na resposta, como o próprio nome diz, é uma estratégia que visa a modificação das respostas emocionais, após as tendências de resposta às emoções já terem se instalado. Gross e colaboradores (Gross \& Levenson, 1993; Gross, 2001, Gross, 2002) definem esta estratégia de regulação como de supressão emocional, em que o indivíduo procura inibir um comportamento ou uma reação fisiológica que expresse a resposta emocional evocada. Neste caso, a emoção já foi instalada e, então, o indivíduo procura inibir as respostas emocionais de maneira que as outras pessoas não percebam o que ele está sentindo.

Os trabalhos atuais têm investigado a relação entre distintas estratégias de regulação e suas conseqüências comportamentais e fisiológicas. As estratégias de regulação produzem resultados diferentes conforme, principalmente, o momento em que atuam no processo de geração da emoção. Por exemplo, a suprimir a expressão de uma emoção, provoca reações diferentes daqueles mecanismos cognitivos, como reinterpretar a situação em que aquela emoção é evocada. A supressão das emoções negativas pode limitar a expressão destas, mas não consegue diminuir a experiência desagradável e, ainda, provoca um aumento da ativação do sistema nervoso simpático. Em contraste, uma regulação cognitiva neutraliza a experiência negativa e pode diminuir a ativação fisiológica (Lazarus et al., 1965; Gross \& Levenson, 1993; Butler et al., 2003; Ochsner \& Gross, 2001). 
Lewis \& Stieben (2004) questionaram se a regulação da emoção deveria ser identificada como algo independente, ou seja, como um processo distinto da ativação emocional [Lewis \& Stieben, 2004]. Nesse caso, se a regulação emocional pudesse ser identificada e medida independentemente da emoção propriamente dita, essa distinção também deveria ser observada no cérebro. Devemos considerar, então, que a regulação é intrínseca a toda atividade neural relacionada à emoção e que, por sua vez, está associada às mudanças de padrão da atividade cerebral. Entretanto, não é simples estabelecer quando um estágio termina e quando o outro começa. Cole e colaboradores (2004) definiram a regulação emocional de uma forma simples: ela seria caracterizada pelas modificações das emoções já ativadas por algum estímulo afetivo. Assim, essas mudanças seriam definidas como um segundo estágio de atividade, que se segue ao estágio inicial de ativação emocional.

Tendo em vista as diferentes estratégias e mecanismos acionados para modular ou regular a experiência emocional, os estudos recentes sobre a regulação das emoções, associados às técnicas de neuroimagem funcional, têm permitido identificar os correlatos neurais desses mecanismos. Há uma série de evidências do envolvimento do córtex pré-frontal na regulação da emoção (Davidson, 2000; Davidson et al. 2000; Ochsner \& Gross, 2005; Goldin et al, 2008; Wager et al, 2008). O recrutamento de regiões frontais está associado à modulação da atividade da amígdala, uma estrutura crítica para a geração e expressão de emoções negativas (Urry et al., 2006; Phan et al., 2005; Hariri, Mattay, Tessitore, Fera, \& Weinberger, 2003; Schaefer et al., 2002; Hariri, Bookheimer, \& Mazziotta, 2000). Portanto, o mecanismo subjacente à regulação da emoção seria possível via um circuito préfrontal-amígdala (Wager et al.,2008).

Os trabalhos que investigaram os circuitos neurais associados à regulação da emoção em humanos revelaram um padrão de funcionamento cerebral que salienta a importância de algumas estruturas frontais por meio de um controle inibitório sobre estruturas mais diretamente relacionadas ao processamento de estímulos emocionais (exemplos na figura 1), como a amígdala (Davidson et al., 2000). O envolvimento de múltiplas áreas frontais durante a regulação emocional e sua relação com a atividade da amígdala tem levantado a questão de como, exatamente, e quais as regiões específicas do córtex pré-frontal embasariam os distintos aspectos de regulação da emoção, bem como as possíveis vias e conexões entre as estruturas apontadas. Estas hipóteses continuam sob investigação. 


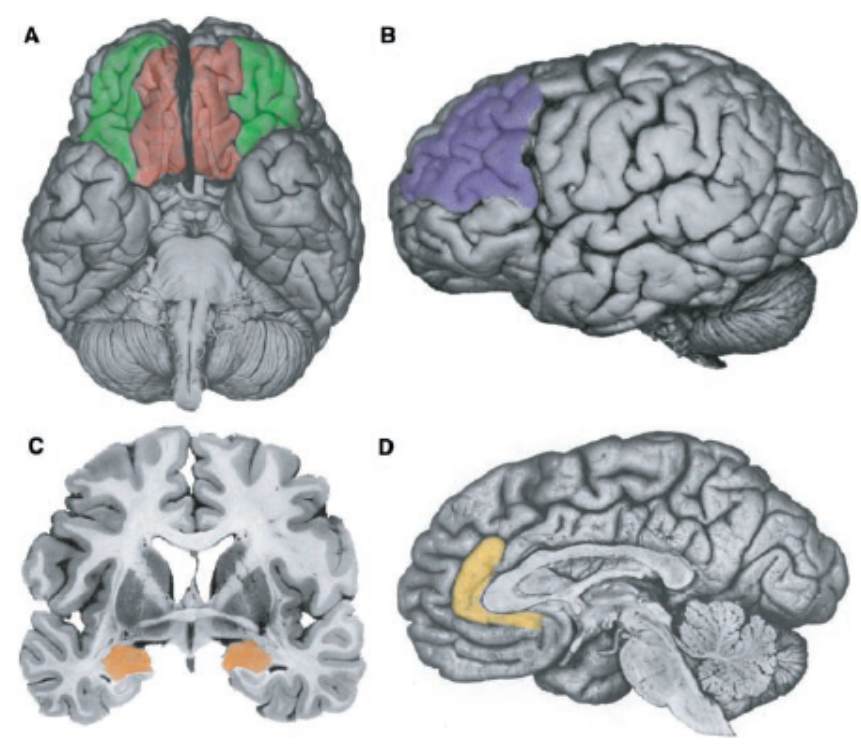

Figura 1: Estruturas provavelmente envolvidas na regulação emocional. (a) Córtex orbitofrontal em verde e córtex pré-frontal ventro-medial em vermelho. (b) Córtex pré-frontal dorsolateral. (c) Amígdala. (d) Córtex cingulado anterior. Cada uma dessas estruturas desempenha um papel nos distintos aspectos da regulação da emoção. (Davidson et al., 2000).

A maior parte dos trabalhos que utilizaram a estratégia de reavaliação cognitiva observou um padrão de ativação cerebral caracterizado por uma ativação significativa do córtex préfrontal nas regiões dorsal e lateral associada à diminuição da ativação da amígdala, sugerindo que o primeiro poderia estar modulando sua atividade via mecanismos inibitórios, descendentes (top-down, do inglês) (Ohira et al., 2006; Ochsner \& Gross, 2005; Phan et al., 2005; Ray et al., 2005; Ochsner et al., 2004; Ochsner et al., 2002; Levesque et al., 2003; Levesque et al., 2004; Beauregard et al., 2001). Por exemplo, em um estudo desenvolvido por Ochsner e colaboradores (2004), o córtex pré-frontal foi mais recrutado durante as estratégias de regulação da emoção em que os sujeitos tentavam diminuir o impacto emocional das figuras e a amígdala apresentou uma diminuição de sua ativação nessa situação. Essa hipótese está de acordo com os trabalhos em animais e humanos que mostram que o córtex pré-frontal é importante para a extinção do medo condicionado (Morgan et al., 1993; Morgan \& LeDoux, 1999), ou seja, é possível que o córtex pré-frontal exerça uma inibição importante sobre a amígdala para controlar as respostas emocionais.

Uma vez que o córtex pré-frontal parece ser fundamental para as estratégias de regulação da emoção, podemos imaginar que os pacientes com lesão nessa estrutura tenham dificul- 
dade em adequar suas respostas emocionais ao contexto social. Na verdade, essa é uma descrição comum feita por pessoas que convivem com esses pacientes. De acordo com a proposta de Damásio e seu grupo, esses pacientes não conseguem antecipar as conseqüências emocionais de seus atos (Eslinger et al., 1992; Damásio et al., 1990; Damásio, 1996; Bechara et al., 2000). Portanto, é possível supor que vários distúrbios psiquiátricos possam estar relacionados com uma disfunção no córtex pré-frontal e sua capacidade de modular a atividade de estruturas sub-corticais tais como a amígdala.

\section{REGULAÇÃO DAS EMOÇÕES: DIFERENÇAS INDIVIDUAIS}

Os indivíduos diferem em sua habilidade de regular emoções, de forma que alguns escolhem estratégias mais bem-sucedidas que outros. Assim, em estudos de regulação da emoção, é importante considerar as diferenças individuais como um fator que influencia os dados experimentais. Alguns trabalhos mostram que as diferenças entre indivíduos em dimensões como traço e estado afetivo (Oliveira et al., 2003), níveis de ansiedade (Mauss et al., 2003) e perfil de assimetria de ativação hemisférica (Jackson et al., 2003) parecem influenciar sua capacidade de regular as emoções.

Trabalhos recentes têm sugerido que essas diferenças individuais interagem fortemente com o contexto em questão, de forma a modificar o comportamento afetivo (Goldsmith \& Davidson, 2004). Em uma revisão recente, Lazarus discute como as emoções podem ser compreendidas levando-se em consideração as diferenças individuais e aponta para o fato de que a forma com a qual os indivíduos lidam com os eventos estressantes seja fundamental na determinação do seu bem-estar (Lazarus, 2006).

As diferenças individuais típicas levam a questionamentos sobre os mecanismos de regulação emocional, no que se refere às estruturas e ao funcionamento dos seus substratos neurais. Por exemplo, em um estudo por ressonância magnética funcional, com o objetivo de identificar os substratos neurais envolvidos na regulação voluntária da emoção, Phan e colaboradores (2005) apontam para uma possível dissociação das respostas cerebrais corticolímbicas, envolvendo aumento da ativação do córtex pré-frontal e atenuação de áreas límbicas, durante a supressão voluntária da emoção negativa. Nos resultados, a inibição da emoção negativa esteve associada com a ativação dos córtices cingulado anterior, préfrontal dorso-medial e pré-frontal lateral e com a atenuação da atividade cerebral nas regi- 
ões límbicas (núcleo acumbens e amígdala estendida). Os voluntários tinham os níveis subjetivos do seu afeto negativo mensurados (pontuação na escala PANAS) que, posteriormente, foram correlacionados com a atividade cerebral. Nesta análise, a ativação no córtex cingulado anterior se correlacionou inversamente com a intensidade do afeto negativo vivenciado pelos voluntários, enquanto que a ativação da amígdala se correlacionou positivamente com o afeto negativo, o que indica uma possível relação entre o traço comportamental e os correlatos neurais.

Em uma análise da relação entre a ativação cerebral durante uma estratégia de reavaliação e as diferenças individuais em um traço comportamental, Ray e colaboradores (2005) mostraram que as diferenças individuais no traço comportamental se correlacionaram com a ativação da amígdala e de regiões pré-frontais conforme os sujeitos procuravam regular suas respostas emocionais. Dessa forma, uma propensão menor à regulação emocional, medida por uma escala psicométrica, foi interpretada como uma alteração no recrutamento de mecanismos que potencializam o afeto negativo. Esses achados colaboram com o esclarecimento das relações entre certos traços psicológicos e processos de regulação da emoção, tendo importantes implicações para transtornos de humor e ansiedade. 


\section{CAPÍtulo 4}

\section{RESSONÂNCIA MAgNÉTICA FUNCIONAL}

A técnica de imagem por ressonância magnética, magnetic resonance imaging (MRI), a partir do desenvolvimento de seqüências de pulso mais rápidas e a descobertas de processos fisiológicos que podem gerar contraste endógeno nessas imagens, possibilitou estudar alguns aspectos das funções cerebrais em humanos. A imagem funcional por ressonância magnética, functional magnetic resonance imaging (fMRI), tem obtido um papel de destaque dentre todas as técnicas de mapeamento funcional, por seu caráter não-invasivo, e a grande prevalência de tomógrafos de ressonância em instituições hospitalares e de pesquisa. Além disso, essa técnica tem oferecido uma melhora substancial da resolução espaço-temporal comparado a qualquer outro método não-invasivo (Logothetis, 2002).

Nesta seção serão descritos os aspectos básicos da técnica de fMRI, como o mecanismo de contraste endógeno utilizado, a aquisição das imagens, os desenhos experimentais, as técnicas de pré-processamento e, por fim, os métodos de análise.

\section{$\operatorname{SINALBOLD}$}

Em 1936, Linus Pauling demonstrou que a hemoglobina apresenta diferentes propriedades magnéticas dependendo do seu estado de oxigenação. Quando a hemoglobina está ligada a uma molécula de oxigênio (oxi-hemoglobina), ela apresenta comportamento diamagnético e, quando não está ligada ao oxigênio, ela se torna paramagnética (deoxi-hemoglobina) e sua susceptibilidade magnética aumenta cerca de $20 \%$. Com isso, o estado de oxigenação da hemoglobina é capaz de alterar a relaxação transversal T2* do sangue e, consequentemente, o sinal por ressonância magnética (Thulborn et al., 1982).

Em 1990, Ogawa e colegas chegaram à descoberta do contraste BOLD (Blood-oxigenationlevel dependent). Eles avaliaram o efeito da manipulação da proporção de deoxihemoglobina no sangue, do fluxo sanguíneo e do metabolismo cerebral sobre o sinal dos vasos em imagens ponderadas em T2* e, por fim, demonstraram uma diminuição de sinal ao redor das 
imagens do sangue desoxigenado (Ogawa et al., 1990a). Em outro trabalho (Ogawa et al., 1990b), eles manipularam a inalação de gases em ratos com diferentes níveis de anestesia, controlaram a diminuição da atividade cerebral deles por eletroencefalografia (EEG) e, também, verificaram que quanto mais anestesiados os ratos estavam, menor era a alteração do sinal nas imagens. Para avaliar o efeito do fluxo sanguíneo, eles compararam duas condições: inalação de 100\% de oxigênio e inalação de uma mistura com 90\% de oxigênio e 10\% de CO2. Considerando que o CO2 é um agente vasodilatador cerebral, sua presença causou aumento do fluxo sanguíneo global que, sem aumento da demanda metabólica, levou a uma redução do contraste BOLD.

O contraste BOLD está relacionado ao aumento inicial de consumo de oxigênio, devido atividade neural, que altera a concentração entre oxi-hemoglobina e deoxi-hemoglobina (Maloneck \& Grinvald, 1996) e que, também, é seguido pelo aumento desproporcional do fluxo sanguíneo cerebral (Fox \& Raichle, 1986). Então, uma combinação de fatores associa, indiretamente, a atividade neural ao contraste BOLD. Contudo, tanto a causa do aumento desproporcional de fluxo sanguíneo em resposta a um estímulo neural, quanto o mecanismo que relaciona o fluxo sanguíneo à atividade neural, permanecem controversos (Huettel et al., 2004).

Muitos modelos têm sido propostos buscando relacionar as alterações hemodinâmicas e metabólicas ocorridas em resposta ao aumento da atividade neural (Kim \& Ugurbil, 1997; Buxton et al., 1998; Van Zijl et al., 1998). Esses modelos têm sido testados experimentalmente e refletem a evolução temporal do sinal de ressonância (alteração de brilho nas imagens ao longo do tempo). A representação da evolução temporal do sinal BOLD recebe o nome de Função da Resposta Hemodinâmica (Hemodynamic Response Function - HRF).

O modelo canônico da HRF é composto por sete fases distintas (Figura 2). Logo após a apresentação do estímulo (fase A da figura), a resposta decresce por um breve intervalo de tempo. Esse padrão (fase B) não é observado consistentemente em todo tipo de estímulo, sendo mais prevalente no córtex visual. Após a depressão do sinal, ele inicia uma etapa de sinal BOLD positivo anterior (fase C), atingindo um máximo, usualmente após 7 a $10 \mathrm{~s}$. Permanecendo em um platô por poucos segundos (fase D), o sinal tende, então, a decrescer, iniciando um efeito BOLD positivo posterior (fase E). Esse decréscimo é comumente seguido por uma nova depressão do sinal, negativo com respeito à linha de base (chamado, do inglês, post-undershoot). Por fim, o sinal retorna a valores comparáveis aos da linha de base inicial (Frahm et al., 1996; Buxton et al., 1998; Logothetis et al., 1999). 


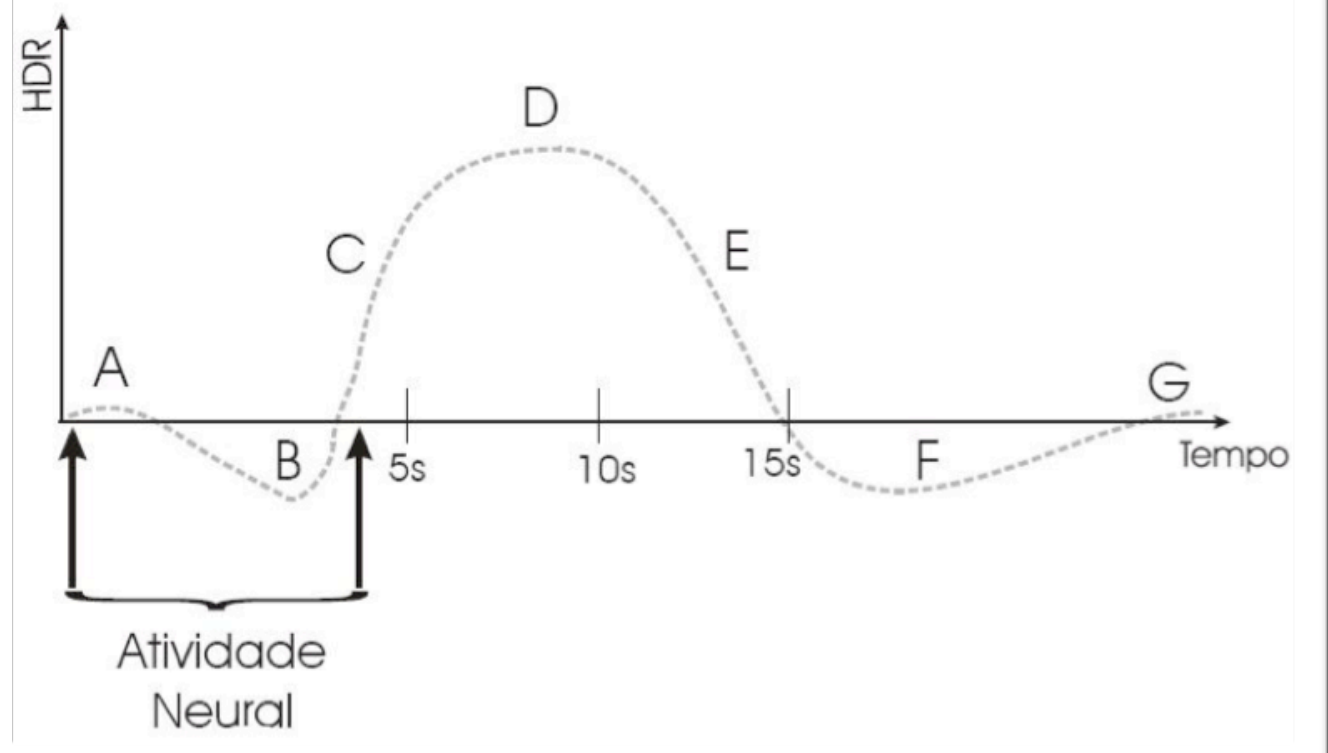

Figura 2: Representação da resposta hemodinâmica (HRF), composta por sete fases distintas: logo após a apresentação do estímulo(A); a resposta decresce por um breve intervalo de tempo (B), padrão mais observado no córtex visual; ela inicia uma etapa de aumento do sinal BOLD até atingir um máximo (C), usualmente após 7 a $10 \mathrm{~s}$; permanecendo em um platô por poucos segundos (D); então, o sinal tende a decrescer (E); seguido por uma nova depressão do sinal (F), negativo com respeito à linha de base (post-undershoot); e, por fim, o sinal retorna a valores comparáveis aos da linha de base inicial $(\mathrm{G})$.

\section{AQUISIÇÃO DAS IMAGENS}

A MRI é uma técnica capaz de gerar imagens em fatias de algum órgão ou tecido biológico, como o cérebro, a partir de características dos sinais de ressonância. A formação dessas imagens envolve, indiretamente, o mapeamento espacial de características físico-químicas distintas dos tecidos pela aplicação de seqüências de pulsos bem específicas.

Primeiro, é necessário entendermos que qualquer imagem digital é formada por um número finito de elementos, sendo cada um desses elementos denominado pixel. O tamanho da imagem pode ser indicado pelo número de pixels contidos nela. Além disso, cabe acrescentar que cada pixel tem, associado a ele, um valor indicativo de intensidade daquele ponto, que, no caso de MRI, refere-se à intensidade do sinal adquirido para uma dada unidade de volume da amostra, chamada de voxel. Podemos, então, considerar que a resolução espacial de uma imagem é dada pela capacidade de distinguirmos dois pontos vizinhos. Isto pode 
ser controlado pelo número de pixels, ou voxels. Quanto menor o voxel, ou volume que se consegue adquirir um sinal, maior será a resolução espacial da imagem. A qualidade de uma imagem também é reflexo do número de voxels que cobre uma dada região do espaço ou campo de visão (do inglês, Field of View - FOV).

O contraste de uma imagem refere-se à representação gráfica e é definido pelas diferenças de intensidades entre uma região e outra. O contraste pode ser entendido como a capacidade de se localizar uma estrutura conforme diferenças na intensidade de brilho da imagem desta estrutura em relação ao brilho de estruturas vizinhas.

A vasta maioria dos estudos por fMRI utiliza seqüências que baseiam seus contrastes nas diferenças de susceptibilidade magnética entre os tecidos em razão do efeito BOLD. A fim de obter as imagens com uma resolução temporal razoável, capazes de acompanhar os eventos fisiológicos subjacentes, vários volumes do cérebro são adquiridos seqüencialmente. Para tanto, é necessária a utilização de seqüências de pulsos rápidas como a imagem ecoplanar (do inglês, echo-planar imaging - EPI). No entanto, para ganhar resolução temporal, essas imagens possuem baixa resolução espacial. Com essa estratégia, a medida repetida de um mesmo ponto da imagem (usualmente conhecido por voxel - sigla do inglês para volume element) forma uma série temporal, que é caracterizada pela evolução do valor de brilho da imagem ao longo do exame. A resolução temporal é, pois, o intervalo de tempo entre aquisições sucessivas do mesmo voxel.

Um exame típico em fMRI é dividido em duas partes. Em um primeiro momento, são adquiridas as imagens funcionais, que resultam nos mapas estatísticos da atividade cerebral após as análises da série temporal de cada voxel. Nessa primeira parte, a série de imagens é gerada pelas seqüências do tipo EPI e, em geral, são compostas de diversas fatias para cobrir todo o cérebro (figura 3). No intuito de melhorar a qualidade dos resultados, deve haver um número razoável de aquisições dessas imagens. Em seguida, um segundo conjunto de imagens é obtido com maior resolução espacial, com voxels em torno de $1 \mathrm{~mm}^{3}$, que são ditas anatômicas, e servem de substrato para a apresentação dos mapas estatísticos. 


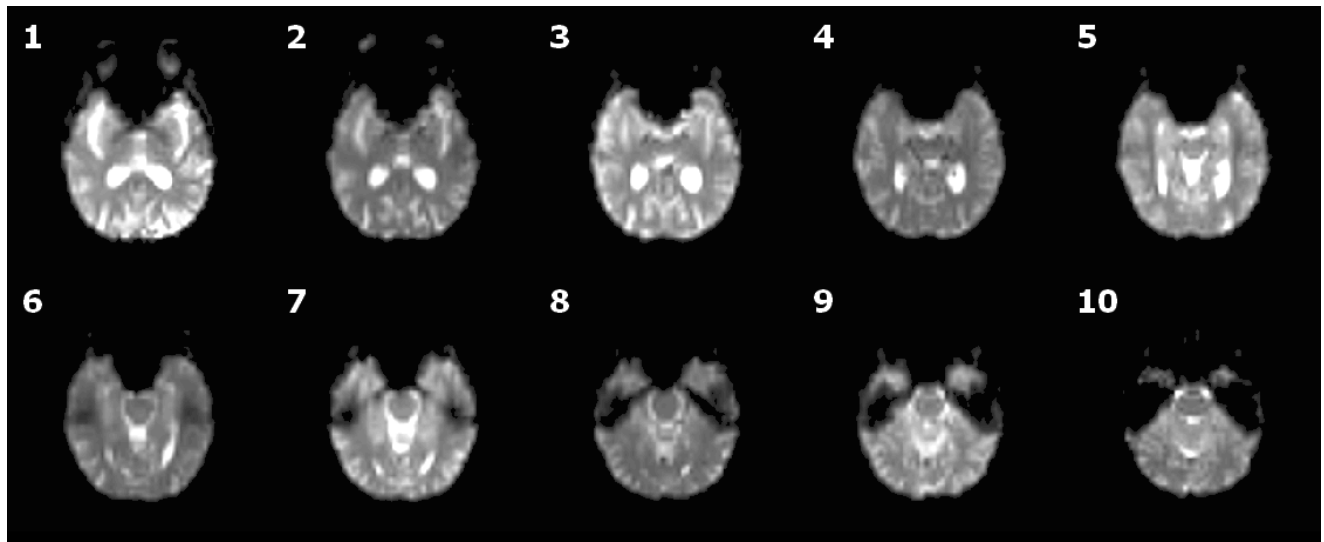

Figura 3: Exemplo de imagens do volume cerebral dividido em 10 fatias, adquiridas por uma seqüência EPI. Pela EPI, é possível fazer uma aquisição rápida de várias fatias do volume cerebral. No entanto, perde-se resolução espacial das imagens às custas deste ganho de resolução temporal.

Para avaliar alguns aspectos da função cerebral, durante a aquisição das imagens EPI do volume cerebral, o sujeito deve realizar uma tarefa de interesse, ou é estimulado por uma via sensitiva. Por exemplo, para o mapeamento da uma função motora, a tarefa pode ser abrir e fechar a mão, intercalada por períodos de repouso em que não se mexe a mão (figura 4). Existem desenhos experimentais mais complexos, em que o protocolo de estimulação visa avaliar respostas hemodinâmicas de sistemas neurais mais complexos, como aquelas das funções cognitivas. 


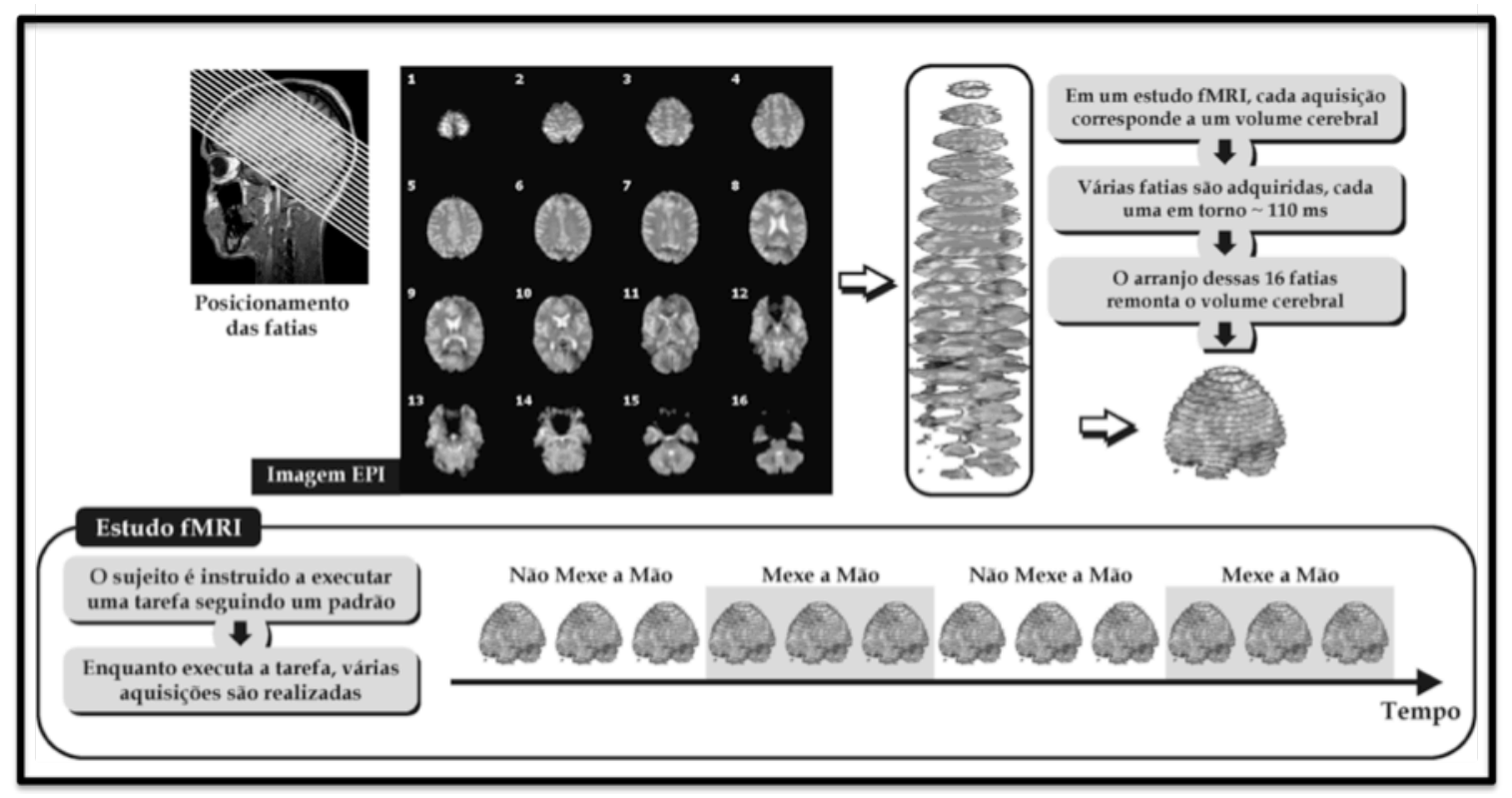

Figura 4: Exemplo de um experimento de fMRI sobre uma atividade motora. No estudo, vários volumes são adquiridos ao longo do tempo. Enquanto as imagens são adquiridas, o sujeito executa uma tarefa pré-estabelecida, como mexer a mão em determinados períodos, com o objetivo de modular o sinal BOLD (figura de Chaim, 2008).

Considerando a pequena amplitude do contraste BOLD, que pode chegar a cerca de 5\% em máquinas de 1,5 T, muitos fatores podem influenciar e confundir a análise das imagens. Para minimizar o efeito de fatores como baixa relação sinal-ruído, movimentação, ruídos fisiológicos e variabilidade anatômica entres os sujeitos, é importante que o protocolo experimental seja cuidadosamente desenhado e as ferramentas de pré-processamento apropriadamente utilizadas.

\section{DESENHOS EXPERIMENTAIS}

Qualquer experimento deve ser adequadamente planejado em todas as suas etapas, muito antes da entrada do voluntário no equipamento. O planejamento deve incluir desde o desenho experimental para a forma de apresentação dos estímulos, até a escolha do método de análise que será adotado. De modo geral, o protocolo experimental de estimulação segue 
desenhos bastante específicos baseados em dois tipos principais, o desenho em bloco e o evento-relacionado (figura 5).

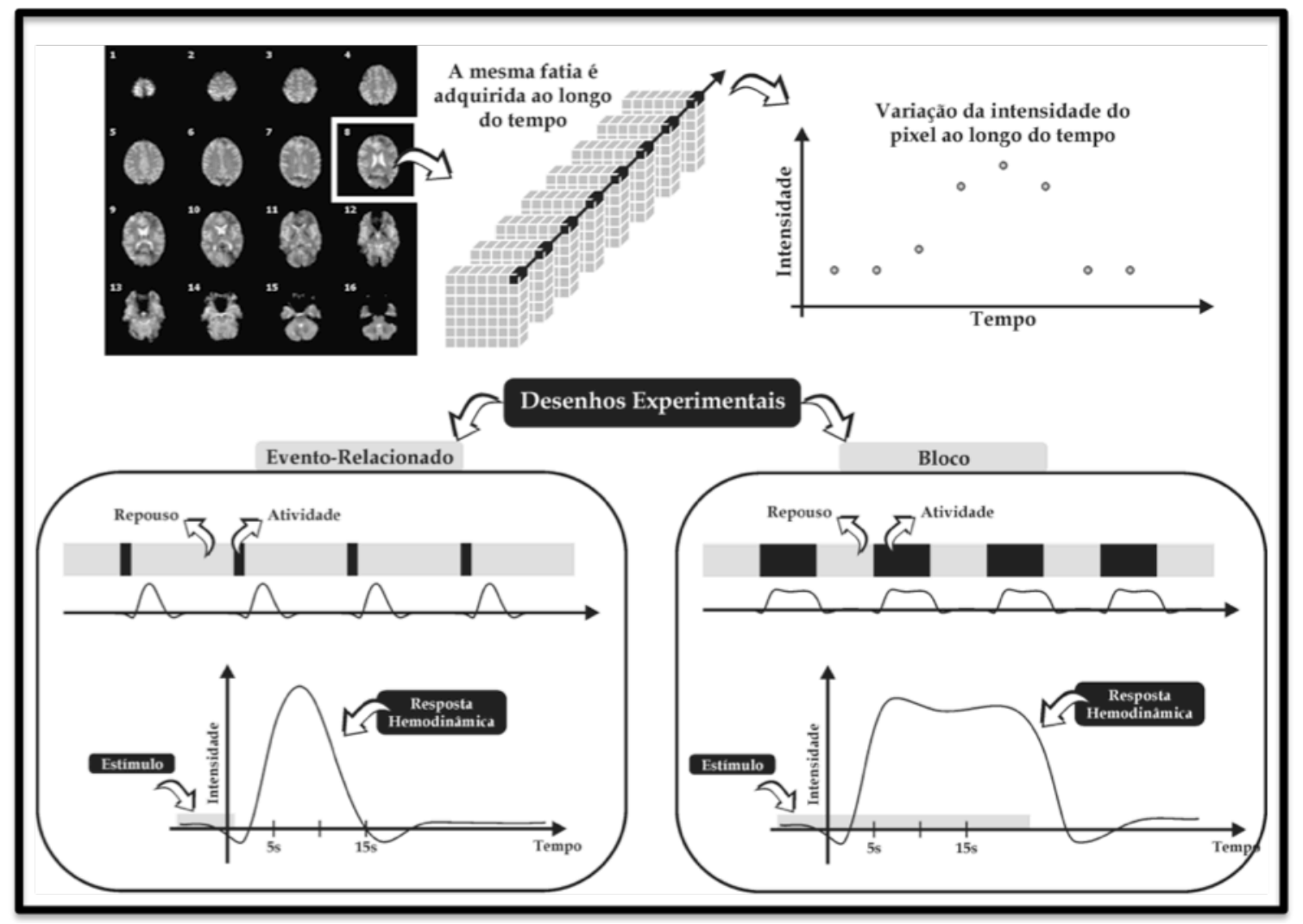

Figura 5: Desenhos experimentais típicos. A aquisição repetida de imagens da mesma região cerebral corresponde a uma variação da intensidade de sinal de cada pixel ao longo do tempo. Variações concomitantes à estimulação são procuradas nas análises estatísticas. Basicamente, os protocolos de estimulação em fMRI tem um desenho evento-relacionado ou em bloco. No desenho evento-relacionado, pode-se caracterizar a HRF desse sistema a partir de uma estimulação pontual. No desenho em bloco, o estímulo é mantido por um intervalo maior e a resposta hemodinâmica esperada é sustentada por mais tempo. Ambos os desenhos experimentais são repetidos ao longo do tempo e intercalados por períodos de repouso (figura de Chaim, 2008).

Os experimentos planejados com desenho em blocos foram os primeiros utilizados em fMRI e, até hoje, esta ainda é a estratégia mais adotada. A idéia central é a mesma utilizada em experimentos de PET em que, em geral, o sujeito executa a tarefa experimental por um período de tempo relativamente longo (15 a 30 segundos), alternando com períodos igual- 
mente longos de repouso ou de uma tarefa controle. A tarefa controle é idealizada para ser similar à tarefa experimental, porém sem desencadear o processo cognitivo de interesse. A apresentação de estímulos em bloco não permite observar o formato e a latência da resposta hemodinâmica (Figura 2). Todavia, esse tipo de protocolo apresenta resultados bastante robustos em relação à detecção da atividade (Glover, 1999; Amaro \& Barker, 2006).

O sinal esperado deve manter um nível médio constante ao longo dos blocos e, assim, qualquer modulação de sinal entre os blocos representa um contraste BOLD detectável. A análise da diferença de sinal observada entre a tarefa de interesse e o período controle é atribuída ao processo cognitivo procurado. Por essa razão, experimentos assim são denominados subtrativos. Ainda, quando o pesquisador modula a intensidade de algum parâmetro experimental em cada bloco, diz-se que o experimento é paramétrico. Já quando o desenho experimental consiste na simples presença ou ausência de um estímulo, ou na realização de uma tarefa não modulável, o experimento é dito categórico (Winkler, 2007; Amaro \& Barker, 2006).

Os desenhos evento-relacionados (ER) são caracterizados por estímulos relativamente curtos e um tempo de repouso relativamente longo (Josephs, 1997; Zarahn et al., 1997; Friston, 1998). A principal vantagem da sua utilização é a possibilidade da observação temporal da resposta hemodinâmica que segue a atividade neural em cada região do cérebro (Buxton et al., 2004), além do fato de ser ideal para estudar respostas neurais transientes ou adaptativas. Ainda, esses desenhos permitem fazer experimentos mais complexos (D'esposito, 1999). A principal desvantagem dessa estratégia é a redução do poder de detecção da área envolvida na tarefa (Bandettini \& Cox, 2000).

O desenho evento-relacionado também pode ser projetado em uma versão rápida em que o intervalo entre estímulos é reduzido a valores mínimos, mas que precisa ser variável (o termo, em inglês, para este tipo de manipulação experimental é jittering), em torno de 4 segundos, e os eventos de diferentes condições devem ser balanceados apropriadamente (Buckner et al., 1998; Dale, 1999; Rosen et al., 1998; Glover, 1999). Esses intervalos entre estímulos estão próximos dos valores usados em experimentos clássicos de neuropsicologia e facilitam a compreensão dos correlatos neurais de muitos experimentos psicofísicos (Volz et al., 2001; Amaro \& Barker, 2006). Também, o desenho evento-relacionado rápido permite aumentar o poder estatístico pelo aumento na taxa de apresentação dos estímulos (Buckner et al., 1998; Friston et al., 1999). No entanto, esse protocolo apresenta limitações para estimar a HRF de um estímulo, já que a resposta a um estímulo se sobrepõe àquela do 
estímulo subsequente. A solução para a separação e análise das propriedades da HRF de cada estímulo é o uso do método de deconvolução (Glover, 1999), mas que depende da linearidade do sinal BOLD sobreposto na HRF (Friston et al., 1999; Glover, 1999).

Recentemente, alguns estudos por fMRI têm usado uma abordagem combinada, entre desenhos em blocos e evento-relacionados rápidos, chamada desenho misto ou, ainda, desenho híbrido. Os blocos controle são intercalados com os blocos das tarefas, os quais são compostos por testes apresentados em intervalos variáveis. O desenho misto possibilita separar as análises dos processos sustentados durante toda a tarefa (nos blocos), dos processos transientes ocorridos em cada teste (evento-relacionado). Além disso, o desenho misto permite relacionar a ativação provocada por processos transientes ao processamento neural sustentado, ao longo da tarefa (Amaro \& Barker, 2006, Donaldson, 2004).

Apesar das diferenças, cada desenho experimental tem as suas vantagens. Conforme a necessidade de um experimento, ele deve ser desenhado para detectar, estimar ou separar processos cerebrais. De forma geral, podemos dizer que os desenhos em bloco são vantajosos para detectar o sinal BOLD. Já os desenhos evento-relacionados facilitam a estimativa do sinal e a caracterização da HRF. Já os desenhos mistos combinam as duas estratégias para revelar tanto a atividade transiente (evento-relacionada) quanto a sustentada (tarefarelacionada). Um resumo dos três principais desenhos experimentais, e o sinal esperado, é descrito na figura 6 , a seguir: 
(a)

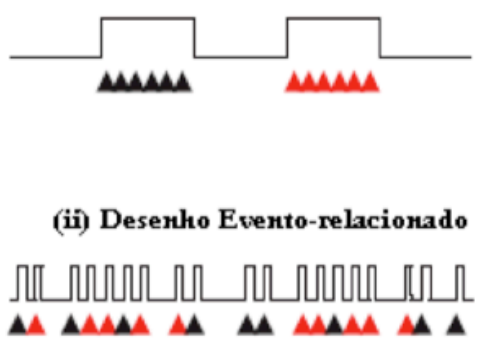

(iii) Desenho Misto

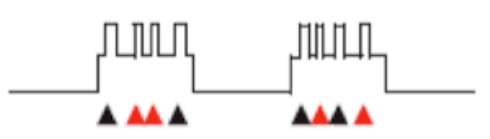

(b)

(i) Sinal de todas as regiöes

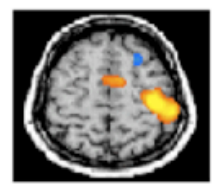

(ii) Sinal da condição teste

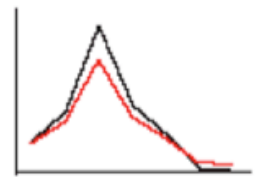

(iii) Sinal da tarefa

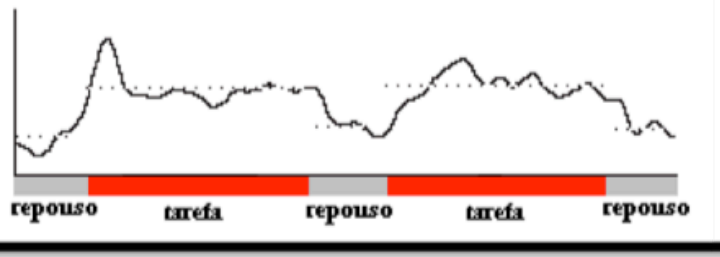

Figura 6: (a) Diferentes desenhos experimentais podem ser usados para detectar, estimar ou separar as atividades cerebrais: (i) desenhos em bloco medem a resposta total (linha preta) de uma série de estímulos relacionadas a uma mesma tarefa (triângulos pretos e vermelhos representam dois testes experimentais distintos); (ii) desenhos evento-relacionados rápidos, com estimulos intercalados aleatoriamente, facilitam a recuperação da atividade relacionada a um único teste; enquanto desenhos mistos combinam as formas blocada e eventorelacionada rápida para revelar tanto a atividade evento-relacionada quanto a tarefarelacionada (associada ao sinal no bloco). (b) Diferentes desenhos permitem diferentes tipos de análises do funcionamento neural: (i) os desenhos em bloco, em um mapa estatístico, revelam as regiões cerebrais provavelmente mais responsivas a uma tarefa do que a uma condição controle; (ii) mas a resposta pode refletir características temporais do sinal BOLD em regiões específicas, que exibem respostas transientes à diferentes tipos de estímulos (linhas preta e vermelha), amplamente buscadas em desenhos evento-relacionados; ainda, os desenhos mistos permitem revelar tanto a atividade evento-relacionada como, também, as regiões que exibem respostas sustentadas relacionadas à tarefa (linha preta, com linha pontilhada descrevendo a média do sinal para o período tarefa-relacionado). Modificado de Donaldson, 2004.

\section{PRÉ-PROCESSAMENTO DAS IMAGENS}

Após as aquisições das imagens, estas deverão passar por um controle de qualidade e algumas etapas de pré-processamento, a fim de melhorar a relação sinal-ruído e de condicionar os dados para o processamento estatístico. No pré-processamento, as principais estratégias são: detecção e correção de movimentos da cabeça; correção temporal entre as fatias; filtros temporais, filtros espaciais e, em muitos casos, normalização das imagens para um espaço 
padrão (por exemplo, um Atlas Talairach). Ainda, uma inspeção visual das imagens, antes e depois do pré-processamento, juntamente com uma avaliação de todas as demais informações coletadas sujeito a sujeito, permitem excluir dados corrompidos. A seguir, uma breve descrição de cada etapa do pré-processamento:

\section{Deteção e correfão de movimentos}

Os artefatos de movimento podem ser classificados como extrínsecos ou intrínsecos. Os artefatos extrínsecos são resultantes da movimentação da cabeça do indivíduo durante o exame. Enquanto os movimentos são pequenos, da ordem de tamanho do voxel adquirido, é possível corrigir o posicionamento de todos as volumes em relação ao primeiro adquirido, utilizando 6 parâmetros: 3 de translação e 3 de rotação. Já os artefatos intrínsecos são causado por flutuações internas dos tecidos intra-cranianos e processos fisiológicos como respiração e batimentos cardíacos. Esses movimentos são bastante difíceis de serem detectados e corrigidos, mas seus efeitos podem ser minimizados pelo uso de filtros espaciais.

\section{Filtros espaciais ou de suavizafão}

A utilização dos filtros espaciais é importante para aumentar a relação sinal-ruído em estudos de grupo, e conseqüente ampliação do poder de detecção. No entanto, o uso desse tipo de estratégia é controverso, pois promovem uma diminuição da resolução espacial. As características do filtro são bem definidas pelo parâmetro largura à meia altura, ou FWHM (Full Width at Half Maximum), que determina a forma de atuação do filtro sobre a imagem. A largura de filtro ideal para a análise de grupo em fMRI depende de vários critérios, entre a tarefa experimental e regiões funcionais específicas, mas do ponto de vista da sensibilidade, a largura FWHM ótima está entre 8 e 10 mm (Mikl et al., 2008).

\section{Filtros temporais}

Os filtros temporais buscam remover componentes de freqüência indesejáveis da série temporal, sem modificar o sinal de interesse. De regra, estudos de fMRI utilizam o filtro passa-alta, que removem as componentes do sinal que possuem freqüência baixa e que são 
provenientes de processos fisiológicos, como a respiração e a pulsação cardiovascular, ou efeitos físicos, como o chamado drift do sinal.

\section{Corregão temporal entre as fatias}

As aquisições de fMRI são formadas por várias fatias do cérebro, que foram adquiridas em tempos ligeiramente distintos. Dessa forma, as fatias que compõem os volumes estão ligeiramente defasadas no tempo. Para corrigir essa defasagem, o método mais utilizado é a interpolação temporal, que utiliza informações dos pontos temporais adjacentes para estimar a amplitude do sinal em diferentes instantes de tempo.

\section{Normalização para o espaço padrão (Atlas Talairach)}

Para efeito de comparação das análises entre diferentes indivíduos, ou para análise de um grupo, é importante redimensionar as imagens cerebrais para um mesmo espaço de coordenadas padronizado. Um espaço padrão bastante utilizado em pesquisas de fMRI é o espaço Talairach (Talairach \& Tournoux, 1988).

As imagens cerebrais de cada sujeito devem, primeiramente, ser posicionadas e orientadas no sistema de coordenadas Talairach. Para isso, utiliza-se o plano formado entre duas estruturas anatômicas como referência: a comissura anterior (Anterior Commissure - AC) e a comissura posterior (Posterior Commissure - PC), chamado de plano AC-PC. Após a definição da orientação no sistema de coordenadas, as imagens devem ser normalizadas, ou seja, devem sofrer deformações de modo que seu tamanho se torne similar ao tamanho do cérebro modelo. Para isto, quatro linhas de referências do sistema Talairach devem ser selecionadas na imagem. São elas: (i) a linha AC-PC, que passa pela borda superior da comissura anterior e pela borda inferior da comissura posterior; (ii) a linha AC vertical, perpendicular à linha AC-PC que atravessa a margem posterior da comissura anterior; (iii) a linha PC vertical, que atravessa a margem anterior da comissura posterior e é, também, perpendicular à linha ACPC; (iv) e a linha média, que é a fissura inter-hemisférica (Figura 7). 


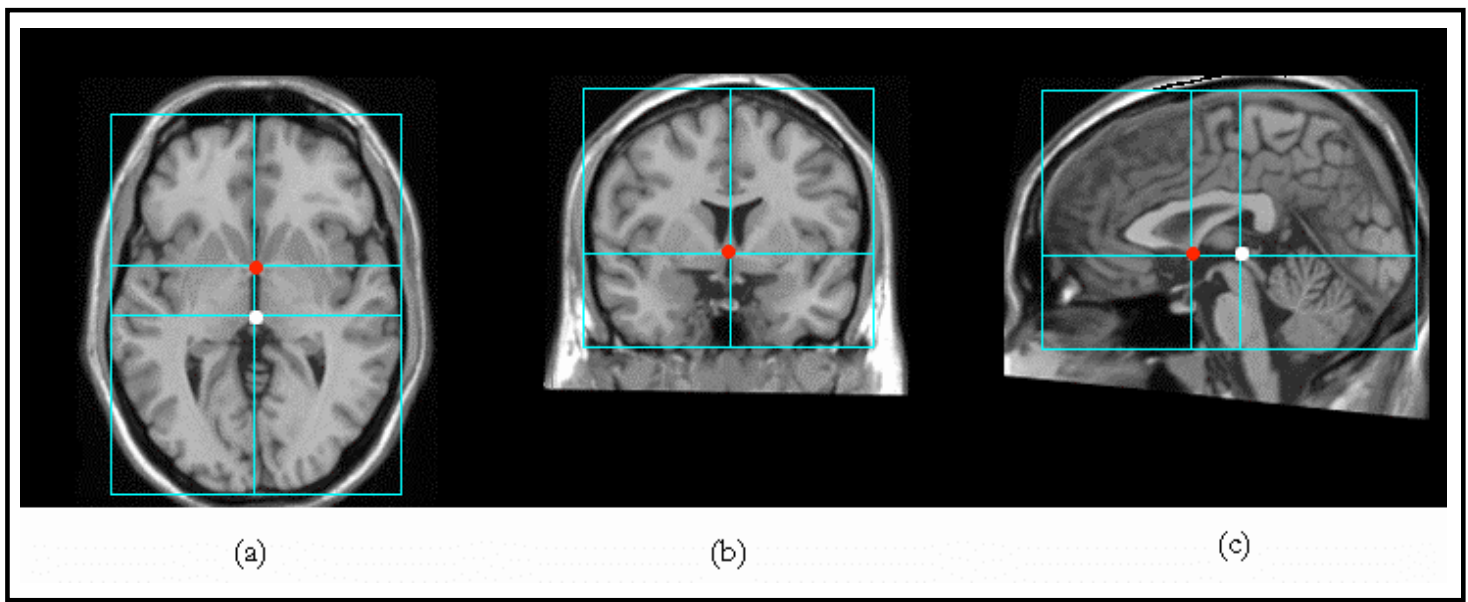

Figura 7: Representação, nos planos axial (a), coronal (b) e sagital (c), das linhas utilizadas para definir o sistema de coordenadas Talairach. (a) Plano AC-PC e linha média (vertical), (b) linha média (vertical) e (c) Linha AC vertical, linha PC vertical e linha AC-PC. O ponto vermelho indica a localização anatômica da comissura anterior e o ponto branco indica a localização anatômica da comissura posterior.

\section{ANÁLISE ESTATÍSTICA DAS IMAGENS}

O objetivo da análise estatística é identificar aquelas regiões cerebrais que foram moduladas por alguma condição experimental específica. A maioria dos testes estatísticos utilizados em fMRI possui três pontos em comum. Primeiro, eles expressam a significância como a probabilidade do resultado ocorrer sobre a hipótese nula (quando o sinal durante uma condição específica não é diferente de outra condição). Além disso, os voxels cujo nível de significância está abaixo de um limiar, conhecido como valor alfa $(\alpha)$, são marcados como significativos e são realçados nos mapas, enquanto os voxels cuja significância está acima do limiar estatístico não são marcados. Ainda, a análise em regiões de interesse (Region of Interest ROI) é feita sobre uma única série temporal com intuito de fazer comparação entre as condições experimentais. Neste caso, o nível de significância $\alpha$ representa apenas a probabilidade do resultado do teste ocorrer sobre a hipótese nula nesta única série, ou seja, não há comparações entre voxels de outras regiões cerebrais. Por fim, todas as inferências costumam ser conservativas, ou seja, enfatizam a exclusão de falso-positivos (erro tipo I).

Até o final da década de 1980, a maioria dos estudos de PET consistia em subtrair imagens adquiridas em períodos de atividade de imagens adquiridas em repouso. Habitualmente, para se obter uma melhor relação sinal-ruído, várias amostragens eram realizadas, e a sub- 
tração era realizada com imagens médias. Caso o pesquisador desejasse calcular um valor de significância estatística para a imagem final, poderia utilizar, por exemplo, o teste-t de Student. No princípio, essas estratégias também foram adotadas em experimentos de fMRI. Porém, em meados dos anos 1990, o modelo linear geral passou a ser utilizado com mais freqüência, em parte, por ele permitir análises estatísticas mais flexíveis em experimentos de maior complexidade.

Embora diversas formas de análise estatística para experimentos de fMRI e PET sejam possíveis, grande parte dessas formas, como testes-t, testes de correlação, ANOVA e ANCOVA, são utilizados como variantes do modelo linear geral, e podem ser implementados utilizando o mesmo conjunto de equações e algoritmos (Winkler, 2003).

\section{MODELO LINEAR GERAL}

Conhecido do inglês como General Linear Model (GLM), esse método ajusta a variação da intensidade de sinal nos pixels das imagens a um modelo preditor da função hemodinâmica (figura 2) que, por sua vez, é um modelo a priori que representa a resposta hemodinâmica esperada durante o estímulo ou a execução de uma tarefa. Além do ajuste, o método testa a significância estatística das respostas.

O princípio do Modelo Linear Geral consiste em explicar o comportamento de uma variável y ao longo de $\mathrm{N}$ observações, composta pelo sinal de fMRI observado nos pixels a cada aquisição, em termos de uma combinação linear de variáveis explanatórias, $x$, ponderadas por uma função modelo, mais um termo de erro $€$. A idéia pode ser resumida pela equação:

$$
\mathrm{y}_{\mathrm{n}}=\beta_{0}+\mathrm{x}_{\mathrm{n} 1} \beta_{1}+\cdots+\mathrm{x}_{\mathrm{nk}} \beta_{\mathrm{k}}+\cdots+\mathrm{x}_{\mathrm{nK}} \beta_{\mathrm{K}}+\epsilon_{\mathrm{n}}
$$

em que $\beta_{\mathrm{k}}$ são os parâmetros, correspondendo a cada uma das $K$ variáveis explanatórias $\mathrm{x}$. O termo $\beta_{0}$ reflete a contribuição de todos os fatores que são tomados como constantes durante o experimento.

Na prática, antes do cálculo do GLM, possuímos apenas uma série temporal dos dados experimentais (sinal de fMRI pixel-a-pixel) e a hipótese a priori de que esses dados são explicados por um modelo da HRF, que aparece em resposta ao estímulo que foi dado, além do acréscimo de um erro. Geralmente, as equações não podem ser simultaneamente e perfei- 
tamente resolvidas. Ou seja, o erro nunca é igual a zero, pois o número de observações é maior do que o número de variáveis explanatórias e erro experimental está sempre presente. Portanto, o que se procura é uma solução que minimize os erros. O termo de erro mínimo é conhecido como erro residual. Então, com os dados experimentais e o modelo da função de estímulo, podemos calcular quais parâmetros de peso $\beta_{\mathrm{k}}$ servem para minimizar o termo de erro. $\mathrm{Na}$ análise, deseja-se conhecer qual a contribuição de cada condição experimental para a resposta obtida em cada voxel ao longo do tempo, ou seja, deseja-se conhecer justamente os valores do vetor $\beta$ e testá-los estatisticamente. O problema de encontrar a melhor solução para $\beta$ pode ser resolvido pelo método dos mínimos quadrados. Supondo que exista um conjunto de valores estimados $\beta_{\mathrm{k}}$ de modo que $\epsilon_{\mathrm{n}}$ seja o menor valor residual possível em cada observação. A melhor estimativa $\beta$ é aquela que resulte na menor soma dos quadrados do erro residual. Esses parâmetros, chamados valores de betas $\left(\boldsymbol{\beta}_{\mathrm{k}}\right)$, indicam o quanto cada fator contribui para o ajuste dos dados. Então, cada valor de beta reflete a amplitude do sinal BOLD de cada condição experimental (figura 8).

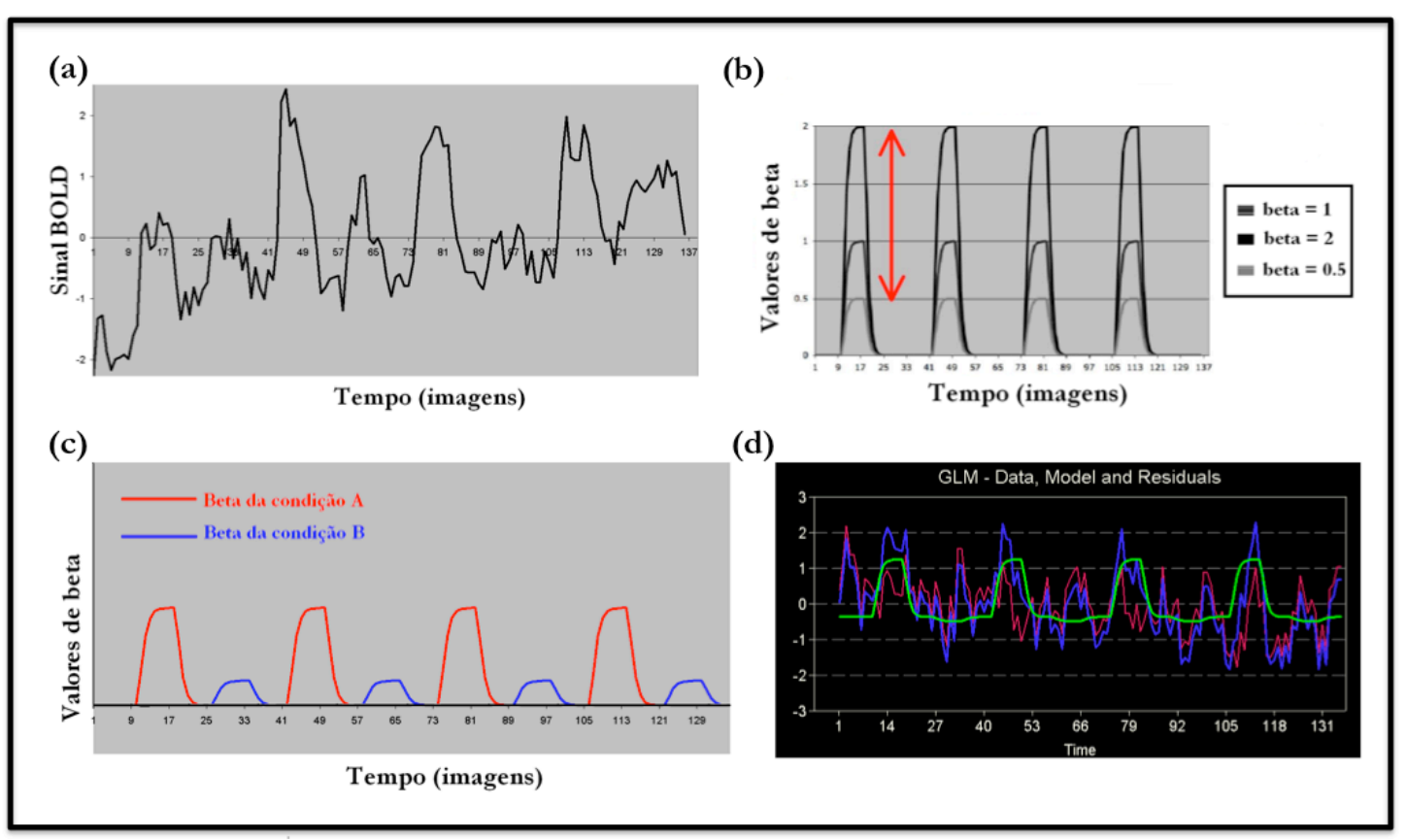

Figura 8: Representações: (a) de um dado bruto de fMRI com sinal BOLD, antes de ser pré-processado e analisado; (b) dos possíveis valores de beta calculados para o melhor ajuste do modelo ao sinal BOLD, que refletem a amplitude do sinal BOLD ajustado; (c) da distinção feita no método GLM entre diferentes condições experimentais (condição A em vermelho e condição B em azul), tal que o cálculo dos valores de beta para cada condição seja separado e permita comparações entre elas; e (d) da sobreposição dos principais parâmetros utilizados no cálculo do GLM, o sinal de fMRI (em azul), o modelo do sinal BOLD (em verde) e o resíduo (em vermelho). 
Para testar a significância estatística de uma condição experimental sobre uma condição controle, em um dado voxel, a amplitude do parâmetro $\beta$ associado é dividida pelo erro residual. Sobre a hipótese nula, essa quantidade deve seguir a distribuição F e, assim, essa significância pode ser avaliada em função dos graus de liberdade do teste. Nota-se, então, que o propósito desse modelo estatístico (GLM) é quantificar a relação entre variáveis independentes (ou preditoras) e uma variável dependente, o sinal. O método avalia o grau de similaridade entre a série temporal da sessão experimental com uma, ou mais, série temporal preditora (matriz do modelo).

Quando há apenas uma variável dependente, a equação é conhecida como um modelo de regressão múltipla univariada. Mas, no modelo linear geral (GLM), devemos lembrar que a mesma equação pode ser estendida para incluir um grande número de variáveis dependentes, como os vários pontos das séries temporais de um estudo de fMRI. Para maior clareza disso, expandimos a equação anterior em um conjunto de equações, cada qual representando uma observação:

$$
\begin{gathered}
\mathrm{y}_{1}=\mathrm{x}_{11} \beta_{1}+\cdots+\mathrm{x}_{1 \mathrm{k}} \beta_{\mathrm{k}}+\cdots+\mathrm{x}_{1 \mathrm{~K}} \beta_{\mathrm{K}}+\epsilon_{1} \\
\mathrm{y}_{2}=\mathrm{x}_{21} \beta_{1}+\cdots+\mathrm{x}_{2 \mathrm{k}} \beta_{\mathrm{k}}+\cdots+\mathrm{x}_{2 \mathrm{~K}} \beta_{\mathrm{K}}+\epsilon_{2} \\
\cdot \\
\cdot \\
\cdot \\
\cdot \\
\mathrm{y}_{\mathrm{N}}=\mathrm{x}_{\mathrm{N} 1} \beta_{1}+\cdots+\mathrm{x}_{\mathrm{N} \mathrm{K}} \beta_{\mathrm{k}}+\cdots+\mathrm{x}_{\mathrm{N} \mathrm{K}} \beta_{\mathrm{K}}+\epsilon_{\mathrm{N}}
\end{gathered}
$$

Esse conjunto de equações também pode ser representado na forma matricial como:

$$
\left[\begin{array}{c}
y_{1} \\
\vdots \\
y_{n} \\
\vdots \\
y_{N}
\end{array}\right]=\left[\begin{array}{ccccc}
x_{11} & \cdots & x_{1 k} & \cdots & x_{1 K} \\
\vdots & \ddots & \vdots & \ddots & \vdots \\
x_{n 1} & \cdots & x_{n k} & \cdots & x_{n K} \\
\vdots & \ddots & \vdots & \ddots & \vdots \\
x_{N 1} & \cdots & x_{N k} & \cdots & x_{N K}
\end{array}\right]\left[\begin{array}{c}
\beta_{1} \\
\vdots \\
\beta_{k} \\
\vdots \\
\beta_{K}
\end{array}\right]+\left[\begin{array}{c}
\epsilon_{1} \\
\vdots \\
\epsilon_{n} \\
\vdots \\
\epsilon_{N}
\end{array}\right]
$$


ou, simplificadamente:

$$
\mathrm{Y}=\mathrm{X} \beta+\epsilon
$$

em que Y é um vetor-coluna das $\mathrm{N}$ observações; $\mathrm{X}$ é a matriz modelo do experimento, em que cada coluna representa uma dentre as $\mathrm{K}$ variáveis explanatórias para as $\mathrm{N}$ observações; $\beta$ é o vetor-coluna em que representa o peso com que cada variável explanatória contribui para o resultado observado Y; $€$ é o vetor de resíduos, ou seja, a porção de Y não explicável pelas variáveis de $\mathrm{X}$.

A matriz do modelo experimental é que torna o modelo linear geral versátil. A matriz X contém o modelo experimental definido pelo pesquisador. Com ela, é possível testar múltiplas condições experimentais simultaneamente, bastando acrescentar as colunas correspondentes à resposta esperada para cada condição experimental, e, conforme dito, as colunas comumente são modeladas pela convolução entre a função de estímulo e a resposta hemodinâmica (HRF).

\section{MATRIZ DO MODELO}

A função de estímulo do tipo boxcar é o regressor mais simples utilizado para compor as colunas da matriz experimental do modelo linear geral. Para experimentos subtrativos categóricos, a coluna que contém a função de estimulo consiste em um padrão ligadodesligado. Em experimentos fatoriais, várias funções de estimulo são utilizadas simultaneamente, cada uma para uma condição experimental. Para experimentos paramétricos, a função de estímulo pode ser decomposta em dois ou mais regressores, um considerando as alterações tipo ligado-desligado, e outro para acomodar as variações na intensidade do padrão ligado ao longo do experimento (Henson, 2003).

Em experimentos do tipo evento-relacionado, a função de estímulo pode ser formada por uma função delta de Kronecker, com amplitude arbitrariamente ajustada para 1, ou para valores correspondendo à magnitude de um fator paramétrico (Josephs \& Henson, 1999). Entretanto, a resposta BOLD é atrasada em relação ao inicio da estimulação, e tem contornos característicos, mais suaves, se comparados à função de estímulo. Então, para aumentar a sensibilidade do teste, é necessário levar em consideração que a resposta BOLD apresenta contornos característicos e que não inicia imediatamente após o inicio de cada condição 
experimental. Dessa forma, é mais vantajoso utilizar um modelo mais fiel à resposta hemodinâmica. Também, a escolha de regressores com maior plausibilidade fisiológica para as colunas da matriz X permite fazer inferências mais confiáveis e com menor erro residual.

Para a construção das colunas da matriz de regressores (matriz X), a função de resposta hemodinâmica (HRF) pode ser modelada como uma simples função de distribuição gama (Lange e Zeger, 1997 apud Winkler, 2007) ou Poisson (Friston et al., 1994). Contudo, um conjunto de funções de distribuição gama (Friston et al., 1998) tende a ser ainda mais exato se incluir o período de negativação da resposta BOLD após o término do estimulo, antes do retorno à linha de base. Além destes aprimoramentos, outros autores propuseram modificações o modelo da HRF, como a "HRF canônica" e a inclusão de parâmetros obtidos experimentalmente (Glover, 1999; Worsley, 2001 apud Winkler, 2007).

\section{CONTRASTES E INFERENCIA}

Comumente, o objetivo do pesquisador é rejeitar a hipótese de que não existe efeito experimental associado com a série temporal de pelo menos parte dos voxels. Essa é denominada a hipótese nula, e representada por $\mathrm{H}_{0}$. Se a hipótese nula é rejeitada, a hipótese alternativa, $\mathrm{H}_{1}$, é declarada verdadeira, indicando que a intensidade do sinal BOLD ao longo do tempo está relacionada à tarefa experimental.

O modelo linear geral caracteriza as relações entre as manipulações experimentais e os dados observados. Essas manipulações são especificadas na matriz experimental X e, para efetuar os testes de hipóteses sobre um efeito em particular, são utilizados os contrastes. Os contrastes são combinações lineares de estimativas de parâmetros, também organizados na forma de vetores ou matrizes e incluídos na equação do GLM. A aplicação de diferentes contrastes permite fazer testes sobre múltiplos efeitos, sem repetir a regressão, ou seja, sem refazer a estimativa dos parâmetros $\beta$. Isso é particularmente importante no contexto de neuroimagem funcional, pois a tarefa de estimação dos parâmetros costuma ser computacionalmente custosa (Poline et al., 2003).

O contraste pode ter a forma de um vetor coluna, e permitir a comparação direta entre diferentes condições. Nesse caso, é denominado contraste T, e é equivalente ao teste-t de Student. O contraste ainda pode ser escrito na forma matricial, e ser utilizado para testar vários contrastes $\mathrm{T}$ simultaneamente, situação em que é denominado contraste $\mathrm{F}$, e é ma- 
tematicamente equivalente ao cálculo da razão F que aparece, por exemplo, em estudos de análise da variância (ANOVA) (Winkler, 2007).

As diferenças entre os parâmetros $\beta$ das condições experimentais são especificadas por um vetor de contraste $\lambda$, com as mesmas dimensões de $\beta$, e que determina uma combinação linear entre esses parâmetros, ou seja, $\lambda$. $\beta$. Por exemplo, para testar o efeito da condição experimental modelada na primeira coluna da matriz experimental $\mathrm{X}$, o vetor de contraste $\lambda$ deve ser igual a $\left[\begin{array}{lllll}1 & 0 & 0 & \ldots & 0\end{array}\right]$. Para testar a diferença entre a primeira e a segunda coluna da matriz, o contraste deve ser $\lambda=[1-1 \ldots 0]$. Nesse último caso, o efeito em estudo será $\lambda . \beta=\beta_{A}-\beta_{B}$, que representa o contraste entre a condição $A$ e a condição $B$ (rever figura 8). A variância do efeito também é estimada e, de posse da magnitude do efeito em estudo e sua variância, uma estatística T pode ser calculada (Marchini \& Smith, 2003).

Os valores para as estatísticas T ou F são computados para cada voxel individualmente, levando em consideração a resposta observada Y e o modelo escolhido para explicar o fenômeno, acomodado na matriz experimental X. Conhecendo-se as distribuições para os valores de T e F sob a hipótese nula, é possível calcular a probabilidade de se detectar um efeito devido ao acaso (Winkler, 2007).

\section{MAPAS ESTATÍSTICOS: ANÁLISE VOXEL-A-VOXEL}

Os resultados dos testes estatísticos, para cada voxel, podem ser acumulados em um mapa do cérebro que representa a significância estatística (p) encontrada voxel-a-voxel. A maneira mais usada para apresentar esses voxels mostra apenas aqueles que excedem o valor de um limiar estabelecido, de tal forma que os voxels das regiões cerebrais exibidas são apenas das regiões que apresentam ajustes calculados pelo GLM que sejam estatisticamente significativos, utilizando uma escala de cores. Geralmente, a escala de cores utilizada vai do vermelho ao amarelo, para valores positivos, e do verde ao azul, para valores negativos. O mapa estatístico ainda pode representar os voxels das regiões cerebrais que apresentam diferenças significativas de amplitude de sinal estimado (betas) entre duas condições experimentais, também conhecido como mapa estatístico de contrastes.

Para conferir ao exame uma maior qualidade de visualização anatômica, de modo que as áreas significativas sejam localizadas com mais precisão, os mapas estatísticos são muitas 
vezes apresentados sobre imagens de alta resolução espacial, utilizando seqüências ponderadas em T1, com voxels em torno de $1 \mathrm{~mm}^{3}$. A figura 9 mostra um mapa estatístico sobreposto a uma imagem de alta resolução. Neste caso, as áreas em tons de amarelo são estatisticamente mais significativas que as áreas em vermelho. Outras áreas que não foram estatisticamente significativas, não são apresentadas. Ainda, na escala de cores, as áreas em tons de verde mostram-se estatisticamente significativas, assim como as áreas em vermelho, porém, elas indicam valores de beta negativos.

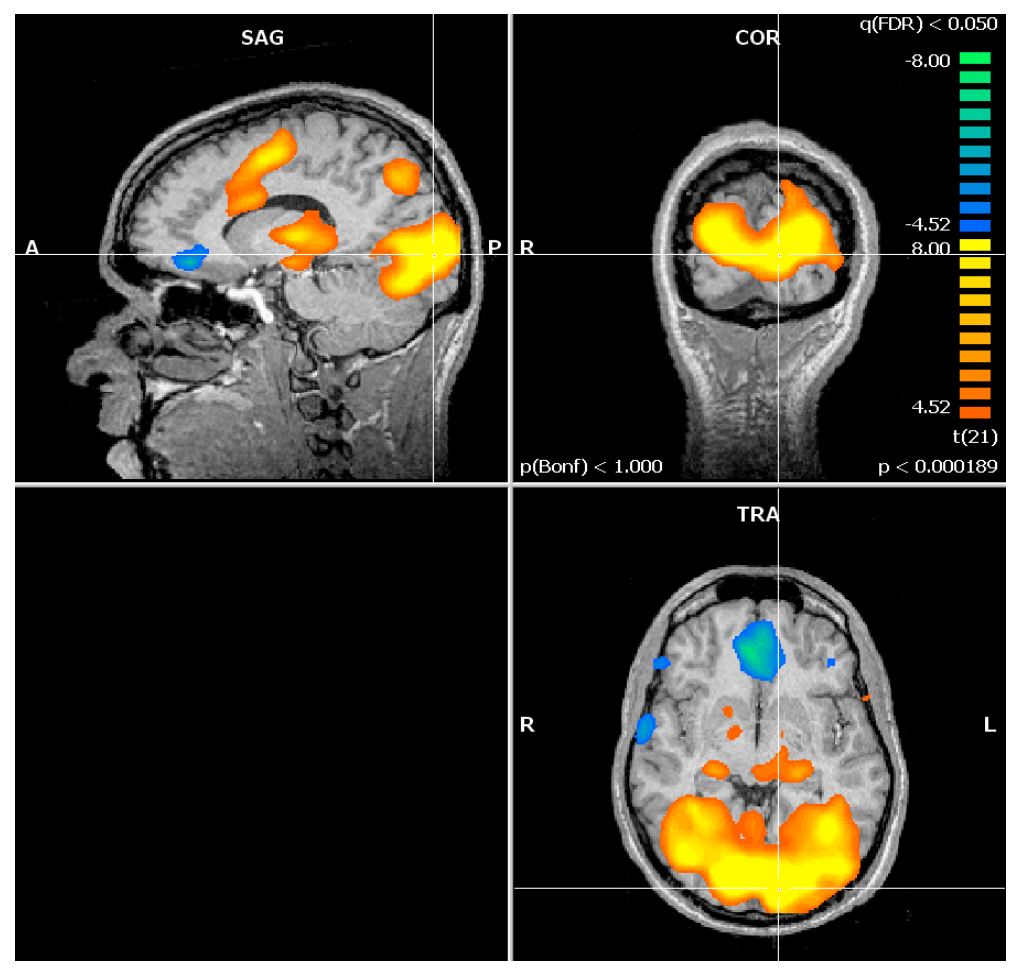

Figura 9: Mapa estatístico das áreas ativadas em resposta a um estímulo visual sobreposto a uma imagem de alta resolução. $\mathrm{Na}$ figura, as áreas em tons de amarelo mostram-se estatisticamente mais significativas que as áreas em vermelho.

Recentemente, outras representações anatômicas têm sido propostas, e que trazem um maior número de informações visuais a um só tempo. São exemplos, as reconstruções da superfície do cérebro. Nesse tipo de visualização avançada, é possível a construção de diferentes formas, como um cérebro inflado tridimensional ou planificado, que podem servir de substrato para a sobreposição de mapas, como pode ser observado na figura 10. 


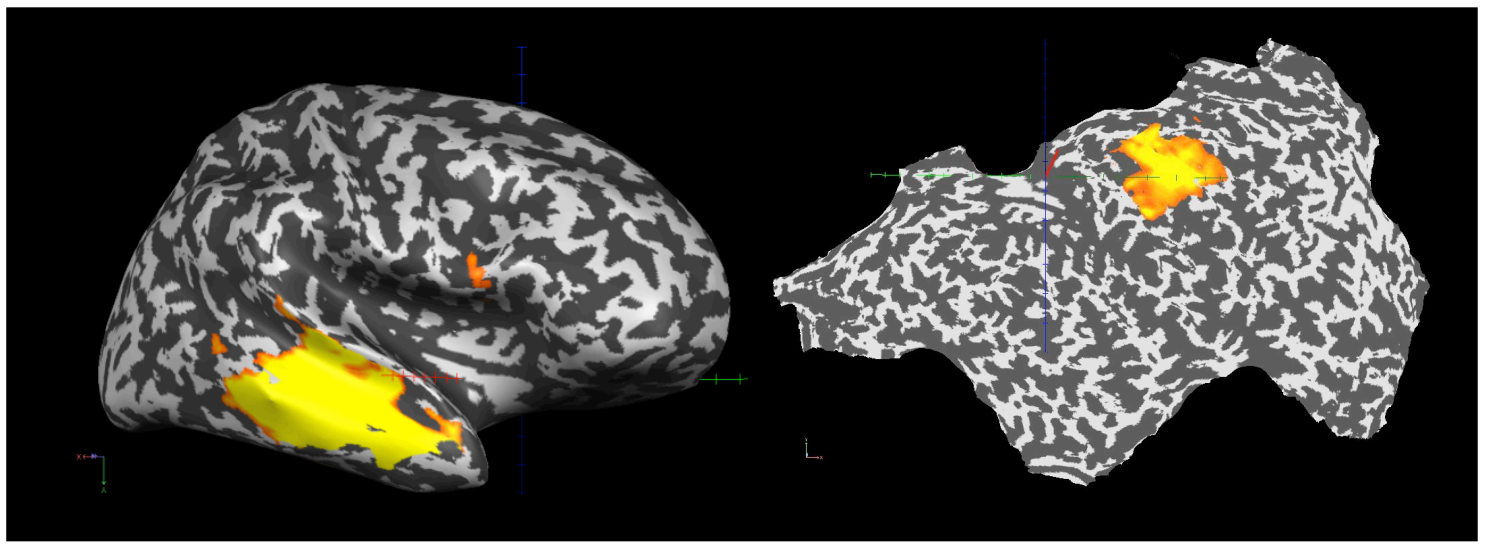

Figura 10: Representações do cérebro para visualização dos mapas estatísticos. (A) hemisfério direito inflado e (B) hemisfério direito planificado.

Geralmente, os mapas de neuroimagem funcional envolvem testes de hipóteses realizados simultaneamente em uma grande quantidade de voxels. Contudo, ao executar muitos testes de hipóteses, a probabilidade de ocorrência de p-valores abaixo do limiar de significância, $\alpha$, estabelecido meramente devido ao acaso, aumenta substancialmente. Isso ocorre de modo que se pode inferir a presença de um efeito experimental, quando na verdade nenhum efeito existe. Este é o denominado problema dos testes múltiplos (Lindquist \& Gelman, 2009).

Tome-se, por exemplo, um exame de fMRI em que tenham sido adquiridos 25 cortes, cada qual contendo uma imagem (matriz) $64 \times 64$ voxels. O número total de voxels é $64 \times 64 \times$ $25=102400$. Supondo que somente sejam testados os voxels contidos dentro do encéfalo, e que o mesmo ocupe somente cerca de metade do volume total de voxels, o número total de testes de hipóteses sendo executados é 102400/2 $=51200$. Para um nível de significância estabelecido em $\alpha=0,05$, espera-se que $51200 \times 0,05=2560$ voxels sejam declarados ativos ao acaso; um número elevado e inaceitável.

Em experimentos que exigem múltiplos testes, o pesquisador deve definir um limiar estatístico para todos os voxels, de maneira que identifique ao máximo os voxels declarados ativos corretamente e, ao mesmo tempo, minimize a quantidade daqueles declarados ativos erroneamente (erro do tipo I). Ainda, o valor limítrofe para múltiplos testes deve permitir algum controle sobre a possibilidade de marcar erroneamente um voxel considerado inativo como ativo (erro do tipo II). Diversos procedimentos podem ser usados para controlar o 
nível de significância, dentre eles os mais comuns são o método de Bonferroni, que é considerado muito conservador, e o método baseado no controle da proporção de falsas descobertas (False Discovery Rate - FDR).

\section{ANALISE DE ROI}

As análises voxel-a-voxel, em geral do cérebro inteiro, buscam detectar quais são os voxels que respondem às diferentes condições experimentais. Essa abordagem é comum em estudos exploratórios, em que ainda não se conhece a rede de estruturas associada à uma determinada função cerebral, comum em estudos cognitivos mais complexos. Porém, alguns estudos ainda requerem uma análise mais aprofundada sobre os processos subjacentes a uma região cerebral em particular. Em geral, o papel fisiológico dessas estruturas já é mais bem conhecido por pesquisas prévias, de modo que uma abordagem restrita a elas pode revelar novos achados. Nesse caso, testes estatísticos podem ser feitos sobre um conjunto de voxels pertencentes apenas à região de interesse, também conhecidas como análises de ROI. A diferença entre essas duas abordagens pode ser exemplificada pelo tipo de pergunta a ser feita em cada caso. Em uma análise voxel-a-voxel do cérebro inteiro se pergunta, por exemplo: “Quais são as regiões cerebrais envolvidas em uma tarefa cognitiva específica?” Já em uma análise de ROI, seria: "Que respostas cerebrais, em diferentes tarefas, ocorrem em uma região cerebral específica?”

Existem diferentes estratégias para a escolha das ROI a serem testadas em um experimento. É possível selecionar a ROI a partir da extensão anatômica da região em estudo (critério anatômico) ou a partir de uma seleção funcional, baseada na resposta daquela região à uma análise exploratória prévia, voxel-a-voxel, do cérebro todo em uma condição controle do mesmo experimento (critério funcional). O método de escolha leva em consideração, principalmente, achados prévios sobre o papel neurofisiológico daquela região cerebral em resposta a determinada tarefa. A partir daí, o pesquisador pode testar a hipótese a priori já estabelecida em outros estudos ou, ainda, propor um novo método de estimulação e análise para testar a resposta da mesma região.

Em geral, para a análise por GLM, a região de interesse é considerada como uma unidade indivisível e homogênea composta pela soma de todos os voxels selecionados previamente, dos quais se faz a média dos dados brutos para formar uma única série temporal. Dessa 
forma, a série temporal da ROI é analisada da mesma forma que um voxel e os resultados dos valores de beta, erro padrão e significância estatística são calculados para todas as condições experimentais.

Existem várias vantagens no uso da análise de ROI sobre métodos de análise voxel-a-voxel. A principal delas é que se reduz o número de testes estatísticos, o que diminui a necessidade das correções para múltiplas comparações (Poldrack, 2007). Além disso, como cada ROI combina os dados de muitos voxels, espera-se uma resposta funcional homogênea em toda a extensão da ROI que permita aumentar a relação sinal-ruído. Finalmente, a análise de ROI pode diminuir os problemas relacionados à comparação entre sujeitos.

Para a seleção da região de interesse, pode-se usar o critério anatômico, baseado em referenciais de um cérebro padrão, como do Atlas Talairach. Como a arquitetura cerebral é específica de cada sujeito, a seleção de uma ROI pelo critério anatômico também pode causar uma diminuição da relação sinal-ruído pela perda da homogeneidade e especificidade da resposta funcional, conforme foi citado no parágrafo anterior. Alternativamente, existem duas formas de selecionar as ROI's visando diminuir a possibilidade de incluir voxels de regiões anatômicas diferentes. Essas estratégias são conhecidas como critério funcional de seleção de ROI. Isto garante que apenas voxels funcionalmente similares sejam incluídos na análise, pois considera que as correções anatômicas no processo de normalização não são precisas (Huettel, 2004). Então, pode-se usar o critério funcional para selecionar, previamente, na análise de grupo voxel-a-voxel, uma região que combina a resposta fisiológica de todos os sujeitos em uma única ROI. Ou, ainda, selecionar as ROI’s na análise individual sujeito-a-sujeito, antes da análise de grupo.

\section{ANÁLISE DE CORRELAÇÃO}

No uso estatístico geral, a correlação se refere à medida da relação entre duas variáveis, embora a correlação não implique causalidade entre elas. As análises de correlação, ou de covariância, podem ser utilizadas para testar o efeito de variáveis categóricas sobre a variável dependente, controlando os efeitos da variável selecionada sobre outras variáveis que co-variam com a variável dependente. A variável de controle é denominada de "covariável". 
Nos pacotes estatísticos desenvolvidos para a análise dos dados de fMRI (BrainVoyager, SPM, AFNI, etc.), é possível extrair os valores de beta ( $\beta$ ) estimados no GLM, associados à amplitude de sinal, em cada condição experimental. Posteriormente, em uma análise de segundo nível, é possível calcular o coeficiente de correlação desses valores com alguma covariável, que pode representar, por exemplo, pontuações em escalas psicométricas, medidas fisiológicas, ou informações sobre idade, gênero, escolaridade, etc.

O efeito BOLD por condição experimental (valores de beta) pode ser analisado em um segundo nível usando uma análise de variância padrão (ANOVA), que permite modelar um ou mais fatores dentre os sujeitos (within subjects, do inglês) com medidas repetidas. Se o estudo representa o dado de muitos grupos de sujeitos, um fator entre os sujeitos (between subjects, do inglês) para comparações de grupo pode ser adicionado. Usando ANOVA, a análise estatística de segundo nível não difere da abordagem estatística usual em outros estudos com humanos, por exemplo, psicológicos ou médicos. A maior diferença para a estatística padrão é que essas análises são realizadas separadamente para cada voxel, o que requer correções apropriadas para o problema das múltiplas comparações. Além do efeito estimado específico por sujeito no desenho de fMRI (valores de beta da análise de primeiro nível), variáveis externas podem ser adicionadas para cada sujeito e incorporadas como covariantes na análise de segundo nível estendendo a ANOVA para uma ANCOVA (análise de covariância). Nesta, o contraste (diferença entre os valores de beta) é calculado para cada sujeito e o seu valor é testado em relação a uma co-variável usando correlação e um teste estatístico. Os coeficientes de correlação entre as co-variáveis e os valores de beta, estimados anteriormente pelo GLM, podem ser testados estatisticamente por teste-t ou estatística f (ANOVA) em análises voxel-a-voxel ou de região de interesse (ROI).

Posteriormente à análise de correlação nos pacotes estatísticos de fMRI, o ideal é apresentar o gráfico de dispersão entre as variáveis, com uma reta ajustada por regressão linear simples. Isso possibilita ao leitor observar como os dados estão em relação à reta, bem como a descrição da equação da reta e o coeficiente de correlação para, por fim, facilitar a interpretação desses parâmetros. Nesse caso, o valor do coeficiente de correlação (r) determina o quanto da variação da variável dependente é explicada pela variação da variável independente (co-variável). Ainda, um teste estatístico entre os valores estimados pelo GLM e os valores da reta ajustada pela regressão linear simples, fornecem um parâmetro sobre a significância do ajuste e, portanto, da correlação. 


\section{MÉTODOS}

Este trabalho de pesquisa, pelo seu perfil interdisciplinar, foi desenvolvimento em colaboração entre o Laboratório de Neuroimagem (Neuroimago) do Departamento de Física e Matemática (FFCLRP) da USP e o Laboratório de Neurofisiologia do Comportamento (LabNeC) de Niterói (RJ).

\section{PARTICIPANTES}

Participaram do experimento 28 voluntários, universitários, assintomáticos, dos quais seis sujeitos tiveram seus dados excluídos, pelos motivos descritos abaixo, para garantir a qualidade do sinal de fMRI, restando um total de 22 voluntários (12 homens; 19-37 anos, média de 26,3 anos) para as análises dos dados. Todos sujeitos desconheciam os objetivos do experimento, não possuíam nenhum histórico de distúrbio neurológico e/ou psiquiátrico e não estavam fazendo uso de medicação com ação sobre o sistema nervoso central. Todos os sujeitos foram informados sobre os procedimentos e possíveis riscos associados às imagens por ressonância magnética, assinaram um termo de consentimento livre e esclarecido antes do início do experimento e, ainda, foram informados de que poderiam interromper a seção experimental a qualquer momento, caso desejassem. Os procedimentos e protocolos experimentais utilizados foram aprovados pelo Comitê de Ética em Pesquisa do CCM/UFF, parecer n $n^{\circ}$ 27/05 de 12/05/2005 e pelo Comitê de Ética em Pesquisa (CEP) do Hospital Clementino Fraga Filho, da UFRJ (CEP - MEMO - 354-05, cópia em anexo). A aquisição das imagens foi realizada no Hospital das Clínicas da Faculdade de Medicina de Ribeirão Preto (Universidade de São Paulo).

Das 6 exclusões realizadas, uma delas foi por perda parcial dos dados brutos (as imagens não foram salvas corretamente) e outras quatro pela presença de artefatos nas imagens (3 artefatos de susceptibilidade e 1 artefato gerado por problemas no cabeçalho DICOM). Ainda, o último descarte foi pautado pela constatação de que o voluntário teve tanto uma pontuação alta na escalas psicométricas, que revelam distúrbios psico-emocionais e históri- 
co de trauma ( $\mathrm{SRQ}=13$ e $\mathrm{THQ}=7$ - escalas presentes em anexo), quanto um desempenho comportamental incompatível com a realização da tarefa (muita aceleração no tempo de resposta quando as figuras eram aversivas). Neste último caso, recorremos aos três critérios para estabelecer o corte, já que a inclusão dos dados do voluntário nas análises de grupo em fMRI poderia favorecer uma alteração de sinal devido a uma variável de confusão, e que poderia mascarar as variáveis de interesse deste estudo.

\section{AQUISIÇÃO DOS DADOS DE FMRI}

Utilizamos um tomógrafo de 1,5 T da Siemens (Magnetom Vision) com uma bobina de cabeça, de quadratura de fase, transmissora e receptora, para a aquisição das imagens. Uma sequência do tipo single-shot $\mathrm{EPI}(\mathrm{TR}=3080 \mathrm{~ms}$, TE $=60 \mathrm{~ms}$, IST (inter-slice-time) $=104 \mathrm{~ms}$, ângulo de flip $90^{\circ}$, matriz de 64 x 64, FOV de $240 \mathrm{~mm}$ e dimensão de voxel igual a 3,75 mm x 3,75 mm x 4,00 mm) foi utilizada para adquirir 188 volumes continuamente, cada volume constituído de 25 fatias axiais, com $4 \mathrm{~mm}$ de espessura cada uma e sem GAP entre as fatias. Os volumes foram adquiridos de forma concomitante com a apresentação dos estímulos (intervalo entre estímulos, ou inter-stimulus-interval, ISI $=3080 \mathrm{~ms}$ ), por meio da utilização de um gatilho (trigger). Após a aquisição das imagens funcionais, uma sequência do tipo MPR ponderada em T1 (TR= 9,7 ms, TE $=4 \mathrm{~ms}$, ângulo flip $12^{\circ}$, de 160 fatias, sem GAP entre as fatias, com matriz de 256 x 256, FOV de $256 \mathrm{~mm}$ e dimensão de voxel igual a $1 \mathrm{~mm}$ x 1 $\mathrm{mm} \times 1 \mathrm{~mm}$ ) foi utilizada para gerar imagens anatômicas de maior resolução espacial, para sobreposição dos mapas estatísticos.

\section{PROTOCOLO DE ESTUDO}

As imagens cerebrais de todos sujeitos foram adquiridas continuamente enquanto eles eram estimulados visualmente, instruídos a executar diferentes tarefas e respondê-las por meio de um dispositivo contendo dois botões. O estímulo visual continha uma figura central e duas barras laterais (figura 11). O sujeito era instruído a manter os olhos fixos em um ponto de fixação no centro da tela e pressionar o botão de resposta o mais rápido possível. Antes do início da sessão, os sujeitos realizaram um treino de quatro minutos, cujos resultados não 
foram analisados. Durante o experimento, o tempo de resposta e a opção escolhida eram registrados para análise. Eram consideradas respostas incompatíveis, e por conseguinte não entraram nas análises, quando o sujeito apertava o interruptor antes do aparecimento do alvo, ou com um tempo de reação menor do que 100 ms, ou maior do que 1000 ms. Nos dados comportamentais, as medianas dos tempos de reação das respostas corretas foram submetidas a análises planejadas usando teste-t de Student. Já para os cálculos da taxa de erros, foram considerados apenas os erros de tecla, sendo que as respostas lentas e antecipadas também foram excluídas. Neste caso, as médias do número de erros foram submetidas a análises de planejadas usando teste-t de Student.

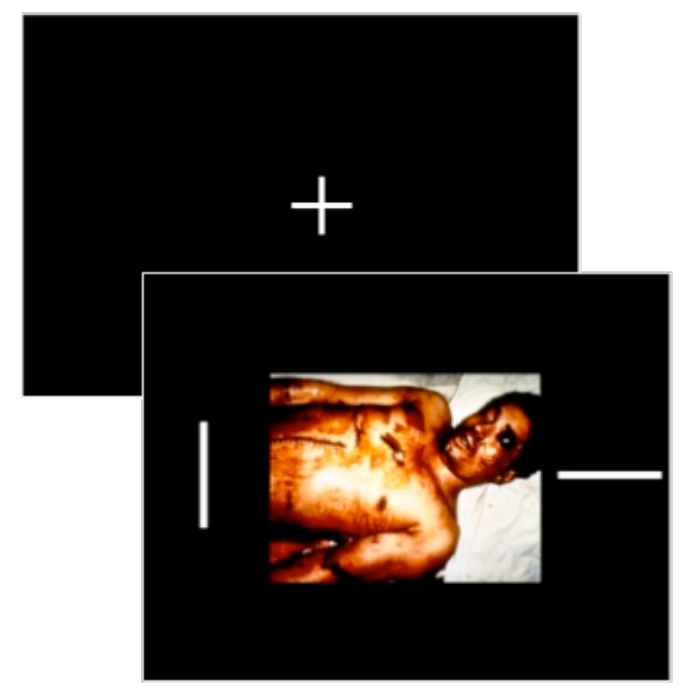

Figura 11: Exemplar da estimulação visual, com a figura central e as barras no campo visual periférico $\left(5,5^{\circ}\right.$ à direita e à esquerda do centro da figura), após o aparecimento da tela indicando o ponto de fixação.

Cada sujeito realizou uma única sessão experimental dividida em quatro séries (RUN), dos quais 2 séries não foram analisadas nesta tese, pois pertenciam a outro estudo (Mocaiber et al., 2009). Na sessão experimental, cada série durava 9 minutos e, ao final, o sujeito ficava mais 8 minutos dentro do tomógrafo para a aquisição das imagens estruturais (figura 12). 


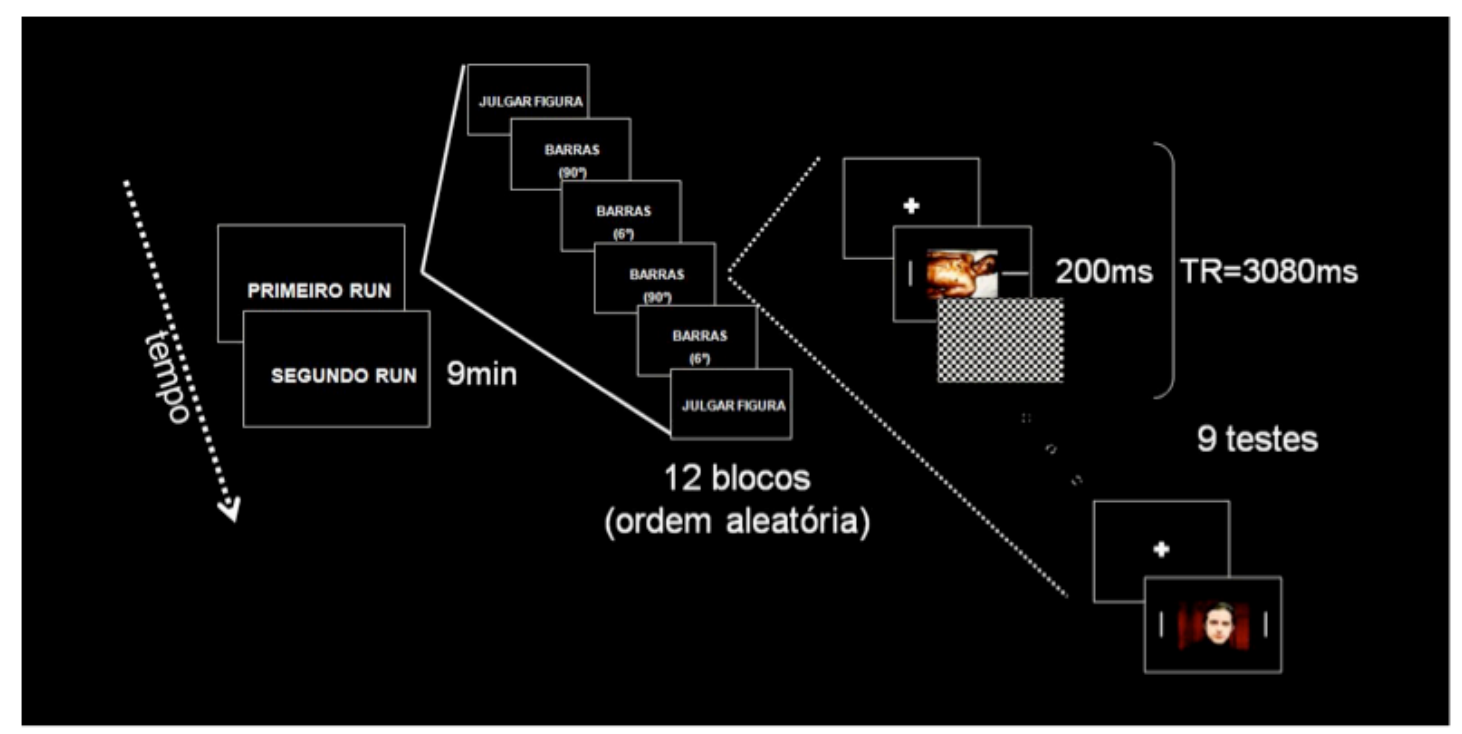

Figura 12. Representação esquemática do protocolo experimental utilizado. Cada teste durava o tempo de um TR $(3080 \mathrm{~ms})$ e os sujeitos eram instruídos a voltar os olhos para um ponto de fixação que aparecia na tela, por 500 milisegundos para, depois, aparecer o estímulo do teste por 200 milisegundos. Cada bloco era composto de 9 testes. O Run, por sua vez, era composto por 12 blocos no total, distribuídos entre as tarefas. Para este experimento, a sessão era composta de dois Runs.

Ao longo do experimento, conforme a alocação e a demanda de atenção dos sujeitos nas tarefas, temos: uma tarefa de julgamento do conteúdo emocional da figura (JULGA); e duas tarefas de discriminação da orientação das barras (BARRAS), uma tarefa mais fácil com barras orientadas com diferença de $90^{\circ}$ entre elas (FÁCIL) e uma tarefa bem mais difícil com barras orientadas com uma diferenças de $6^{\circ}$ entre elas (DIFÍCIL). Na tarefa JULGA, o sujeito deveria avaliar se a figura era aversiva ou neutra e a atenção deveria estar alocada para o centro do campo visual. Nas tarefas FÁCIL e DIFÍCIL, o sujeito deveria avaliar se a orientação das barras era igual ou diferente e a atenção deveria ser alocada para o campo visual periférico, sendo que a tarefa DIFÍCIL deveria demandar muito mais atenção do que a tarefa FÁCIL. É importante notar que, nas tarefas DIFICIL e FÁCIL, as figuras também poderiam aparecer com conteúdo aversivo ou neutro, aleatoriamente. Em resumo, havia três tipos de blocos de tarefa no experimento: JULGA, FÁCIL e DIFÍCIL. A ordem de apresentação dos blocos também era aleatória e diferente para cada sujeito, assim como a ordem das figuras ao longo das tarefas.

Na tarefa JULGA, o sujeito recebia a instrução para ignorar as barras e direcionar sua atenção para a figura central a fim de discriminar seu conteúdo emocional, que poderia ser aversiva ou neutra. Se julgasse que a figura era de conteúdo aversivo, o sujeito deveria pres- 
sionar o botão direito e se julgasse que ela era neutra, pressionaria o botão esquerdo. Já nas duas tarefas de BARRAS, o sujeito era instruído a ignorar a figura e concentrar-se nas barras, pois sua tarefa era discriminar se as barras tinham orientação igual ou diferente. Se as barras fossem julgadas como tendo a mesma orientação, o sujeito deveria pressionar o botão direito e, se fossem diferentes, pressionaria o botão esquerdo. Tanto a opção selecionada como o o tempo de resposta eram registrados para todas as tarefas. Ao todo, pela combinação dos fatores atentivos e emocionais, temos 6 condições experimentais possíveis (ver figura 13): Julga-MUT, Julga-NEU, Fác-MUT, Fác-NEU, Dif-MUT, Dif-NEU.

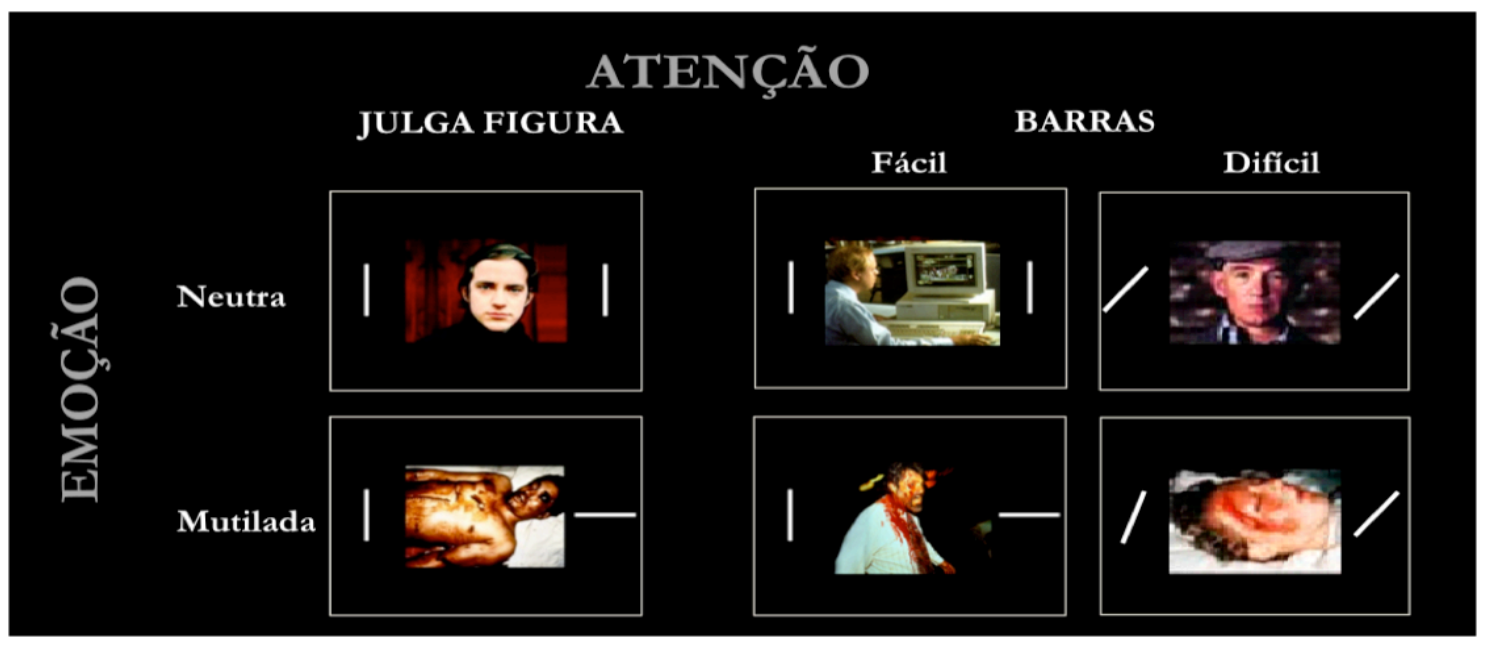

Figura 13: Ilustração das 6 condições experimentais possíveis: ao longo das três tarefas atentivas (JULGA, FÁCIL e DIFÍCIL), a figura central poderia ter conteúdo neutro ou emocional (imagens de mutilados). Na combinação dos fatores atenção e emoção, temos as condições Julga-MUT, Julga-NEU, Fác-MUT, Fác-NEU, Dif-MUT, Dif-NEU.

Ao todo foram apresentadas 72 figuras em cada uma das tarefas, sendo 36 aversivas e 36 neutras, em ordem aleatória e balanceadas nos blocos. Todas as figuras utilizadas na estimulação foram retiradas do banco de dados do IAPS (Lang et al., 1999b). Criamos um banco de imagens para o nosso experimento com um total de 144 imagens (72 aversivas e 72 neutras) seguindo alguns critérios de seleção. Todas figuras aversivas eram, caracteristicamente, de pessoas com seus corpos mutilados, com alta ativação (arousal) e baixa valência (valência negativa), enquanto que as figuras neutras eram compostas por pessoas ou partes de seus corpos íntegras. As figuras aversivas de mutilados também foram pareadas com as figuras neutras conforme o enfoque das fotografias à uma ou outra parte do corpo. As médias e desvio-padrão da ativação e da valência das figuras foram calculadas segundo os va- 
lores do IAPS (Lang et al., 1999b) e são apresentadas na tabela 1. Esse banco de imagens foi dividido em 5 conjuntos diferentes para diversificar os imagens entre os sujeitos.

\begin{tabular}{|c|c|c|c|}
\hline \multicolumn{4}{|c|}{ IAPS (144 FIGURAS) } \\
\hline \multicolumn{2}{|c|}{ VALÊNCIA } & \multicolumn{2}{|c|}{ ATIVACĀO } \\
\hline MUTILADO & NEUTRO & MUTILADO & NEUTRO \\
\hline $2,1(\mathrm{dp}=0,5)$ & $5,1(\mathrm{dp}=0,4)$ & $6,6(\mathrm{dp}=0,6)$ & $3,4(d p=0,7$ \\
\hline
\end{tabular}

Tabela 1: Descrição do banco de imagens selecionado e utilizados no experimento. As imagens foram separadas em função da média (e desvio padrão - dp) da valência e da ativação nas figuras, as quais foram pareadas conforme as categorias mutilado e neutro.

Utilizamos um desenho experimental do tipo misto (figura 14) para a apresentação dos estímulos. Cada série continha 12 blocos de tarefa (figura 12) e estes, por sua vez, eram de três tipos (4 blocos de cada) conforme tarefa requisitada. Já cada bloco de tarefas era composto de um período de instrução seguido de 9 períodos de testes com duração de 3 segundos cada um. Ao longo da série, os blocos de tarefa eram intercalados com períodos de repouso, durante os quais os sujeitos foram instruídos a manter os olhos na cruz de fixação, que era apresentada no centro da tela do computador por 15 segundos.

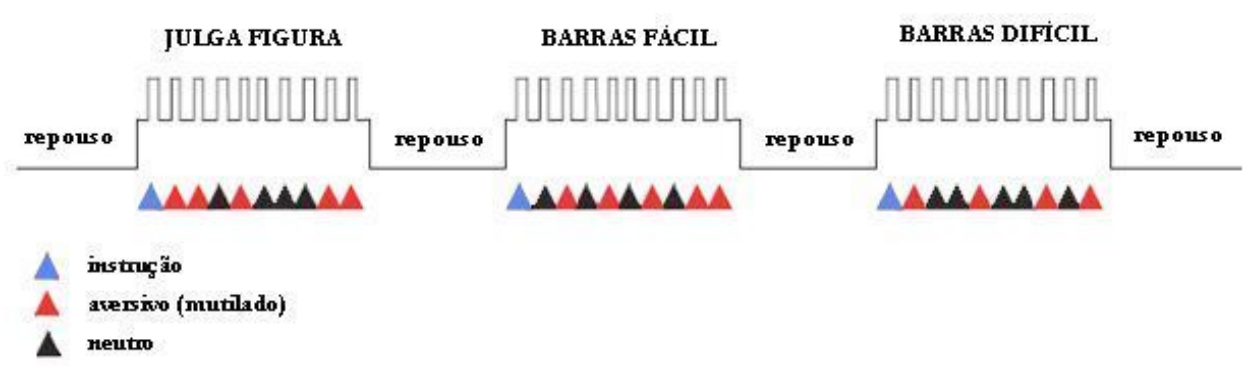

Figura 14: Representação do desenho misto com os três diferentes tipos de tarefa, separados em blocos, e a distribuição aleatória dos testes (triângulos coloridos) por tipo de figura utilizada no estímulo, com conteúdo neutro (triângulo preto) ou aversivo (triângulo vermelho). O primeiro evento do bloco é sempre a instrução da tarefa daquele bloco (triângulo azul).

Ao início de cada bloco, durante o período de instrução, permanecia na tela um texto que informava o tipo de tarefa daquele bloco e as duas opções de escolha da respectiva tarefa, 
que deveriam ser registradas nos botões de resposta. Em seguida, a sequência de 9 testes daquela tarefa era apresentada e o período de cada teste era dividido em três etapas distintas (ver figura 12): inicialmente, os sujeitos eram instruídos a voltar os olhos para um ponto de fixação que reaparecia na tela, desta vez, por 500 milisegundos; a seguir, o estímulo do teste era apresentado numa tela por 200 milisegundos e consistia de 2 pequenas barras posicionadas lateralmente, no campo visual periférico $\left(5,5^{\circ}\right.$ à direita e à esquerda do centro da figura), enquanto uma figura (aversiva ou neutra) aparecia no centro do campo visual (figura 11); por fim, após o estímulo teste apagar da tela, uma tela xadrez era apresentada até a resposta do sujeito àquela tarefa. Após a resposta do sujeito ao teste, e completado o intervalo entre testes de 3080 milissegundos, uma nova tela com a cruz de fixação aparecia reiniciando um novo teste até o término daquele bloco de tarefa.

\section{FMRI VOXEL-A-VOXEL DE CÉREBRO INTEIRO}

As análises foram feitas em duas etapas: sobre os dados voxel-a-voxel de cérebro inteiro, e sobre os dados de ROI's selecionadas a priori. Ambas foram conduzidas no software de processamento Brain Voyager TM (versão QX 1.9) com modelo linear geral (GLM). As quatro primeiras aquisições foram descartadas e as demais imagens foram pré-processadas para correção de movimento, correção temporal entre as fatias com interpolação linear, aplicação de um filtro temporal passa alta (FFT-Fast Fourier Transformation com 3 ciclos/ponto) e de um filtro gaussiano de suavização espacial FWHM de 8mm que, por fim, foram normalizadas pelo espaço padrão Talairach. A dimensão dos voxels foi redefinida durante o processo de normalização no Talairach em $1 \mathrm{~mm}$ x $1 \mathrm{~mm}$ x $1 \mathrm{~mm}$.

Para os cálculos do GLM, os estímulos foram modelados por uma função de resposta hemodinâmica (HRF) e separados em 7 modelos preditores independentes, um para cada condição experimental (Julga-MUT, Julga-NEU, Fác-MUT, Fác-NEU, Dif-MUT, Dif$\mathrm{NEU}$ ) e um último para as instruções das tarefas. Os parâmetros (betas) melhor ajustados, assim como o erro padrão e a significância estatística (valor-p) dos contrastes foram calculados individualmente antes de serem combinados nas análises de grupo por efeito aleatório (random effect analysis) voxel-a-voxel.

Para a análise dos dados voxel-a-voxel do cérebro inteiro, dois contrastes foram testados: Julga-MUT > Julga-NEU e BARRAS > JULGA FIGURA, de forma a localizar as mais 
prováveis redes emocional e atencional, respectivamente. Cada um desses contrastes reflete o cálculo dos múltiplos testes-t sobre a diferença dos valores de beta entre as condições Julga-MUT e Julga-NEU, e entre as tarefas BARRAS e JULGA FIGURA. O resultados desses cálculos serão apresentados nos mapas estatísticos voxel-a-voxel para diferentes limiares de corte (valor-p). Como o objetivo da análise de dados voxel-a-voxel do cérebro inteiro é apenas de localização de áreas cerebrais minimamente sensíveis às nossas manipulações experimentais para um uso posterior nas análises de ROI, manipulamos o limiar de corte para atingir um cluster (agrupamento) contíguo de, pelo menos, 50 voxels e que, também, não fosse muito extenso. Para isso, utilizamos um limiar de corte menos restritivo para o contraste Julga-MUT > Julga-NEU, de p $<0,05$ (não corrigido para múltiplas comparações) e, no contraste BARRAS > JULGA FIGURA, para restringimos a extensão das áreas cerebrais sensíveis a esse contraste, usamos um limiar mais restritivo, de $p<0,00005$ (corrigido para múltiplas comparações em qFDR<0,001).

\section{ANÁLISE DE ROI}

Todas as ROI's foram criadas a partir das regiões localizadas nos mapas voxel-a-voxel do cérebro inteiro para os contrastes Julga-MUT > Julga-NEU e BARRAS > JULGA FIGURA, filtradas e combinadas com as coordenadas anatômicas (do Atlas Talairach) de regiões de interesse para o nosso estudo. Os critérios de filtragem eram os que as áreas selecionadas deveriam ter um agrupamento contíguo de pelo menos 50 voxels, corresponder à substância cinzenta e que as coordenadas espaciais deveriam estar próximas de regiões anatômicas que correspondam uma hipótese a priori funcional, baseda em resultados de pesquisas similares como, no caso da emoção: amígdala, ínsula, giro do cíngulo, córtex pré-frontal medial, lateral e orbitofrontal. Ou seja, as regiões selecionadas deveriam ser coerentes com um processamento neural emocional e atentivo, tanto por hipóteses a priori, mas também por um critério de seleção funcional, pelo processamento emocional e atentivo, que tivesse sido detectável em nosso próprio experimento (variabilidade na citoarquitetura anatômica).

Os parâmetros (betas) melhor ajustados, assim como o erro padrão e a significância estatística (valor-p) dos contrastes, neste caso, foram calculados sobre a série temporal média de todos os voxels contidos em cada região de interesse (ROI) para cada sujeito. Posteriormen- 
te, esses mesmos valores de betas foram extraídos para as análises de correlação com as medidas das escalas psicométricas.

\section{ANALISE DE CORRELAÇÃO (ANCOVA)}

A partir das ROI's das amígdalas (direita e esquerda) criadas anteriormente, extraímos os valores de beta e calculamos os valores dos contrastes de interesse para cada sujeito. De posse dos valores de beta da resposta BOLD de cada indivíduo, calculamos a correlação desses dados com os dados comportamentais (tempo de resposta e erro nas tarefas), as escalas psicométricas (PANAS, IDATE-T e questionário de mutilados-MQ; em anexo) e, ainda, o critério de gênero dos sujeitos. A análise de correlação foi feita no software Brain Voyager TM (versão QX 1.9) e, em seguida, fizemos uma regressão linear e descrevemos os dados graficamente usando o software Statistica TM (versão 7)

Dos 22 sujeitos submetidos à análise por fMRI, houve falha no registro de dados comportamentais de 5 destes sujeitos. Desta forma, restaram 17 sujeitos para análise de correlação entre os dados comportamentais e os valores de beta da amígdala. Já as análises de correlação com as pontuações nas escalas psicométricas foram feitas sobre os mesmos 22 sujeitos avaliados na fMRI. 


\section{RESULTADOS}

\section{DADOS COMPORTAMENTAIS}

O desempenho nas tarefas, influenciado pela demanda de atenção e pela interferência das figuras emocionais sobre essas tarefas, pode ser observado na tabela 2, onde são apresentadas as taxas de erro e os tempos de resposta manual (TR) médios, acompanhados dos respectivos desvios-padrão (DP), nas condições de interesse. A combinação dessas duas informações nos permite avaliar a performance geral dos sujeitos nas tarefas e, ainda, os efeitos da demanda de atenção e da valência das figuras na resposta manual ao longo do experimento.

\begin{tabular}{|c|c|c|c|c|}
\hline & ERRO (\%) & DP & TR (mseg) & DP \\
\hline Julga NEU & 31,3 & 7,2 & 912,0 & 110,4 \\
\hline Julga MUT & 27,5 & 4,8 & 924,3 & 153,3 \\
\hline Fácil NEU & 25,8 & 7,1 & 926,8 & 112,1 \\
\hline Fácil MUT & 28,0 & 8,3 & 948,4 & 113,8 \\
\hline Difícil NEU & 46,6 & 8,9 & 1003,2 & 205,8 \\
\hline Difícil MUT & 45,3 & 11,2 & 1023,0 & 224,4 \\
\hline
\end{tabular}

Tabela 2: Acurácia no teste comportamental: médias e desvios padrão (DP) das taxas de erro (ERRO) e dos tempos de reação (TR), separados para cada condição experimental testada.

As diferenças das taxas de erro e dos tempos de resposta entre as condições experimentais foram avaliadas em comparações planejadas utilizando testes-t pareados. A figura 15 ilustra as diferenças nas taxas de erro nas tarefas. Observamos uma taxa de erro mais alta do que em estudos similares fora de um tomógrafo de ressonância magnética (Erthal et al., 2005). Isto pode indicar uma demanda de atenção ainda mais alta do que o esperado em todas as tarefas. Especialmente, a análise da taxa de erro na tarefa difícil, próximo de $50 \%$, poderia sugerir que os sujeitos adotaram escolhas ao acaso e, dessa forma, poderia representar uma diminuição da carga atentiva. Entretanto, devemos notar que uma diferença entre o tempo de resposta nas tarefas difícil e fácil, maior na tarefa difícil $(\mathrm{p}<0,05)$, assim como os resulta- 
dos de fMRI que serão apresentados na próxima seção, são indicativos do engajamento dos sujeitos nesta situação e do aumento expressivo da demanda de atenção na tarefa difícil.

\section{ERRO (\%)}

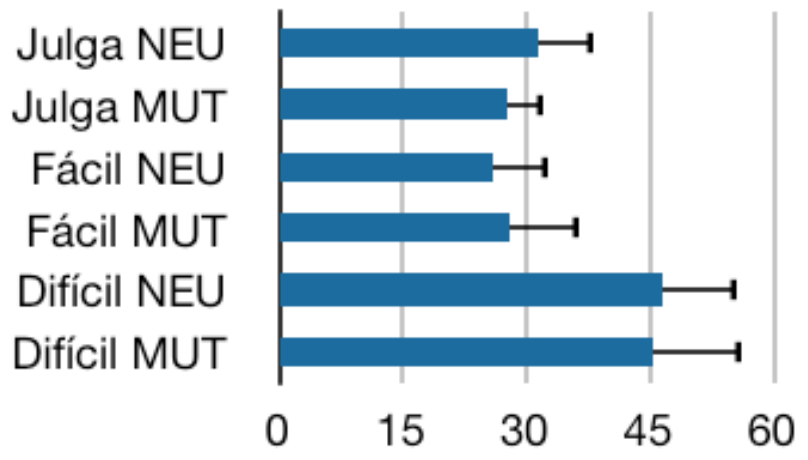

Figura 15: Médias e desvios padrão das taxas de erro em cada condição experimental. Há diferença na performance dos sujeitos na comparação entre a tarefa difícil (Difícil MUT e Difícil NEU) e as outras tarefas $(p<0,05)$. Já entre as tarefas fácil e de julgamento de figuras a performance foi equivalente.

Não houve efeito significativo da valência sobre a taxa de erro nas tarefas, ou seja, as figuras aversivas não interferiram na performance dos sujeitos. $\mathrm{Na}$ análise dos tempos de resposta manual, só houve efeito da valência na tarefa fácil (tabela 3), diferentemente das tarefas difícil e de julgar figuras. Na tarefa fácil, os sujeitos foram significativamente mais lentos $(\mathrm{p}<0,04)$ para julgar a orientação das barras quando a figura não-atendida era de conteúdo emocional aversivo (média de 948,4ms) do que quando a figura era neutra (média de 926,8ms). Esse resultado é indicativo de que as imagens aversivas, mesmo irrelevantes para a tarefa, interferiram no processamento da tarefa principal (BARRAS) lentificando os tempos de resposta. No entanto, não houve retardo no tempo de reação por efeito da valência emocional da figura nas tarefas difícil (MUTILADOS: média=1023,0ms; NEUTRA: média=1003,2ms; $p=0,61$ e de julgar figura (MUTILADOS: média= 924,3ms; NEUTRA: média $=912,0 \mathrm{~ms} ; \mathrm{p}=0,92)$. Especialmente na tarefa difícil, a altíssima demanda de processamento (performance da tarefa foi de $\sim 53 \%$ de acertos) deve ter sido crítica para modular o efeito de interferência das figuras aversivas. 


\begin{tabular}{|lllll|l|}
\hline \multicolumn{1}{c}{ TR (mseg) } & \multicolumn{2}{c}{ DP } & \multicolumn{1}{c|}{ p } \\
\hline Julga MUT - Julga NEU & $-1,7$ & 66,5 & 0,92 \\
\hline Fácil MUT - Fácil NEU & 21,6 & 57,1 & 0,04 \\
\hline Difícil MUT - Difícil NEU & 19,8 & 86,0 & 0,61
\end{tabular}

Tabela 3: Médias e desvios padrão da diferença nos tempos de reação (TR) representativos do efeito da valência em cada tarefa. Existe efeito da valência na tarefa fácil $(p=0,04)$.

\section{FMRI}

A primeira análise dos dados de fMRI, de cérebro inteiro (voxel-a-voxel) teve um caráter exploratório, e permitiu localizar as regiões cerebrais que compõe as duas principais redes neurais envolvidas nas tarefas, uma associada ao processamento emocional e a outra associada às diferenças no processamento da atenção. Em seguida, em uma etapa mais específica, foram realizadas as análises de ROI e de correlação, sobre as regiões cerebrais identificadas na primeira fase de análise.

As principais áreas da rede de processamento emocional foram detectadas pelo efeito da valência na tarefa de julgamento emocional das figuras, com o contraste Julga-MUT > Julga-NEU e com limiar estatístico p<0,05 (não-corrigido) (ver tabela 4). Elas são mostradas na figura 16 no formato de córtex inflado. 


\begin{tabular}{|c|c|c|c|c|c|c|}
\hline Área & $\begin{array}{l}\text { Área de } \\
\text { Brodmann }\end{array}$ & $\begin{array}{l}\text { Esquerda } \\
\text { /Direita }\end{array}$ & $\begin{array}{l}\text { Coo } \\
X\end{array}$ & $\begin{array}{r}\text { adas } \\
Y\end{array}$ & $\begin{array}{r}\text { irach } \\
\text { Z }\end{array}$ & $\begin{array}{l}N^{\circ} \text { de } \\
\text { voxels }\end{array}$ \\
\hline Amígdala & & $\begin{array}{l}E \\
D\end{array}$ & $\begin{array}{l}-24 \\
20\end{array}$ & $\begin{array}{l}-5 \\
-4\end{array}$ & $\begin{array}{l}-12 \\
-13\end{array}$ & $\begin{array}{l}233 \\
107\end{array}$ \\
\hline CPF Medial & 10 & $\begin{array}{l}E \\
D\end{array}$ & $\begin{array}{l}-5 \\
5\end{array}$ & $\begin{array}{l}53 \\
53\end{array}$ & $\begin{array}{l}11 \\
11\end{array}$ & $\begin{array}{l}645 \\
351\end{array}$ \\
\hline $\begin{array}{l}\text { CPF Ventrolate- } \\
\text { ral }\end{array}$ & 46 & $\begin{array}{l}E \\
D\end{array}$ & $\begin{array}{l}-47 \\
45\end{array}$ & $\begin{array}{l}41 \\
34\end{array}$ & $\begin{array}{l}10 \\
14\end{array}$ & $\begin{array}{l}589 \\
322\end{array}$ \\
\hline Cíngulo Posterior & $30 / 29 / 23$ & $\mathrm{E}$ & -3 & -41 & 22 & 201 \\
\hline Cíngulo Anterior & $24 / 32$ & $\begin{array}{l}E \\
D\end{array}$ & $\begin{array}{l}-4 \\
5\end{array}$ & $\begin{array}{l}42 \\
38\end{array}$ & $\begin{array}{c}7 \\
10\end{array}$ & $\begin{array}{l}387 \\
385\end{array}$ \\
\hline Ínsula & 13 & $\mathrm{E}$ & -36 & 16 & -1 & 448 \\
\hline Orbitofrontal & 47 & $\mathrm{E}$ & -38 & 18 & -7 & 574 \\
\hline
\end{tabular}

Tabela 4: Áreas prováveis de processamento emocional, dadas pelo efeito BOLD na tarefa de julgar a valência das figuras com contraste JulgaMUT > JulgaNEU. Para todas estas áreas, o efeito da valência foi maior na condição de baixa valência (JulgaMUT) do que neutra (JulgaNEU). CPF: Córtex Pré-Frontal.

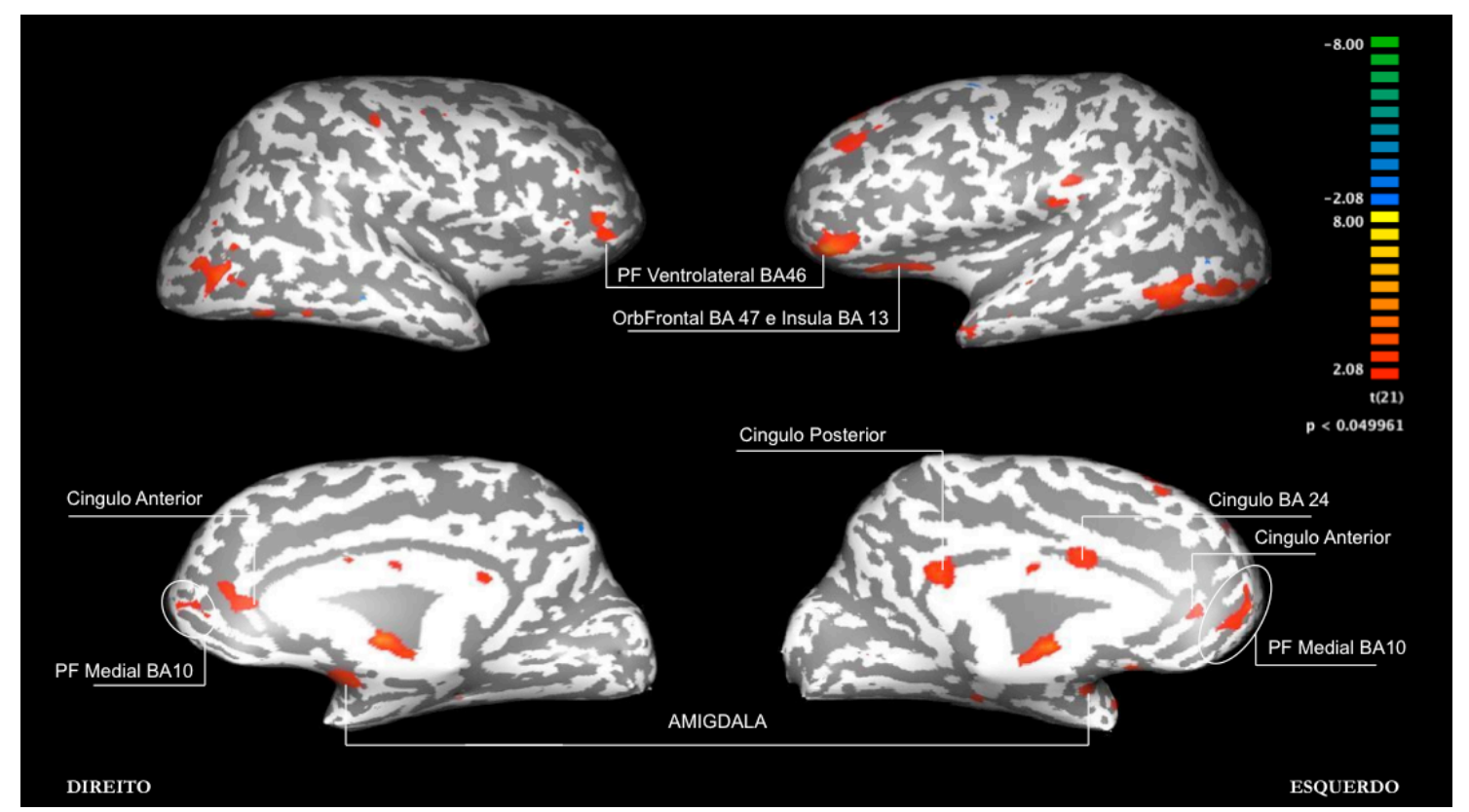

Figura 16: Mapa inflado do córtex cerebral com os dois hemisférios separados, direito e esquerdo, e sob uma visão lateral (acima) e uma visão medial (abaixo). O contraste Julga- 
MUT $>$ JulgaNEU, com limiar estatístico $\mathrm{p}<0,05$ (não-corrigido), denota regiões cerebrais com diferenças de processamento emocional.

Para detectar as principais regiões cerebrais envolvidas no processamento da atenção, utilizamos o contraste Julgar BARRAS $>$ Julgar FIGURA e um limiar estatístico qFDR<0,001 $(p<0,00005)$. Desta forma, visamos selecionar as regiões sujeitas, principalmente, ao efeito da atenção espacial nas tarefas de julgamento de figura e de julgamento de barras (figura 17). Podemos dividir essas regiões em dois grupos: daquelas que apresentaram maior amplitude da resposta BOLD estimada (valores de beta) na tarefa de julgar BARRAS (ver tabela 5), representadas por cores quentes na figura 17, e daquelas que apresentaram maior amplitude da resposta BOLD na tarefa de Julgar FIGURA (ver tabela 6), representadas por cores frias na figura 17.

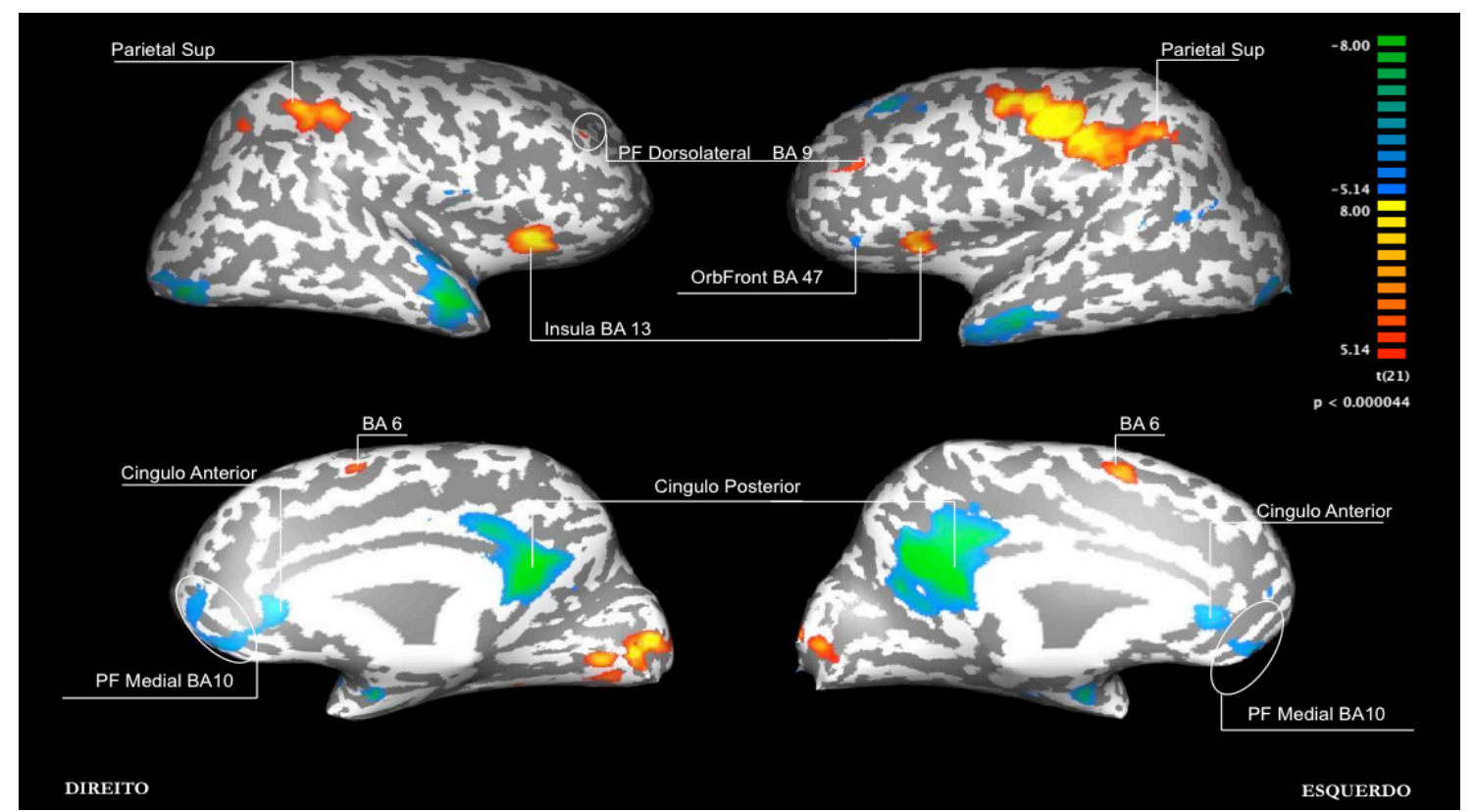

Figura 17: Mapa inflado do córtex cerebral com os dois hemisférios separados, direito e esquerdo, e sob uma visão lateral (acima) e uma visão medial (abaixo). O contraste Julgar BARRAS > Julgar FIGURA, com limiar estatístico qFDR $<0,001 \quad(p<0,00005)$, denota regiões cerebrais com diferenças de processamento da atenção. 


\begin{tabular}{|c|c|c|c|c|c|c|}
\hline \multirow[t]{2}{*}{ Área } & \multirow{2}{*}{$\begin{array}{l}\text { Área de } \\
\text { Brodmann }\end{array}$} & \multirow{2}{*}{$\begin{array}{l}\text { Esquerda/ } \\
\text { Direita }\end{array}$} & \multicolumn{3}{|c|}{ Coordenadas Talairach } & \multirow{2}{*}{$\begin{array}{l}N^{\circ} \text { de } \\
\text { voxels }\end{array}$} \\
\hline & & & & $\mathbf{Y}$ & Z & \\
\hline CPF Dorsolateral & 9 & $E$ & -43 & 35 & 35 & $\begin{array}{l}193 \\
79\end{array}$ \\
\hline Parietal Superior & 7 & $\begin{array}{l}E \\
D\end{array}$ & $\begin{array}{l}-25 \\
26\end{array}$ & $\begin{array}{l}-58 \\
-58\end{array}$ & $\begin{array}{l}44 \\
45\end{array}$ & $\begin{array}{l}117 \\
152\end{array}$ \\
\hline Ínsula & 13 & $\begin{array}{l}E \\
D\end{array}$ & $\begin{array}{l}-35 \\
36\end{array}$ & $\begin{array}{l}15 \\
18\end{array}$ & $\begin{array}{c}11 \\
8\end{array}$ & $\begin{array}{l}319 \\
588\end{array}$ \\
\hline $\begin{array}{l}\text { Área Motora Su- } \\
\text { plementar }\end{array}$ & 6 & $\begin{array}{l}E \\
D\end{array}$ & $\begin{array}{l}-3 \\
4\end{array}$ & $\begin{array}{l}0 \\
1\end{array}$ & $\begin{array}{l}51 \\
51\end{array}$ & $\begin{array}{l}272 \\
228\end{array}$ \\
\hline
\end{tabular}

Tabela 5: Áreas prováveis de processamento da atenção, sujeitas à modulação neural pela alocação da atenção nas tarefas de julgamento de barras. Na condição indicada pelo contraste BARRAS > JULGAR FIGURA, estas regiões cerebrais apresentaram maior amplitude da resposta BOLD estimada para BARRAS do que para a tarefa de julgamento de valência das figuras. CPF: Córtex Pré-Frontal.

\begin{tabular}{|c|c|c|c|c|c|c|}
\hline \multirow[t]{2}{*}{ Área } & \multirow{2}{*}{$\begin{array}{l}\text { Área de } \\
\text { Brodmann }\end{array}$} & \multirow{2}{*}{$\begin{array}{c}\text { Direita/ } \\
\text { Esquer } \\
\text { da }\end{array}$} & \multicolumn{3}{|c|}{ Coordenadas Talairach } & \multirow{2}{*}{$\begin{array}{l}N^{\circ} \text { de } \\
\text { voxels }\end{array}$} \\
\hline & & & $\mathbf{x}$ & $\mathbf{Y}$ & $\mathbf{z}$ & \\
\hline CPF Medial & 10 & $\begin{array}{l}E \\
D\end{array}$ & $\begin{array}{c}-5 \\
5\end{array}$ & $\begin{array}{l}48 \\
48\end{array}$ & $\begin{array}{l}-6 \\
-5\end{array}$ & $\begin{array}{l}257 \\
232\end{array}$ \\
\hline Órbitofrontal & 47 & $E$ & -33 & 30 & -10 & 177 \\
\hline Cíngulo Posterior & $30 / 29 / 23 / 31$ & $\begin{array}{l}E \\
D\end{array}$ & $\begin{array}{l}-5 \\
5\end{array}$ & $\begin{array}{l}-51 \\
-49\end{array}$ & $\begin{array}{l}16 \\
17\end{array}$ & $\begin{array}{c}1304 \\
993\end{array}$ \\
\hline Cíngulo Anterior & $24 / 32 / 10$ & $\begin{array}{l}E \\
D\end{array}$ & $\begin{array}{c}-4 \\
4\end{array}$ & $\begin{array}{l}38 \\
39\end{array}$ & $\begin{array}{l}-1 \\
-2\end{array}$ & $\begin{array}{l}560 \\
552\end{array}$ \\
\hline
\end{tabular}

Tabela 6: Áreas prováveis de processamento emocional sujeitas à modulação pela alocação da atenção na tarefa. No contraste BARRAS > JULGAR FIGURA, estas regiões cerebrais apresentaram maior amplitude da resposta BOLD estimada para JULGAR FIGURA do que para as tarefas de julgamento de barras. CPF: Córtex Pré-Frontal. 
A análise de ROI revelou as diferenças entre os valores de beta estimados para cada uma das condições experimentais, sobre as áreas cerebrais de interesse para este estudo. Somente nesta etapa da análise pudemos fazer as comparações entre cada uma das condições. Conforme descrito na última seção (para melhores detalhes, consultar o capítulo de métodos), as ROI foram criadas a partir das regiões cerebrais localizadas na etapa anterior, pela análise de cérebro inteiro, sobre as quais é possível obter os valores de beta para cada uma das condições e construir gráficos a partir desses valores. A apresentação desses resultados está agrupada e se refere àquelas regiões associadas ao processamento emocional e às relacionadas ao processamento da atenção. Além disso, foi feita uma separação das ROIs conforme as características das modulações nos valores de beta.

Primeiramente, apresentaremos um conjunto de resultados associado ao processamento emocional. Nestes, dois tipos de modulação nos valores de beta foram encontrados ao longo das condições experimentais. No primeiro tipo, observado caracteristicamente na amígdala, os valores de beta encontrados na condição Julga-MUT (representativos do processamento emocional) foram reduzidos durante as tarefas de barras. Esse resultado é indicativo de um processo de regulação emocional. O segundo tipo de modulação, observado nas ROIs da ínsula anterior e do córtex orbitofrontal, descreve que os valores de beta encontrados na condição Julga-MUT foram inicialmente reduzidos na tarefa FÁCIL mas, posteriormente, aumentados na condição Difícil-MUT. Esse resultado sugere a ocorrência de um segundo processo, que não era previsto, de características emocionais e que aparecem apenas na condição Difícil-MUT. Estes dois tipos de modulação serão descritos a seguir.

A amígdala, como uma estrutura central para o processamento emocional de estímulos ameaçadores, apresentou um comportamento típico de regulação emocional visto no sinal BOLD, assim como o córtex pré-frontal medial (BA10), o córtex pré-frontal ventrolateral (BA46), do giro cingulado posterior, apresentados na figura 18. O comportamento característico, nesse caso, é um aumento dos valores de beta por efeito da valência na tarefa de julgamento de figuras, ou seja, aumento de resposta BOLD para o julgamento de figuras aversivas em relação ao julgamento de figuras neutras mas, ainda, nas condições em que a atenção foi direcionada para outra tarefa (tarefas de barras), houve uma atenuação dos valores de beta mesmo nas condições em que foram apresentadas as figuras aversivas (FacMUT e Dif-MUT). Esse efeito não foi significativo no giro cingulado anterior (figura 19). 

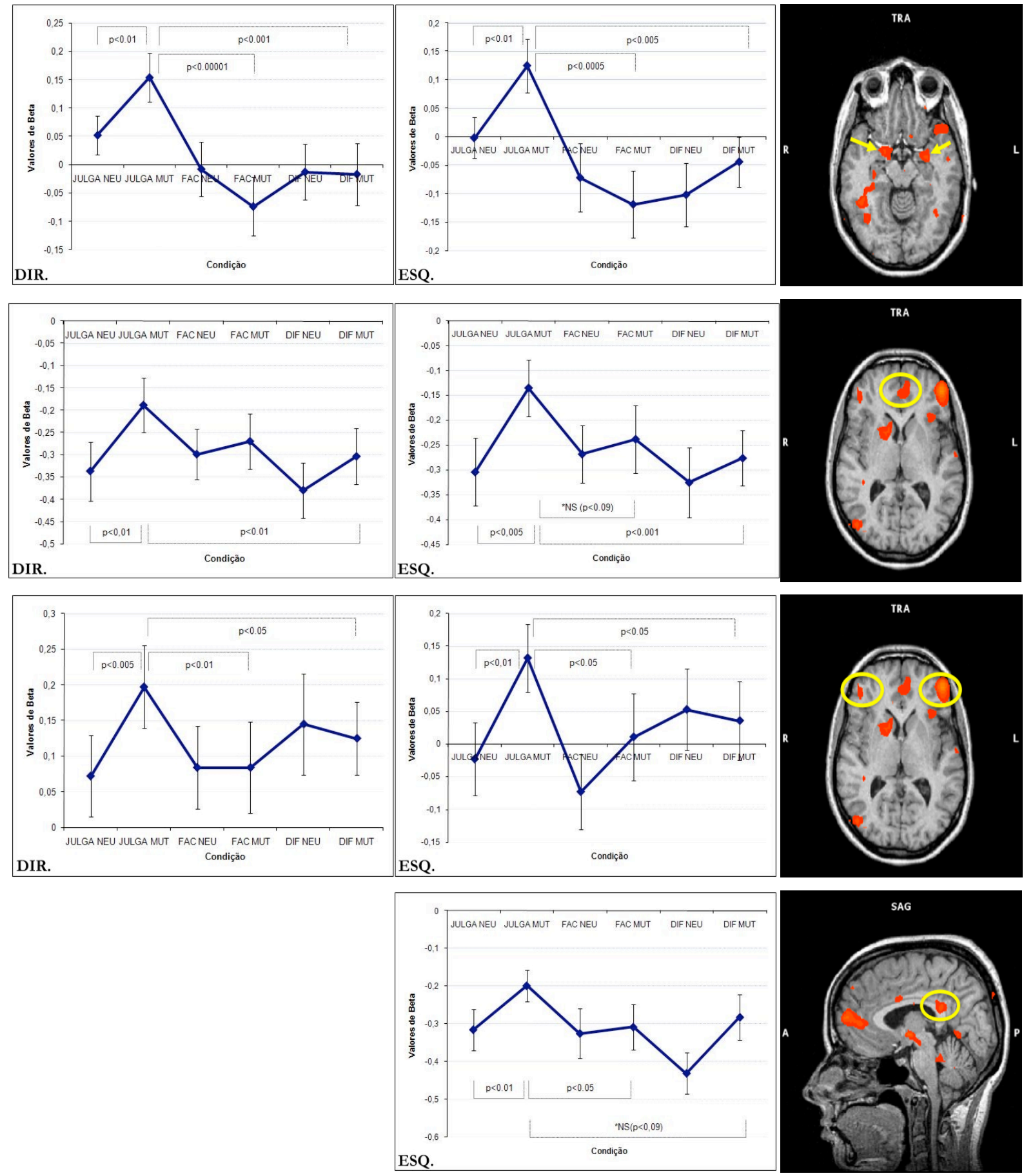

Figura 18: De cima para baixo, gráficos das ROIs da Amígdala, Córtex Pré-frontal Medial (BA10), Córtex Pré-frontal Ventrolateral (BA46) (bilaterais) e Cíngulo Posterior (lateralizada à esquerda), com a representação dos valores de beta estimados para o sinal BOLD. Neste conjunto de ROI's, observamos uma diminuição significativa de sinal se compararmos a condição Julga-MUT com as demais condições experimentais, representativa da regulação emocional pela atenção. 

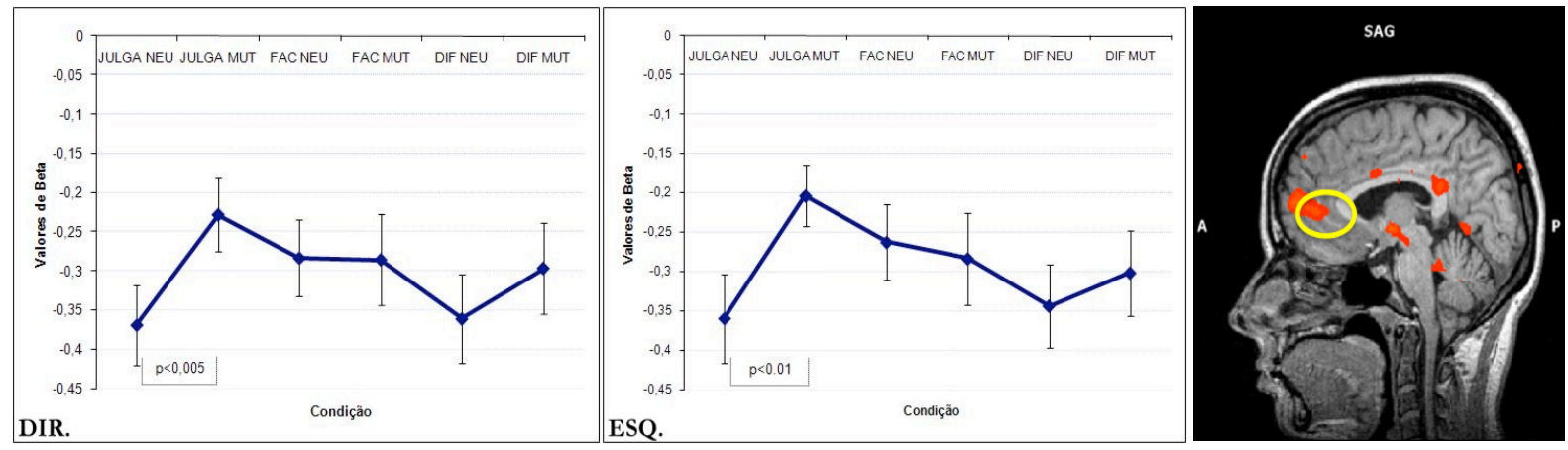

Figura 19: Gráfico da modulação do sinal no Córtex Anterior do Cíngulo, bilateral, pelo efeito da valência das figuras entre as condições Julga-MUT e Julga-NEU. Nesta ROI não houve efeito de regulação significativo nas tarefas fácil e difícil.

Regiões da ínsula e do córtex órbito-frontal apresentaram um comportamento um pouco diferente das ROI's apresentadas anteriormente (Figura 20). Nesse caso, tomando a condição Julga-MUT como referência, observamos um valor de beta menor tanto na condição Julga-NEU, por efeito da valência, como na tarefa de barras fácil (Fac-MUT) por efeito da alocação da atenção. Porém, esse valor volta a crescer na condição Dif-MUT e alcança o mesmo patamar daqueles encontrados na condição Julga-MUT. Ao longo das tarefas, os resultados são compatíveis com a idéia de que apesar do processsamento emocional dessas estruturas na condição Julga-MUT ser reduzido na condição Fácil-MUT, indicando uma regulação emocional nesta condição, o processamento emocional volta a ser equivalente entre as condições Julga-MUT e Dif-MUT e, neste caso, o processamento emocional não pôde modulado pela atenção na tarefa. Então, considerando que estas ROIs estão envolvidas no processamento emocional, a regulação emocional parece não ter efeito sobre esse processamento na condição Dif-MUT. 

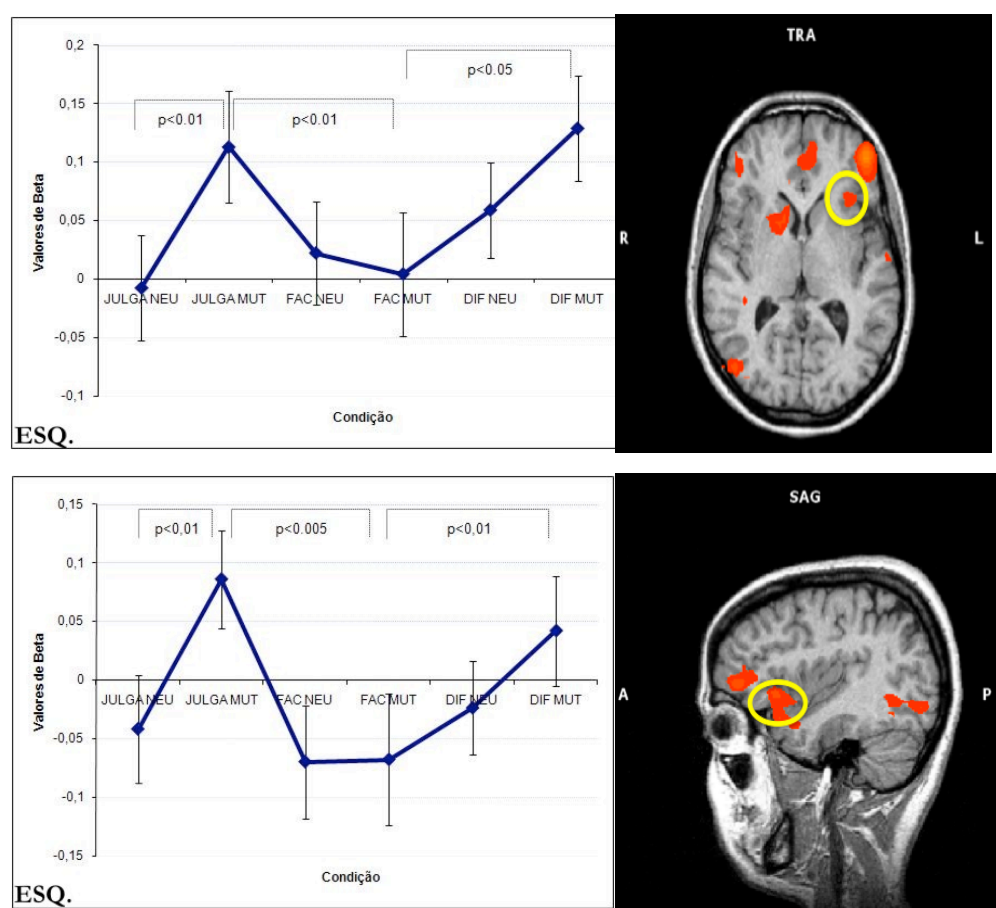

Figura 20: De cima para baixo, gráficos das ROIs na Ínsula Anterior e no Córtex Orbitofrontal, lateralizados à esquerda, com diferença significativa de sinal por efeito da tarefa entre Julga-MUT e Fac-MUT ( $\mathrm{p}<0,01$ para a ínsula anterior e $\mathrm{p}<0,005$ para o córtex orbitofrontal), representativo de uma regulação emocional pela atenção. Porém, o mesmo não ocorre entre as condições Julga-MUT e Dif-MUT, pois os valores de beta tornam-se equivalentes. Na condição Dif-MUT, a regulação emocional parece não ter efeito.

Outro conjunto de resultados descreve o comportamento das ROI's associadas ao processamento da atenção. Também dividimos as ROI's em dois conjuntos, conforme as semelhanças encontradas nos valores de beta: aquelas ROIs representativas da condição em que a atenção está alocada fora do alvo emocional, que respondem relativamente mais às tarefas de barras e que, neste caso, apresentam valores de beta maiores; e aquelas ROIs que respondem relativamente mais para a tarefa de julgamento das figuras e então, apresentam valores de beta maiores para JULGA.

$\mathrm{Na}$ figura 21, a seguir, apresentamos os gráficos com os resultados das análises de ROI do conjunto de ROI's associados à maior alocação da atenção nas tarefas. Em geral, nessas ROIs, observamos que os valores de beta são relativamente maiores, conforme era esperado, para as tarefas de barras do que para a tarefa de julgamento das figuras (JULGA). Isto pode sugerir tanto um efeito pelo deslocamento espacial da atenção para as tarefas fácil e difícil, quanto um efeito do aumento de demanda de atenção, conforme as diferenças dos valores de beta estimados em cada tarefa. Em especial, em todas as ROIs apresentadas na 
figura 21, os valores de beta foram significativamente maiores na tarefa difícil do que na tarefa de julgamento das figuras. Assim, podemos dizer que existe um efeito da atenção nas tarefas sobre o processamento neural nessas regiões.
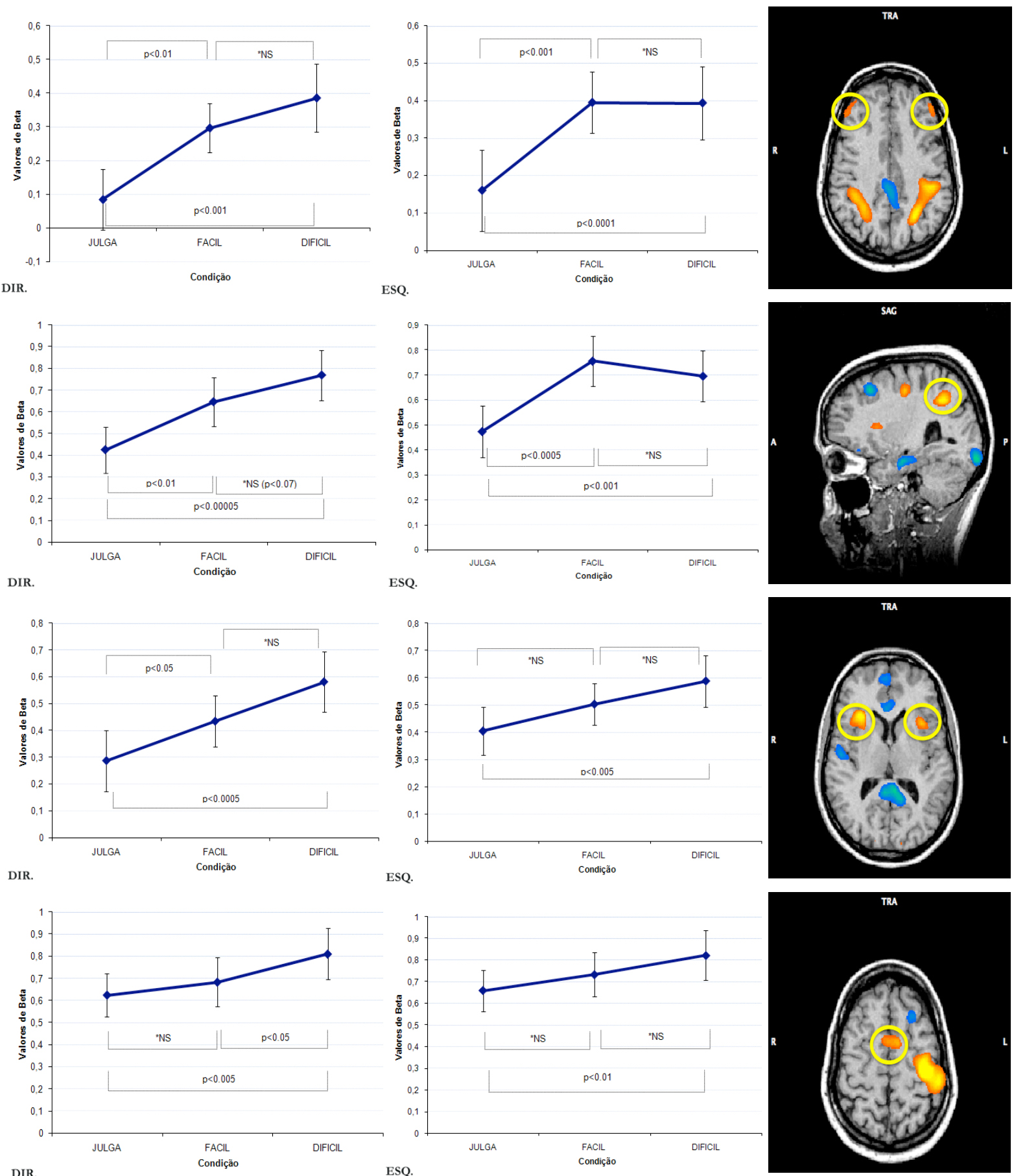

Figura 21: De cima para baixo, gráficos das ROIs dos córtices PF Dorsolateral, Parietal Superior, Ínsula Anterior e Área Motora Suplementar (BA 6). Nestas ROI's, observamos uma tendencia de aumento gradual de sinal BOLD entre a tarefa de julgamento de figura (JULGA) e as tarefas FÁCIL e DIFÍCIL. Os valores de beta foram significativamente maiores na tarefa difícil do que na tarefa de julgamento das figuras e podem representar o aumento da demanda de processamento para a atenção. 
No segundo conjunto de ROI's, temos regiões que responderam relativamente mais para a tarefa de julgamento das figuras, em que a atenção está alocada para o próprio alvo emocional, do que para as tarefas de julgamento de barras (Figura 22). Nos gráficos da análise dessas ROIs, observamos que os valores de beta são relativamente maiores para a tarefa de julgamento das figuras (JULGA) do que para as tarefas de barras, associados ao efeito da atenção para o julgamento das figuras. Em contraste com o primeiro conjunto de ROIs (figura 21), todas essas ROIs apresentadas na figura 22 tem valores de beta significativamente maiores na tarefa de julgamento das figuras do que na tarefa difícil, que são indicativos efeito do julgamento emocional sobre processamento neural nessas regiões.
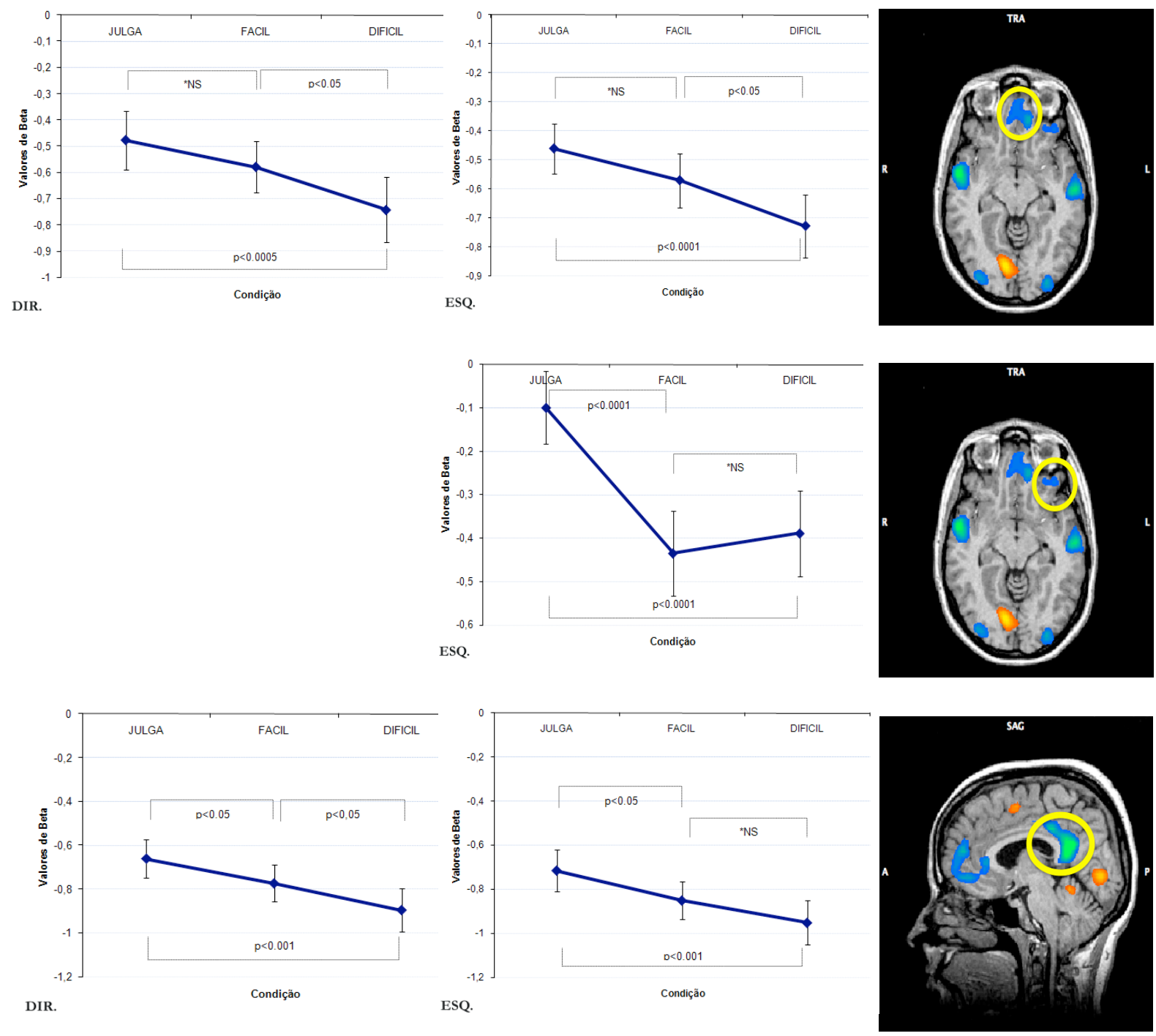

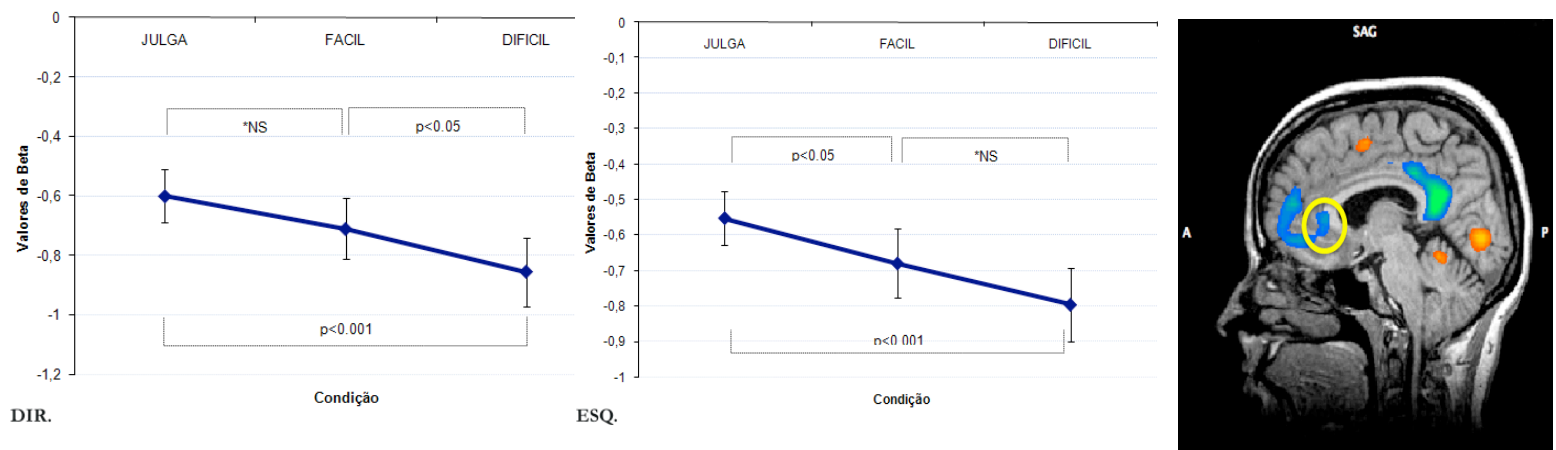

Figura 22: De cima para baixo, gráficos das ROI's no Córtex Pré-frontal Medial, Orbitofrontal BA47, Cíngulo Posterior, Cíngulo Anterior. Observamos uma tendência de diminuição gradual de sinal BOLD entre a tarefa de julgamento de figura (JULGA) e as tarefas de barras FÁCIL e DIFÍCIL. Os valores de beta foram significativamente maiores na tarefa de julgamento das figuras do que na tarefa difícil e representam o efeito do julgamento emocional sobre processamento neural nessas regiões.

ANALISE DE CORRELAÇÃO (ANCOVA)

\begin{tabular}{|l|c|c|}
\hline Escala Psicométrica & Média & Desvio padrão \\
\hline Afeto Positivo (PANAS) & 33,3 & 4,7 \\
\hline Afeto Negativo (PANAS) & 17,4 & 5,6 \\
\hline Idate-T & 36,8 & 10,5 \\
\hline Questionário Mutilados & 8,9 & 3,6 \\
\hline
\end{tabular}

Tabela 7: Médias e desvios padrão da pontuação dos voluntários nas escalas psicométricas.

A análise de correlação permite verificar a influência de algum covariante sobre os resultados das analises de ROI. Neste sentido, é possível detectar o efeito da variabilidade dos valores de beta dos sujeitos para algum contraste específico. Em uma análise inicial, testamos a correlação dos valores sujeito-a-sujeito dos valores de beta na ROI da amígdala para os contrastes que podem apresentar um efeito do processamento emocional (entre as condições com figuras aversivas menos as condições neutras: Julga-MUT - Julga-NEU, FácilMUT - Fácil-NEU e Difícil-MUT - Difícil-NEU) com possíveis co-variantes obtidos dos dados comportamentais (TR e ERRO), da pontuação individual dos sujeitos nas escalas psicométricas aplicadas (idateT, PANAS e questionário de mutilados - médias e desvios 
padrão na tabela 7) e, por fim, com o fator gênero. Entretanto, encontramos apenas uma correlação negativa (figura 23) para o contraste Fac-MUT > Fac-NEU (a diferença nos valores de beta nas condições: Fac-MUT menos Fac-NEU) com a pontuação da escala de afeto positivo do PANAS $(r=-0,48$ e $\mathrm{p}<0,03)$.

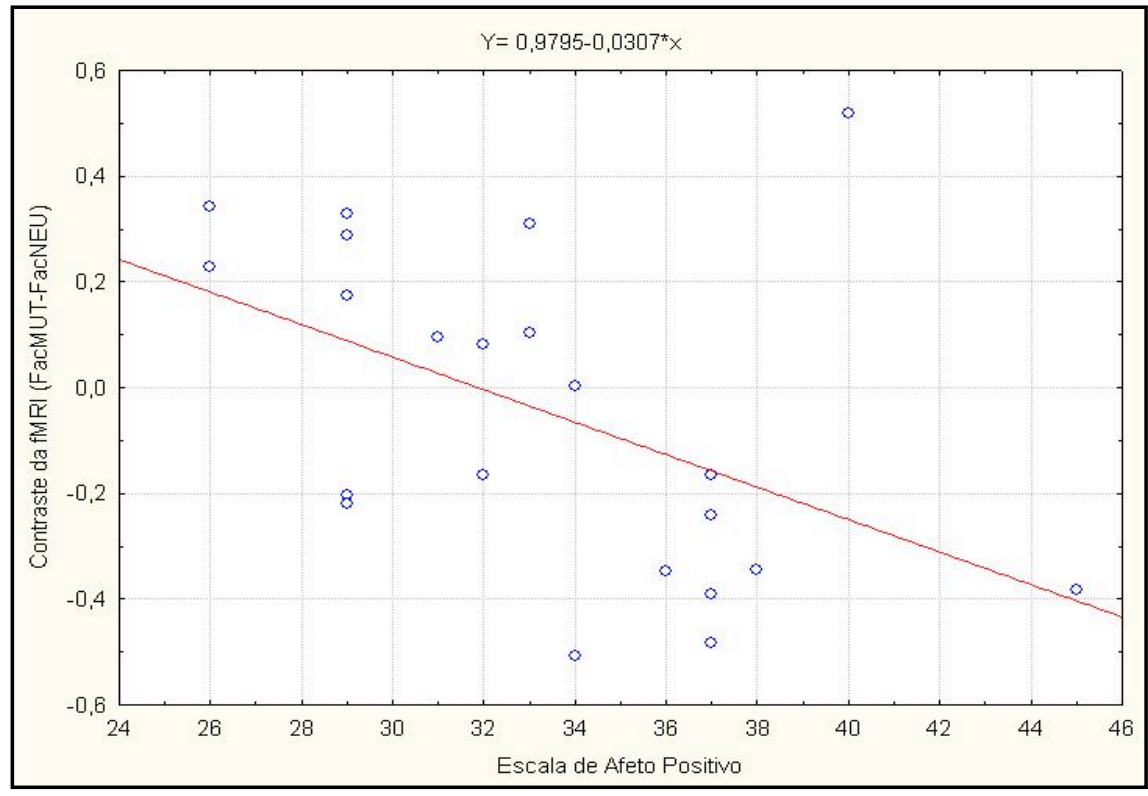

Figura 23: Gráfico da correlação entre o afeto positivo (PANAS) e a diferença dos betas na tarefa fácil (Fac-MUT - Fac-NEU) de fMRI na ROI da amígdala esquerda, com $\mathrm{r}=-0,48$ e $\mathrm{p}<0,03$.

$\mathrm{Na}$ figura 23, podemos notar que a distribuição entre altos e baixos escores na escala de afeto positivo são agrupados em torno de um eixo associativo em que os valores altos de afeto positivo, ou seja, maiores que a pontuação média de 33, correspondem aos mais reduzidos valores da diferença dos betas na tarefa fácil, gerada pelo efeito da valência das figuras (Fác-MUT menos Fác-NEU). Um efeito reverso ocorre para os sujeitos com valores baixos de afeto positivo. 


\section{DISCUSSÃO}

Neste trabalho, investigamos o efeito regulatório da atenção sobre o processamento de estímulos emocionais. Para tanto, manipulamos o foco espacial da atenção e o grau da dificuldade nas tarefas, enquanto os estímulos emocionais eram apresentados. O principal efeito encontrado aqui é consistente com trabalhos prévios (Pessoa et al, 2002; Pessoa et al, 2005), em que a amígdala apresenta respostas emocionais moduladas pela atenção. Nossos resultados também revelaram uma supressão do efeito da valência emocional sobre a amígdala pela manipulação da atenção nas tarefas (tarefas de barras), quando comparada com o a resposta da amígdala na tarefa de julgamento de figuras entre a condição aversiva (figuras de mutilados) e a condição neutra. Este resultado é representativo da regulação emocional pela atenção e, ao contrário das teorias de automaticidade para o processamento de estímulos emocionais pela amígdala (Anderson et al., 2003; Vuilleumier et al., 2001), ele favorece as hipóteses de que esses estímulos também devem competir por recursos neurais.

Além disso, investigamos o comportamento de outras regiões cerebrais associadas ao processamento emocional e de regiões associadas à atenção espacial. Além da amígdala, toda um conjunto de estruturas envolvidas no processamento emocional, incluindo a ínsula, o giro do cíngulo, os córtices pré-frontais medial, ventrolateral e o órbitofrontal, foi caracterizada quanto ao efeito de regulação emocional exercida pela atenção sobre elas. Também notamos que, além da atenção, outros fatores podem ter influenciado a resposta emocional neste experimento, como um possível efeito do estresse causado por uma tarefa muito difícil, em especial sobre as regiões da ínsula e do córtex órbitofrontal, e uma possível influência do traço de afeto positivo sobre a regulação emocional na amígdala.

Nas regiões envolvidas no processamento da atenção, principalmente o córtex pré-frontal dorsolateral e o córtex parietal superior, observamos um aumento da demanda de processamento gerado pelas tarefas em que a alocação da atenção espacial era alterada (atenção voltada para as barras em relação a julgar figuras). 


\section{PROCESSAMENTO EMOCIONAL E DEMANDA DE ATENÇÃO}

Os efeitos do processamento emocional foram analisados pelas diferenças das respostas entre as condições em que apresentávamos fotografias aversivas (MUT) e neutras (NEU). Nos dados comportamentais, vistos na tabela 3, encontramos efeito da valência emocional somente para a tarefa FÁCIL $(\mathrm{p}<0,04)$. Os sujeitos foram mais lentos na tarefa FÁCIL quando a figura distrativa era aversiva (FAC-MUT) do que quando ela era neutra (FAC$\mathrm{NEU}$ ), o que sugere que haja uma facilitação no processamento dos estímulos aversivos, em relação aos neutros, de forma que eles promovam um engajamento prioritário sobre os recursos de atenção. Tal retardo no tempo de resposta não foi observado na tarefa DIFÍCIL, em que havia uma maior dificuldade na realização da tarefa e, portanto, exigiu uma maior carga ou demanda de processamento pela atenção.

Comparamos nossos dados comportamentais com os resultados obtidos por Erthal e colaboradores (2005), em que foram adotadas condições experimentais similares às nossas, apesar de não terem realizado experimentos de neuroimagem. Os resultados de Erthal e colaboradores, mostraram o retardo do tempo de resposta durante a apresentação das fotos aversivas também em tarefas fáceis, médias e difíceis $\left(12^{\circ}\right)$, Porém, quando a tarefa era muito difícil $\left(6^{\circ}\right)$, os estímulos emocionais deixaram de promover uma interferência no desempenho da tarefa. Isso é similar ao que ocorreu em nosso experimento, em que o desaparecimento da interferência emocional no bloco DIFÍCIL (barras com diferenças de $6^{\circ}$ ) pode ser atribuído à grande dificuldade imposta pela tarefa, ainda maior do que a tarefa difícil usada por Erthal e colaboradores (barras com diferenças de $12^{\circ}$ ). Além disso, devemos considerar que outros fatores também podem ter contribuído no desempenho da tarefa na condição difícil, principalmente em um ambiente claustrofóbico e estressante, como é o caso daquele encontrado em um tomógrafo de ressonância.

Na tarefa FÁCIL, o estímulo afetivo parece ser capaz de capturar os recursos de processamento e interferem com o desempenho mesmo quando eles não são relevantes para a tarefa principal (Pessoa e Ungerleider, 2004; Vuilleumier, 2005). Assim também é explicado o retardado do tempo de resposta dos sujeitos em um experimento em que eles vêem figuras distrativas que são desagradáveis, comparadas com figuras neutras, ao mesmo tempo que executaram uma tarefa auditiva (e.g., discriminação de palavras) (Bradley et al., 1996; Buodo et al., 2002). Essa interferência tem sido observada mesmo quando a tarefa principal é muito fácil, como na detecção de um estímulo visual simples (Pereira et al., 2006). 
Diferentes paradigmas experimentais tem mostrado que o processamento do estímulo visual de caráter emocional é priorizado. $\mathrm{O}$ mecanismo de priorização afetiva ainda é alvo de muita pesquisa, mas geralmente é relacionado ao aumento do processamento sensório do estímulo afetivo em relação a um estímulo neutro. Bradley e colaboradores (2003) mostraram uma ativação de maior amplitude e mais extensa no córtex visual quando os participantes viam figuras emocionais, comparadas às neutras. Padmala e Pessoa (2008) propuseram uma forte ligação entre a melhora no desempenho comportamental e o aumento da amplitude da resposta no córtex visual primário durante o processamento de informações visuais de significado afetivo. Padmala e Pessoa (2008) sugerem que a modulação das respostas no córtex visual primário para estímulos afetivos pode ocorrer devido a um acoplamento destas estruturas com a sinalização modulatória da amígdala. Além disso, pacientes com lesões na amígdala falham em exibir respostas diferentes no córtex visual quando vêem faces com expressão emocional (Vuilleumier et al., 2004).

A demanda por recursos de atenção espacial em cada tarefa (JULGA, FÁCIL e DIFÍCIL) foi avaliada pelo registro comportamental e, também, pela resposta BOLD estimada. As informações comportamentais (tabela 2) indicaram uma demanda de atenção alta em todas as tarefas quando comparadas às respostas de trabalhos similares (Erthal et al, 2005). Especificamente, o alto percentual de erros cometidos na tarefa DIFÍCIL ( $46 \%$ ) poderia indicar que os sujeitos desengajavam da tarefa e escolhiam as respostas ao acaso, se não fossem as evidências do aumento do tempo de resposta (maior na tarefa difícil do que na tarefa fácil, $\mathrm{p}<0,05$ ) e a ativação de sinal BOLD em áreas associadas à atenção (figura 17). Isso mostra que o alto nível de dificuldade foi atingido, conforme era esperado, além de indicar que os sujeitos precisaram de maior esforço e engajamento atentivo nessa tarefa.

Detectamos as regiões cerebrais associadas ao processamento da atenção espacial, que modularam o sinal BOLD, e que responderam ao contraste criado entre tarefas com diferente alocação espacial da atenção (BARRAS > JULGA FIGURA), listadas na tabela 5. Observamos duas estruturas sabidamente envolvidas em processos de atenção espacial, o córtex pré-frontal dorsolateral e o córtex parietal superior, além de outras menos citadas na literatura, como a área motora suplementar e a ínsula (tabela 5). De forma geral, o aumento da atividade neural estendendo-se desde a porção dorsolateral do córtex pré-frontal até o córtex parietal superior está implicado na atenção espacial seletiva (Nobre et al., 2004; Liu et al., 2004), de controle cognitivo (MacDonald III et al., 2000), e de regulação emocional pela atenção (Pessoa et al, 2005; Mitchel et al., 2007; Blair et al., 2007). 
$\mathrm{Na}$ análise do sinal BOLD, também encontramos um efeito da valência na tarefa JULGA. No contraste Julga-MUT > Julga-NEU ( $\mathrm{p}<0,05$ não corrigido), o conjunto de regiões cerebrais encontradas (figura 16) são comumente associadas ao processamento emocional. Estudos recentes sobre as emoções, utilizando PET e fMRI, sugerem o envolvimento de regiões específicas no processamento neural das emoções, como a amígdala, o córtex préfrontal medial, orbitofrontal e ventrolateral, o córtex do cíngulo e a ínsula, que também são consistentes com outros estudos de lesão cerebral humana e experimentos com animais (Davidson \& Irwin, 1999; Phan et al., 2002; Phan et al., 2004). Desse modo, neste estudo, selecionamos essas mesmas ROI para, posteriormente, fazer os cálculos da estimativa do sinal BOLD em todas as outras condições experimentais (figuras 18 a 20).

\section{EFEITO DA ATENÇÃO SOBRE O PROCESSAMENTO EMOCIONAL}

Atualmente, o mecanismo de regulação da emoção pela atenção pressupõe que o grau de orientação de recursos de atenção aos estímulos emocionais, ou as suas características específicas, é capaz de modular o processamento neural de avaliação emocional, envolvendo estruturas como a amígdala (Ochsner \& Gross, 2005; Pessoa et al., 2002b; Pessoa et al., 2005). Porém, o quanto o processamento emocional ocorre de forma independente da viabilidade de recursos atentivos permanece em discussão (Pessoa et al, 2005).

Neste trabalho, variamos o foco espacial da atenção e o grau de dificuldade das tarefas para avaliarmos o efeito da atenção sobre o processamento emocional. De uma forma geral, vimos que a amplitude da resposta BOLD às figuras de mutilados foi reduzida pelo efeito do deslocamento e da demanda de atenção em várias regiões envolvidas no processamento emocional, e não somente na amígdala (figura 18 e 20). Também, na região da ínsula e do córtex orbitofrontal, após a redução da amplitude da resposta observada durante a apresentação de figuras de mutilados, a amplitude da resposta BOLD voltou a aumentar na condição Dif-MUT (figura 20). A observação desse efeito em diversas estruturas envolvidas no processamento emocional é limitada. Até hoje, os trabalhos a respeito do impacto da atenção sobre o processamento emocional tem concentrado seus esforços na análise do sinal da amígdala. Poucos estudos mostram um efeito regulatório da atenção sobre outras estruturas cerebrais, dentre as quais podemos citar o córtex medial pré-frontal (Mitchel et al, 2007; Erk et al, 2006; Pessoa et al, 2002), outras regiões pré-frontais (Blair et al, 2007; Pessoa et 
al, 2002), regiões occiptotemporais (Pessoa et al, 2002) e a ínsula anterior (Anderson et al, 2003).

Para compararmos os nossos achados com os de trabalhos semelhantes, em que se analisa principalmente o sinal da amígdala, tomamos a modulação da ativação observada nessa estrutura (figura 18) como representativa da regulação emocional pela atenção em todas as outras regiões (figura 18 e 20). Inicialmente, encontramos um aumento significativo da amplitude do sinal BOLD bilateral na amígdala para figuras aversivas, em relação a figuras neutras, evidenciado durante o julgamento da valência $(\mathrm{p}=0,01)$. Porém, não foi verificado o mesmo em condições não-atendidas (figura 18), com a atenção alocada para as barras (tarefas FÁCIL e DIFÍCIL). Além disso, nas análises pareadas entre as condições com figuras de mutilados (diferentes tarefas), observamos um efeito significativo da demanda de atenção sobre o processamento emocional na amígdala $(\mathrm{p}<0,0005)$.

Apesar das teorias de automaticidade predizerem que a resposta da amígdala aos estímulos emocionais é independente da atenção, talvez por uma via sub-cortical (Morris et al, 1998), os dados encontrados neste trabalho suportam a idéia de que os estímulos emocionais aversivos não são imunes aos efeitos da atenção (Pessoa et al, 2002, 2005a, 2005b) e, também, de que devem competir pela representação neural. Essa proposta recai sobre um modelo de atenção que supõe uma competição pela representação neural (Desimore \& Duncan, 1995) e da teoria de demanda perceptual (Lavie, 1995). Dessa forma, o processamento do estímulo emocional deve ser suprimido se uma demanda suficiente de processamento neural for estabelecida pela atenção em uma tarefa cognitiva concorrente.

Neste estudo, observamos um aumento significativo da ativação do córtex pré-frontal dorsolateral, córtex parietal superior, ínsula anterior e área motora suplementar de acordo com manipulação da atenção (figura 21). Não está claro, ainda, como essas estruturas atuam na resposta emocional durante uma tarefa de atenção. A redução da resposta emocional pode surgir devido a um fator cognitivo por meio de mecanismos de controle executivo (i.e., os recursos de processamento podem ficar indisponíveis) ou, então, por limitações das capacidades de processamento sensorial-perceptivo. É interessante notar que, apesar das limitações na capacidade de processamento perceptivo, qualquer estímulo pode ser selecionado pelos mecanismos associados ao controle seletivo da atenção, que aumentam o processamento do estímulo alvo em detrimento de outros irrelevantes (Desimore \& Duncan, 1995). Então, por causa da capacidade finita de processamento perceptivo, podemos supor que a 
competição entre as informações visuais permite selecionar o que é mais importante a cada instante (Grossberg, 1980; Desimone and Duncan, 1995).

O controle executivo da atenção é em boa parte estabelecido no córtex pré-frontal, particularmente, no córtex pré-frontal dorsolateral esquerdo (MacDonald et al., 2000), em presença de aumento de conflito e de estímulos distratores (Botvinick et al., 2004). Durante situações de grande conflito, uma possibilidade seria de que as estruturas do córtex pré-frontal, particularmente da porção lateral, processariam as representações provenientes de estruturas do córtex temporal de estímulos relevantes da tarefa em detrimento dos estímulos distratores (Botvinick et al., 2004). Por exemplo, a modulação das representações auditivas parece resultar da atividade neural das projeções regulatórias do córtex pré-frontal dorsolateral sobre as estruturas de processamento auditivo no córtex temporal (Chao \& Knight, 1997). Um mecanismo similar deve existir para as representações de objetos e de faces incluindo um processamento por meio de projeções diretas entre o córtex do lobo temporal e o córtex pré-frontal ou, indiretamente, por conexões com o córtex parietal (Mitchell et al., 2007).

Já a hipótese de que estímulos não atendidos sejam pouco processados reforça a importância da atenção para a percepção dos estímulos visuais. De fato, evidências convergentes mostram que a percepção de estímulos fora do foco de atenção pode ser atenuada ou mesmo eliminada (Rees, Frith, \& Lavie, 1997). Em estudos de cegueira atentiva (inattentional blindness), os indivíduos falham em detectar a presença de outros estímulos mesmo que sejam salientes quando têm sua atenção focalizada em um outro objeto ou evento relevante (Simons, 2000). Dessa forma, a capacidade de processamento visual é considerada limitada, e o fenômeno de cegueira atentiva pode ser interpretado com base na teoria da Lavie (Lavie, 1995b; Rees et al., 1997), em que a percepção de um estímulo pode não ocorrer em função do esgotamento de recursos neurais que já estariam voltados para a tarefa principal. Desse modo, somente quando os recursos neurais não são totalmente consumidos, a capacidade de processamento disponível é utilizada para o processamento das informações não atendidas (Lavie, 1995).

Pela teoria de Lavie, que tem sido aplicada para estímulos não-emocionais, sugere-se que a hipótese da automaticidade do processamento afetivo também possa ser testada por manipulações da atenção que consumam mais os recursos de processamento disponíveis. Então, uma variável crítica para entender os limites do processamento do estímulo emocional não atendida é a demanda de atenção da tarefa. Muitos estudos de fMRI têm usado uma estra- 
tégia similar para contradizer a teoria da automaticidade (Pessoa et al, 2002; Pessoa et al, 2005; Silvert et al., 2007, Mitchell et al., 2007, Lim et al., 2008). Assim, a falha em observar a modulação da emoção pela atenção nas respostas da amígdala em alguns experimentos (Vuilleumier et al., 2001; Anderson et al., 2003) pode ser atribuída ao fato da tarefa relevante não possuir uma demanda de atenção alta o suficiente para exaurir os recursos envolvidos na tarefa.

Essa divergência também pode ser questionada em decorrência das diferenças entre os paradigmas experimentais empregados (Pessoa, 2005), principalmente, devido a diferenças espaciais e o tipo de estímulo emocional (Mitchell et al, 2007). Em alguns estudos, alvos e distratores aparecem separadamente, no ponto de fixação e na periferia do campo visual (Pessoa et al, 2002), separadamente e fora do ponto de fixação (Vuilleumier et al, 2001), sobrepostos e no ponto de fixação (Anderson et al, 2003) ou, então, sobrepostos e na periferia (Williams et al, 2005). Então, em certos paradigmas, o fato de que as tarefas demandam uma carga maior de atenção do que outras possibilitaria que elas limitassem mais fortemente o processamento de entradas perceptuais e, consequentemente, as respostas da amígdala em cada tipo de tarefa (Mitchell et al., 2007).

Tanto os resultados que sugerem que a percepção emocional é automática, quanto os que afirmam que ela dependeria da atenção, podem ser conciliados usando o conceito de demanda de atenção de Lavie (Pessoa et al, 2005). Quando a demanda é baixa, existiria capacidade de processamento disponível para os estímulos emocionais irrelevantes para a tarefa. Entretanto, com o aumento da demanda, menos recursos ficariam disponíveis e, no limite da capacidade, a percepção emocional é reduzida. Enquanto essa teoria pode ser usada para explicar muitos dos resultados encontrados na literatura, outras evidências resistem a ela. Em um estudo recente, por eletroencefalografia, a amplitude da resposta evocada foi aumentada para figuras agradáveis e desagradáveis, em relação às neutras, independentemente do nível de demanda da tarefa auditiva concorrente (Schupp et al., 2008). Dessa forma, acreditamos que o mecanismo de regulação emocional pela atenção ainda pode ser melhor descrito com o surgimento de novas evidências e um modelo que seja capaz de conciliar os diversos resultados já encontrados. 


\section{UMA HIPÓTESE ALTERNATIVA PARA A REGULAÇÃO PELA $A$ - TENÇAOO POR UM PROCESSO INIBITÓRIO}

De forma geral, o comportamento adaptativo parece envolver o equilíbrio entre demandas opostas: de um lado, a seleção de estímulos que exigem o engajamento de mecanismos de atenção, de outro, a necessidade da detecção de eventos relevantes que possam surgir inesperadamente fora do foco da atenção. As evidências de que o processamento de um estímulo visual de caráter emocional é priorizado, senão automático, sugerem a existência de um via de processamento rápida. Dados envolvendo a amígdala apontam para a ocorrência de uma resposta neural 30 ms após a apresentação de um estímulo de reconhecimento explícito de faces de medo (Luo et al., 2007), e um tempo de resposta entre 50 e $150 \mathrm{~ms}$ para distinguir entre imagens aversivas ou agradáveis (Oya et al., 2002). Um estudo de potenciais elétricos evocados detectou uma resposta neural sustentada durante o reconhecimento de expressões faciais aversivas, mesmo sem ser o alvo da atenção, e outra resposta neural transiente e extinguida em 220 ms (Holmes et al., 2006).

O potencial de atrair a atenção por meio de um processamento automático, independente da alocação voluntária da atenção, seria de grande relevância biológica. Tal processamento diferenciado poderia ser explicado pela necessidade da detecção rápida de estímulos potencialmente perigosos (LeDoux, 2000). Entretanto, na regulação emocional, as respostas emocionais rápidas poderiam ocorrer mesmo sob um alto nível de processamento neural, mas elas poderiam estar sujeitas à modulação por mecanismos de controle executivo. Para testar isto, o ideal seria fazer um registro do curso temporal da resposta fisiológica em estruturas de processamento emocional durante o mecanismo de regulação.

Segundo a definição de Cole e colaboradores (2004), a regulação emocional seria dada pelas modificações das respostas emocionais, definidas como um segundo estágio de ativação, que segue o estágio inicial de ativação emocional. Em estudos por neuroimagem funcional, as causas e o curso temporal dessas respostas emocionais ainda não foram bem descritos. Nesse caso, o mais comum é analisar as mudanças na ativação emocional em estágios distintos, com ou sem o efeito da regulação. Em geral, analisa-se a diminuição da amplitude do sinal na amígdala, por exemplo, enquanto se procura regiões do córtex pré-frontal que poderiam estar relacionadas a este processo regulatório.

No trabalho de Ochsner e colaboradores (2004), por fMRI, eles mostram que tanto as situações de aumento quanto as de diminuição da emoção negativa estão associadas à ativação 
de áreas relacionadas ao controle cognitivo, como regiões dos córtices pré-frontais e do cingulado anterior. Especificamente, na situação de diminuição da resposta emocional, eles observaram um maior recrutamento dos córtices pré-frontal lateral e orbital direitos durante as estratégias de regulação da emoção em que os sujeitos tentavam diminuir o impacto emocional das figuras, enquanto a amígdala apresentou uma diminuição de sua atividade nessa situação.

Deve-se notar que, neste trabalho, o padrão de diminuição da resposta devido à regulação emocional corresponde ao que já foi descrito por outros estudo de regulação emocional, nos quais os sujeitos deviam aumentar ou reduzir voluntariamente suas respostas emocionais a estímulos visuais positivos e negativos. Verificamos uma redução da amplitude da resposta, com o aumento da demanda de atenção, na amígdala, no córtex pré-frontal medial, córtex pré-frontal ventrolateral, córtex cingulado posterior (figura 18) e, parcialmente, na ínsula anterior e no córtex orbitofrontal (figura 20), regiões implicadas no processamento emocional. Enquanto a resposta BOLD observada nessa rede de processamento emocional foi diminuída com o deslocamento da atenção, houve um aumento nas regiões associadas à atenção espacial, como o córtex pré-frontal dorsolateral e o córtex parietal superior (figura 21).

Uma primeira avaliação levaria a um candidato natural para promover o efeito regulatório sobre o processamento emocional é o córtex pré-frontal medial, por meio de um mecanismo inibitório. Essa relação funcional tem sido proposta como fundamento analítico de dados, tanto de experimentos com animais (Quirk e Gehlert, 2003) como por neuroimagem funcional (Pezawas et al, 2005). Existem circuitos inibitórios que controlam a expressão de respostas condicionadas na amígdala partindo do córtex pré-frontal, sendo aparentemente a região medial a principal implicada nesse mecanismo em animais (Milad e Quirk, 2002; Quirk e Gehlert, 2003) e, possivelmente, em humanos (Lang et al, 2009; Milad et al, 2007). As principais evidências para isso vem de estudos com animais sobre extinção do medo condicionado e efeitos ansiogênicos pela injeção de antagonistas gabaérgicos na amígdala (Quirk e Gehlert, 2003). Entretanto, o efeito observado em nossos resultados contraria a possibilidade o córtex pré-frontal medial ter esse papel inibitório sobre a amígdala. Isto porque o córtex pré-frontal medial também foi significativamente modulado pela atenção (figura 18) durante as condições não-atendidas (BARRAS).

Além do córtex pré-frontal medial, a porção pré-frontal ventrolateral também poderia ser a responsável pelo efeito regulatório sobre o processamento emocional. Na presença de um 
estímulo aversivo durante a condição atendida (Julga-MUT), observamos um aumento da amplitude da resposta dessa região (figura 18), em relação ao estímulo neutro (Julga-MUT), que representa o processamento emocional. Porém, durante as condições não-atendidas com alta demanda de processamento (BARRAS), o efeito da valência não foi mais observado. Isso difere da noção de que a região do córtex pré-frontal ventrolateral estaria envolvida apenas em reações de conflito e de controle (Botvinick et al., 2004; Blair et al., 2007), ou na regulação emocional pela atenção (Mitchell et al., 2007). Pelos nossos resultados, essa região participa do processamento emocional junto com outras estruturas, e está sujeita aos efeitos da regulação pela atenção.

Supomos que outras estruturas do córtex pré-frontal poderiam vir a suprimir as vantagens competitivas de suporte a estímulos emocionais por conexões modulatórias sobre a amígdala, direta ou indiretamente. Há evidências de que o controle executivo é necessário para a regulação emocional e que o córtex pré-frontal dorsolateral, que especificamente, iniciaria um processo de regulação emocional inibitório sobre as regiões límbicas, como a amígdala (Davidson, 2000; Drevets \& Raichle, 1998; Ochsner, 2002, Pessoa, 2008). Desse modo, no processo de regulação emocional, a ativação do córtex dorsolateral deve resultar em uma redução das respostas emocionais. Porém, parece não existir uma conexão direta entre o córtex dorsolateral e a amígdala. Assim, acredita-se que o efeito inibitório do córtex dorsolateral sobre a amígdala seria mediado por conexões com córtex ventromedial, o orbitofrontal e o cíngulo anterior (Siegle et al., 2007). Portanto, em nosso experimento, se considerarmos que o estímulo emocional está sujeito às modulações de seleção pela atenção, promovida pelo controle executivo descendente (do termo em inglês “top down control'), então, a regulação da resposta emocional pode ter ocorrido pela via fronto-parietal, através do córtex pré-frontal dorsolateral e do córtex parietal superior.

O método utilizado neste trabalho não nos permite tirar conclusões sobre as estruturas cerebrais responsáveis pela regulação emocional. Para se confirmar a existência de causalidade na relação entre as estruturas analisadas, e que participam da resposta emocional e de sua regulação, outros estudos são necessários. Por hora, existe uma série de evidências sobre a conectividade estrutural e funcional das estruturas neurais envolvidas nos processos citados aqui (Pessoa, 2008).

Também, Young e colaboradores (1994) analisaram quantitativamente a conectividade cerebral e mostraram que as regiões pré-frontais estão entre as mais distantes das regiões sensoriais primárias, sugerindo que elas recebem a informação sensória já integrada e altamente 
processada. Tal isolamento do córtex pré-frontal é visto como uma forma anatômica estratégica dessa região para conferir ao cérebro dos primatas e humanos uma maior flexibilidade (Mesulam apud Pessoa, 2008). A análise de Young e colaboradores revelou que a amígdala é igualmente distante dessas regiões sensoriais, apesar de haver uma projeção sensória que, em algumas espécies, ocorre via tálamo (Ledoux, 2000). Eles concluem que a amígdala ocupa uma posição central no mapa topológico da conectividade cerebral, sugerindo que essa estrutura é uma das regiões mais conectadas em todo o cérebro (Barbas, 1995; Swanson, 2003). Nessa linha de raciocínio, Pessoa (2008) sugere que as regiões reconhecidas como puramente afetivas, como a amígdala, o hipotálamo, o córtex orbitofrontal, o córtex pré-frontal ventromedial e o cíngulo anterior, funcionariam como importantes centros de conectividade, o que seria de grande relevância para a integração da informação. Ele propõe que estruturas envolvidas no controle executivo, como o córtex dorsolateral, parietal e o cíngulo anterior, fazem parte de um circuito mais amplo de controle afetivo-cognitivo. Então, o controle executivo poderia integrar os processos emocionais e atentivos que, portanto, não deveriam ser vistos separadamente.

Além disso, recentemente, uma maior integração funcional entre a atenção e a emoção tem sido proposta (Vuilleumier e Huang, 2009; Pessoa, 2008), as quais também dariam mais subsídios para a compreensão dos mecanismos de regulação da atenção. Também, apesar da visão simplificada de Cole e colaboradores (2004), que define a regulação emocional pelas modificações das respostas emocionais, outros neurocientistas definem a emoção como um recrutamento recíproco de subsistemas inferiores e superiores ao longo da hierarquia neural, que é acompanhada por mudanças endócrinas e musculares em um rápido processo de auto-organização (Panksepp, 2003). Assim, o problema em definir a regulação da emoção como sendo um processo independente é que a sincronização dos subsistemas subjacentes à emoção inclui a possibilidade de um subsistema ser regulado pelos outros. Além disso, esses processos regulatórios nem sempre ocorrem em estágios temporais distintos. Eles podem desenvolver-se paralelamente à medida que a atenção, percepção e emoção se tornam espontaneamente coordenados. Portanto, por meio de uma perspectiva neural, os processos regulatórios seriam intrínsecos à cascata de modificações neurais subjacentes à emoção, de forma que a regulação da emoção poderia ser vista como um processo intrínseco na geração da emoção (Lewis \& Stieben, 2004). Assim, esses sistemas poderiam ser vistos de forma mais integrada. 


\section{INSULA E ORBITOFRONTAL}

Neste experimento, vimos que a ativação da ínsula anterior e do córtex orbitofrontal esquerdos na tarefa de julgamento das figuras de mutilados foi reduzida pelo efeito da manipulação da atenção na tarefa FÁCIL. Porém, diante das figuras aversivas na tarefa DIFÍCIL a amplitude da resposta voltou a aumentar (figura 20). No caso da ínsula anterior, vimos que ela esteve associada ao processamento da atenção espacial. Ela também apresentou uma amplitude maior para a tarefa de BARRAS, visto no mapa da figura 17, para o contraste criado entre tarefas com diferente alocação da atenção espacial (BARRAS > JULGA FIGURA). Especificamente, essa região teve um sinal BOLD estimado significativamente maior na tarefa DIFÍCIL do que na tarefa JULGA (figura 21).

Observamos que a ínsula anterior, assim como a área motora suplementar, também podem estar envolvidas na atenção espacial, junto com o córtex pré-frontal dorsolateral e o córtex parietal superior. De forma geral, a ínsula está relacionada a representação visceral que tem papel importante na experiência emocional (Damásio, 1996). Entretanto, sua ativação também é encontrada em experimentos envolvendo atenção espacial (Kim et al, 1999), o que é similar ao que vemos na figura 21. Lesões na ínsula também parecem comprometer a atenção espacial em tarefas que envolvem memória de trabalho (Malhotra et al, 2005).

Por outro lado, também acreditamos que o aumento da resposta na condição Dif-MUT esteja relacionado a um efeito de estresse mental, já que, além da apresentação do estímulo aversivo, os sujeitos encontraram muita dificuldade para desempenhar a tarefa nessa condição, conforme a observação da alta taxa de erros (figura 15). Essa hipótese também é sugerida para os resultados do córtex orbitofrontal esquerdo. O trabalho de Critchley e colaboradores (2000) também mostra um aumento da resposta nas regiões da ínsula e orbitofrontal esquerdos, que estaria associada, segundo esses autores, ao controle do sistema parasimpático, pois estavam correlacionados com a redução das medidas autonômicas cardiovasculares geradas por um estímulo estressante.

O córtex ortitofrontal é uma região cerebral que tem sido bastante associada à avaliação de recompensa ou punição, o que é pré-requisito para um comportamento social e emocional mais complexo e flexível (Kringelbach, 2006). Estudo de neuroimagem funcional recentes tem mostrado um suposto envolvimento do córtex orbitofrontal no processamento emocional (Drevets, 2007). Alterações funcionais são encontradas em distúrbios do humor, 
como na depressão, e o tratamento por antidepressivos está associado à redução da resposta nessa região. Esses dados indicam que algumas regiões orbitofrontais participam da inibição, enquanto outras favorecem o aumento da expressão das emoções (Drevets, 2007). Também, lesões no órbitofrontal reduzem a ativação (arousal) antecipatória a estímulos emocionais (Damásio et al, 1990).

\section{SISTEMA DEFAULT}

Em geral, os estudos de neuroimagem revelam as modulações positivas ou negativas da resposta que são dependentes das tarefas específicas empregadas. Porém, surpreendentemente, pode surgir um padrão de diminuição da ativação em certas regiões, independente da tarefa. Em nossos resultados, observamos que os valores estimados do sinal BOLD eram negativos em relação à linha de base, em regiões condizentes com as regiões dessa rede, conhecida por default network, e que envolveram o córtex pré-frontal medial, orbitofrontal (BA47), cíngulo anterior e cíngulo posterior (figuras 18, 19 e 22) (Gusnard e Raichle, 2001; Stark e Squire, 2001).

Essas reduções de sinal têm sido associadas ao estado de repouso, ou basal, do cérebro e que envolve uma série de operações mentais específicas, como, por exemplo, aquelas voltadas à memória autobiográfica, considerações futuras, consideração da perspectiva alheia, entre outras condições mentais em que o sujeito não está focado no meio externo. Um possível papel adaptativo para o sistema default seria no uso de experiências passadas no planejamento do futuro, na orientação e no monitoramento do ambiente, do corpo, ou da interação entre os dois. Todas essas funções são espontâneas e tendem a ser contínuas, o que faz com que sejam atenuadas em atividades com atenção direcionada. Além disso, a relevância do sistema default tem sido testada e discutida na compreensão das desordens mentais incluindo transtorno e déficit de atenção (TDA), esquizofrenia, autismo e doença de Alzheimer. 
A análise de correlação entre a resposta BOLD e dados comportamentais pode trazer um importante contribuição para a compreensão da variabilidade nas respostas emocionais pela avaliação das diferenças individuais (Oliveira et al., 2003; Souza, 2005). Neste trabalho foi encontrada uma correlação negativa $(r=-0,48$ e $p<0,03)$ entre a resposta emocional da amígdala na condição FÁCIL (diferenças entre Fácil-MUT e Fácil-NEU) com a pontuação dos voluntários na escala de afeto positivo (figura 23). Esses dados são consistentes com a idéia de que sujeitos com maior traço psicológico para afeto positivo possam ter desenvolvido uma maior capacidade de regulação das informações emocionais aversivas, inclusive por processos de controle executivo envolvidos na atenção espacial seletiva. No entanto, não observamos correlação expressiva de mais nenhuma outra co-variável testada.

Acreditamos que este resultado deva ser discutido com cautela, até pelas recentes polêmicas envolvendo altas correlações em estudos de fMRI sobre emoção, cognição social e personalidade (Vul et al., 2009). Porém, é importante citar que Oliveira e colaboradores (2004) também mostraram o efeito do afeto positivo em um experimento de regulação emocional, em que foi evidenciado que as respostas de sudorese à figuras desagradáveis seriam atenuadas pela manipulação do contexto no qual elas eram apresentadas. Os voluntários eram expostos à visualização de um bloco de fotos de corpos mutilados e um de fotos neutras de utensílios domésticos. Essa visualização ocorria em um contexto neutro ou em um contexto atenuado, em que o conteúdo emocional da figura desagradável era atenuado. Nesse estudo, somente voluntários que pontuaram acima da média na escala de afeto positivo exibiram uma redução da resposta de sudorese no bloco desagradável. 


\section{CoNClusões}

Observamos em nossos resultados um padrão geral de regulação da emoção influenciado pela manipulação atencional nas tarefas:

- Nos dados comportamentais, vimos que a interferencia do processamento afetivo no desempenho na tafefa fácil deixou de existir na tarefa difícil.

- $\quad \mathrm{Na}$ fMRI, todo um conjunto de estruturas envolvidas no processamento emocional (amígdala, cíngulo posterior e córtices pré-frontais medial e ventrolateral) apresentou uma diminuição da resposta aos estímulos aversivos durante as tarefas FÁCIL e DIFÍCIL sugerindo uma regulação emocional nestas tarefas, com exceção da ínsula e do córtex pré-frontal, que tiveram a resposta reduzida na tarefa FÁCIL e aumentada DIFÍCIL, talvez porque a alta dificuldade na tarefa gerou um fator estressante.

- O sinal BOLD estimado em regiões implicadas processamento atentivo, principalmente, o córtex pré-frontal dorsolateral e pré-frontal parietal superior, foi aumentou gradualmente desde a tarefa JULGA, com uma tendência maior na tarefa FÁCIL e, significativamente maior na tarefa DIFÍCIL.

- Observamos uma correlação negativa entre o valor da diferença de amplitude estimada do sinal BOLD entre as condições Fac-MUT e Fac-NEU e a pontuação na escala afeto positivo dos sujeitos, indicando que os indivíduos com maior traço de afeto positivo tem uma menor resposta para figuras mutilados na tarefa fácil e possam ter uma capacidade maior de regulação emocional. Porém, não observamos correlação com outros traços individuais dos nossos voluntários, gênero ou com o desempenho comportamental deles.

Neste estudo por fMRI, promovemos maiores evidências para a noção de que uma resposta BOLD significativa da amígdala com estímulos emocionais centrais requerem atenção. Ainda não está claro quais seriam os fatores que condicionariam a resposta emocional durante uma tarefa com demanda de atenção. A explicação fica em aberto: a redução da resposta emocional pode surgir devido a limitações das capacidades de processamento sensorial-perceptivo (i.e., os recursos de processamento podem estar indisponíveis) mas, também, por um processo cognitivo por meio de mecanismos de controle executivo. Coleti- 
vamente, os dados sugerem que o processamento de estímulos emocionais, tanto quanto de estímulos neutros, estão sujeitas aos mecanismos de relacionados à atenção.

Os resultados também têm implicações sobre os modelos de regulação emocional (Ochsner \& Gross, 2005). A participação de estruturas dos córtices pré-frontal dorsolateral e do córtex parietal superior podem contribuir para a regulação emocional pela manipulação da atenção. Nesse caso, a regulação emocional pode ser vista como um mecanismo que integra cognição e emoção por um controle executivo (Pessoa, 2008). As estruturas que participam da atenção espacial poderiam operar paralelamente à função inibitória que outras estruturas pré-frontais, como o córtex pré-frontal medial, tem com a amígdala. Entretanto, trabalhos futuros a respeito do impacto de estímulos emocionais sobre o comportamento humano, principalmente por análises de conectividade e do curso temporal dos processos de regulação emocional, deverão ajudar a determinar a participação relativa de cada processo e os parâmetros neurais que determinam essas funções cognitivas complexas. 



\section{REFERÊNCIAS}

Amaro, Jr. E. \& Barker, G.J. Study design in fMRI: basic principles, Brain Cogn. (2006) 60: $220-232$.

Anderson A.K. e Phelps E.A. Lesions of the human amygdala impair enhanced perception of emotionally salient events. Nature (2001); 411: 305-309.

Anderson A.K., Christoff K., Panitz D., de Rosa E. and Gabrieli J.D.E. Neural correlates of the automatic processing of threat facial signals. J. Neurosci. 23 (2003) (13), pp. 56275633.

Anderson AK Affective influences on the attentional dynamics supporting awareness. J Exp Psychol Gen (2005) 134(2): 258-81.

Bandettini, P. A., \& Cox, R. W. Event-related fMRI contrast when using constant interstimulus interval: Theory and experiment. Magnetic Resonance in Medicine (2000) 43: 540_ 548.

Barbas, H. Anatomic basis of cognitive-emotional interactions in the primate prefrontal cortex. Neurosci.Biobehav.Rev. (1995) 19: 499-510.

Beauregard M., Levesque, J., \& Bourgouin, P. Neural Correlates Of Conscious SelfRegulation Of Emotion. J.Neurosci. (2001) 21(18): Rc165.

Bechara, A., Damasio, H., \& Damasio, A. R. Emotion, decision making and the orbitofrontal cortex. Cerebral Córtex (2000) 10: 295-307.

Beck, D.M. \& Lavie N. Look here but ignore what you see: effects of distractors at fixation. Journal Of Experimental Psychology: Human Perception And Performance (2005) 31(3): 592-607.

Bishop, S. J., Duncan, J., \& Lawrence, A. D. State anxiety modulation of the amygdala response to unattended threat-related stimuli. J.Neurosci. (2004) 24: 10364-10368. 
Blair K.S., Smith B.W., Mitchell D.G.V., Morton J., Vythilingam M., Pessoa L., Fridberg D., Zametkin A., Nelson E.E., Drevets W.C., Pine D.S., Martin A. and Blair R.J.R. Modulation of Emotion by Cognition and Cognition by Emotion. NeuroImage (2007); 35(1): 430-440.

Botvinick M.M., Cohen J.D. and Carter C.S. Conflict monitoring and anterior cingulate cortex: an update. Trends Cogn. Sci. 8 (2004) (12), pp. 539-546.

Bradley M. M., Greenwald, M. K., Petry, M. C., \& Lang, P. J. Remembering pictures: pleasure and arousal in memory. J.Exp.Psychol.Learn.Mem.Cogn. (1992) 18 (2): 379-390.

Bradley, M. M. \& Lang, P. J. Measuring emotion: the self-assessment Manikin and the semantic differential. J.Behav.Ther.Exp.Psychiatry (1994) 25(1): 49-59.

Bradley, M. M. Natural selective attention: orienting and emotion. Psychophysiology (2009) 46(1): 1-11.

Bradley, M. M., Codispoti, M., Cuthbert, B. N., \& Lang, P. J. Emotion and motivation I: defensive and appetitive reactions in picture processing. Emotion. (2001) 1 (3): 276-298.

Bradley, M. M., Cuthbert, B. N., \& Lang, P. J. Picture media and emotion: effects of a sustained affective context. Psychophysiology (1996) 33(6): 662-670.

Bradley, M. M., Sabatinelli, D., Lang, P. J., Fitzsimmons, J. R., King, W., \& Desai, P. Activation of the visual cortex in motivated attention. Behav.Neurosci. (2003) 117 (2): 369-380.

Broadbent D. E. Perception And Communication. London: Pergamon, 1958

Buckner, R. L., Goodman, J., Burock, M., Rotte, M., Koutstaal, W., Schacter, D., et al. Functional-anatomic correlates of object priming in humans revealed by rapid presentation event-related fMRI. Neuron (1998) 20: 285-296.

Buodo, G., Sarlo, M., Palomba, D. Attentional resources measured by reaction times highlight differences within pleasant and unpleasant, high arousing stimuli. Motivation and Emotion (2002) 26: 123-138.

Butler, E.A., Egloff, B., Wilhelm, F.H., Smith, N.C., Erickson, E.A., Gross, J. J. The social consequences of expressive suppression. Emotion (2003) 3(1): 48-67.

Buxton, R. B., Uludag, K., Dubowitz, D. J., e Liu, T. T. Modelling the hemodynamic response to brain activation. NeuroImage (2004) 23: S220-S233. 
Buxton, R. B., Wong, E. C., e Frank, L. R. Dynamics of blood flow and oxygenation changes during brain activation: the balloon model. Magnetic Resonance in Medicine (1998) 39: $855-864$.

Campbell-Sills, L., Barlow, D. H., Brown, T. A., \& Hofmann, S. G. Effects of suppression and acceptance on emotional responses of individuals with anxiety and mood disorders. Behav.Res.Ther. (2006) 44: 1251-1263.

Chaim, K. T. Imagem Funcional por Ressonância Magnética para Mapeamento de Memória em Pacientes com Epilepsia de Difícil Controle (2009).

Chao L.L. and Knight R.T. Prefrontal deficits in attention and inhibitory control with aging. Cereb. Cortex 71 (1997), pp. 63-69.

Cole P.M, Martin S.E., Dennis T.A. Emotion regulation as a scientific construct: methodological challenges and directions for child development research. Child Development, v.75, n.2, p.317-333, 2004

Cole P.M..; Martin, S.E.; Dennis, T.A. Emotion regulation as a scientific construct: methodological challenges and directions for child development research. Child Development (2004) v.75, n.2, p.317-333.

Compton R. J. The interface between emotion and attention: a review of evidence from psychology and neuroscience. Behav.Cogn Neurosci.Rev. (2003) 2(2): 115-129.

Critchley, H.D., Corfield, D.R., Chandler, M.P., Mathias, C.J., Dolan, R.J. Cerebral correlates of autonomic cardiovascular arousal: a functional neuroimaging investigation in humans. J. Physiol. (2000) 523, 259-270.

D’Esposito, M., Zarahn, E., \& Aguirre, G. K. Event-related functional MRI: Implications for cognitive psychology. Psychological Bulletin (1999) 125: 155-164.

Dale, A. M. Optimal experimental design for event-related fMRI. Human Brain Mapping (1999) 8: 109-114.

Damasio, A. R. , Tranel, D., \& Damasio, H. Individuals with sociopathic behavior caused by frontal damage fail to respond autonomically to social stimuli. Behavioural Brain Rese$\operatorname{arch}(1990)$ 41: 81-94.

Damásio, A. R. O erro de Descartes: emoção, razão e o cérebro humano. São Paulo: Companhia das Letras (1996). 
Darwin, C. A Expressão das Emoções no Homem e nos Animais. São Paulo: Companhia das Letras (2000).

Davidson R. J. \& Irwin W. The functional neuroanatomy of emotion and affective style. Trends in Cognitive Sciences (1999) 3(1): 11-21.

Davidson R. J., Putnam, K. M., \& Larson, C. L. Dysfunction in the neural circuitry of emotion regulation: a possible prelude to violence. Science (2000) 289: 591-594.

Davidson, R.J. Affective style, psychopathology, and resilience: brain mechanisms and plasticity. Am. Psychol. (2000) 55: 1196-1214

Davidson, R.J. Toward a biology of personality and emotion. Ann N Y Acad Sci. (2001) 935: 191-207.

Desimone R. \& Duncan J. Neural mechanisms of selective visual attention. Annu.Rev.Neurosci. (1995) 18: 193-222.

Dolan R.J. and Vuilleumier P. Amygdala automaticity in emotional processing. Ann. N. Y. Acad. Sci. 985 (2003), pp. 348-355.

Donaldson, D. I. Parsing brain activity with fMRI and mixed designs: what kind of a state is neuroimaging in. Trends in Neurosciences (2004) 27: 442-444.

Drevets WC. Orbitofrontal cortex function and structure in depression.Ann N Y Acad Sci. (2007) 1121: 499-527.

Drevets, W. C. \& Raichle, M. E. Reciprocal suppression of regional cerebral blood flow during emotional versus higher cognitive processes: Implications for interactions between emotion and cognition. Cogn. Emot. 12, 353-385 (1998).

Eimer M., Holmes A., \& McGlone F. P. The role of spatial attention in the processing of facial expression: an ERP study of rapid brain responses to six basic emotions. Cogn Affect.Behav.Neurosci. (2003) 3 (2): 97-110.

Ekman P. Basic Emotions. In T. Dalgleish and M. Power (Eds. ) Handbook of Cognition and Emotion. Sussex, U.K.: John Wiley \& Sons, Ltd., 1999b.

Ekman, P. Facial Expressions In: Dalgleish, T., \& Power, M. Handbook of Cognition and Emotion. New York: John Wiley \& Sons Ltd., 1999a.

Erk, S., Abler, B., \& Walter, H.. Cognitive modulation of emotion anticipation. Eur.J.Neurosci. (2006) 24: 1227-1236. 
Erthal, F., Oliveira, L., Machado-Pinheiro, W., Pessoa, L., \& Volchan, E. Captura da atenção por estímulos emocionais. Cadernos de Psicologia e Educação (2004) 14 (27): 35-44.

Erthal, F. S., de, O. L., Mocaiber, I., Pereira, M. G., Machado-Pinheiro, W., Volchan, E. et al. Load-dependent modulation of affective picture processing. Cogn Affect.Behav.Neurosci. (2005) 5: 388-395.

Eslinger P.J.; Grattan, L.M.; Damasio, H.; Damasio, A.R. Developmental consequences of childhood frontal lobe damage. Archives Of Neurology (1992) 49(7): 764-769.

Fox, E., Russo, R., Bowles, R., \& Dutton, K. Do threatening stimuli draw or hold visual attention in subclinical anxiety? J.Exp.Psychol.Gen. (2001) 130: 681-700.

Fox, P. T., e Raichle, M. E. Focal physiological uncoupling of cerebral blood flow and oxidative metabolism during somatosensory stimulation in human subjects. Proceedings of the National Academy of Sciences of USA (1986) 83: 1140-1144.

Friston, K. J., Fletcher, P., Josephs, O., Holmes, A. P., Rugg, M. D., e Turner, R. Eventrelated fMRI: characterizing differential responses. NeuroImage (1998) 7: 30-40.

Friston, K. J., Jezzard, P., e Turner, R. Analysis of functional MRI time series. Human Brain Mapping (1994) 1:153-171.

Friston, K. J., Zarahn, E., Josephs, O., Henson, R. N., \& Dale, A. M. Stochastic designs in event-related fMRI. NeuroImage (1999) 10: 607-619.

Globisch J.; Hamm, A.O.; Esteves, F.; Ohman, A. Fear appears fast: temporal course of startle-reflex potentiation in animal fearful subjects. Psychophysiology, v.36, p.66-75, 1999.

Glover, G. H. Deconvolution of impulse response in event-related BOLD fMRI. NeuroImage (1999) 9: 416-429.

Goldin, P. R., McRae, K., Ramel, W., \& Gross, J. J. The neural bases of emotion regulation: reappraisal and suppression of negative emotion. Biol.Psychiatry (2008) 63: 577-586.

Goldsmith H.H. \& Davidson R.J. Disambiguating the components of emotion regulation. Child Development (2004) 75(2): 361-365.

Gray, J. R., Braver, T. S. \& Raichle, M. E. Integration of emotion and cognition in the lateral prefrontal cortex. Proc. Natl Acad. Sci. USA (2002) 99: 4115-4120.

Gross J.J. \& Levenson R.W. Emotional suppression: physiology, self-report, and expressive behavior. Journal of Personality and Social Psychology (1993) 64(6): 970-986. 
Gross J.J. Antecedent- and response-focused emotion regulation: divergent consequences for experience, expression, and physiology. Journal of Personality and Social Psychology (1998) 74(1): 224-237.

Gross J.J. Emotion regulation: affective, cognitive, and social consequences. Psychophysiology (2002) 39(3): 281-291.

Gross, J.J. Emotion regulation in adulthood: timing is everything. Current directions in Psychogical Science (2001) 214-219.

Gross, J.J., \& Munoz, R.F. Emotion regulation and mental health. Clinical Psychology: Science and Practice (1995) 2: 151-164.

Grossberg S. How does a brain build a cognitive code? Psychol Rev (1980) 87:1-51.

Gusnard DA, Raichle ME. Searching for a baseline: functional imaging and the resting human brain. Nat Rev Neurosci (2001). 2:685- 694.

Hariri A. R., Bookheimer, S. Y., \& Mazziotta, J. C. Modulating Emotional Responses: Effects Of A Neocortical Network On The Limbic System. Neuroreport (2000) 11: 43-48.

Hariri A. R., Mattay, V. S., Tessitore, A., Fera, F., \& Weinberger, D. R. Neocortical modulation of the amygdala response to fearful stimuli. Biol.Psychiatry (2003) 53 (6): 494-501.

Hartikinen K. M., Ogawa, K. H., \& Knight, R. T. Transient interference of right hemispheric function due to automatic emotional processing. Neuropsychologia (2000) 38 (12): 1576-1580.

Haxby J.V., Hoffman E.A. and Gobbini M.I. The distributed human neural system for face perception. J. Cogn. Neurosci. 4 (2000), pp. 223-233.

Henson, R. N. A. Analysis of fMRI time series: linear time-invariant models, event-related fMRI and optimal experimental design. In: Human Brain Function (editors Frackowiak, R. S. J., Friston, K. J., Frith, C., Dolan, R., Price, C. J., Zeki, S., Ashburner, J., e Penny, W. D.).

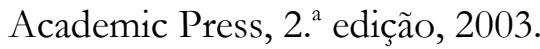

Holmes A., Kiss M. and Eimer M. Attention modulates the processing of emotional expression triggered by foveal faces. Neurosci. Lett. 394 (2006) (1), pp. 48-52.

Holmes, A., Vuilleumier, P., \& Eimer, M. The processing of emotional facial expression is gated by spatial attention: evidence from event-related brain potentials. Brain Res.Cogn Brain Res. (2003) 16: 174-184. 
Huettel, S. A., Song, A. W., e McCarthy, G. Functional Magnetic Resonance Imaging. Sinauer Associates, Sunderland, MA, Estados Unidos, 2004.

Hutcherson C.A.; Goldin, P.R.; Ochsner, K.N.; Gabrieli, J.D.; Barret, L.F.; Gross, J.J. Attention and emotion: does rating emotion alter neural responses to amusing and sad films? Neuroimage (2005) 27(3): 65-668.

Ishai, A., Pessoa, L., Bikle, P. C., \& Ungerleider, L. G. Repetition Suppression Of Faces Is Modulated By Emotion. Proc.Natl.Acad.Sci. U.S.A (2004) 101: 9827-9832.

Jackson D.C.; Mueller, C.J.; Dolski, I.; Dalton, K.M.; Nitschke, J.B.; Urry, H.L.; Rosenkranz, M.A.; Ryff, C.D.; Singer, B.H.; Davidson, R.J. Now you feel it, now you don't. Frontal brain electrical asymmetry and individual differences in emotion regulation. Psychological Science (2003) 14(6): 612-617.

James W. Attention: The Principles of Psychology. New York: Dover Publications, 1890. 689p. 2v.

Jenkins R., Lavie N., Driver J. Recognition Memory For Distractor Faces Depends On Attentional Load At Exposure. Psychonomic Bulletin Review (2005) 12 (2): 314-320.

John O.P. \& Gross J.J. Healthy and unhealthy emotion regulation: personality processes, individual differences, and life span development. Journal of Personality (2004) 72 (6): 1301-1333.

Joseph J.S.; Chun, M.M.; Nakayama, K. Attentional requirements in a 'preattentive' feature search task. Nature (1997) 387(19): 805-807.

Josephs, O., e Henson, R. N. A. Event-related functional magnetic resonance imaging: modelling, inference and optimization. Philosophical Transactions of The Royal Society of London - Series B: Biological Sciences (1999) 354: 1215-1228.

Josephs, O., Turner, R., e Friston, K. J. Event-related fMRI. Human Brain Mapping (1997) 5: 243-248.

Kim YH, Gitelman DR, Nobre AC, Parrish TB, LaBar KS, Mesulam MM. The large-scale neural network for spatial attention displays multifunctional overlap but differential asymmetry. Neuroimage. (1999) 9(3):269-277.

Kim, S. G. \& Ugurbil, K. Comparison of blood oxygenation and cerebral blood flow effects in fMRI: estimation ofrelative oxygen consumption change. Magn. Resonance Med. (1997) 38: 59-65. 
Kringelbach, M. L. \& Rolls, E. T. The functionalneuroanatomy of the human orbitofrontal cortex: evidencefrom neuroimaging and neuropsychology. Prog. Neurobiol. (2004) 72: $341-372$.

Krolak-Salmon, P., Henaff, M. A., Vighetto, A., Bertrand, O., \& Mauguiere, F. Early amygdala reaction to fear spreading in occipital, temporal, and frontal cortex: a depth electrode ERP study in human. Neuron (2004) 42: 665-676.

Lang P. J., Bradley M. M., Cuthbert B. N. Emotion, Motivation, and Anxiety: Brain Mechanisms and Psychophysiology. Soc. Biol. Psychiatry (1999a); 44: 1248-63.

Lang P. J., Bradley M. M., Cuthbert B. N. International affective picture system (IAPS): Instruction manual and affective ratings, NIMH Center for the Study of Emotion and Attention, 1999b.

Lang S., Kroll A., Lipinski S. J., Wessa M., Ridder S., Christmann C.,1 Schad L. R., Flor H. Context conditioning and extinction in humans: differential contribution of the hippocampus, amygdala and prefrontal cortex European Journal of Neuroscience (2009) 29: 823832.

Lang, P. J. The Emotion Probe. American Psychologist (1995) 50: 372-385.

Lang, P.J.; Bradley M.M.; Fitzsimmons, J.R.; Cuthbert, B.N.; Scott, J. D.; Moulder, B.; Nangia, V. Emotional arousal and activation of the visual cortex: an fMRI analysis. Psychophysiology (1998) 35(2): 199-210.

Lang, P.J.; Bradley, M.M.; Cuthbert, B.N. International affective picture system (IAPS): Instruction manual and affective ratings, NIMH Center for the Study of Emotion and Attention, 1999.

Lang, P.J.; Bradley, M.M.; Cuthbert, B.N. Motivated attention: affect, activation, e action. In: Attention e orienting: Sensory e motivational processes. (P.J.Lang, Simons RF, Balaban MT, eds), pp 97-135. Hillsdale, NJ: Lawrence Erlbaum Associates, 1997.

Lange, N., e Zeger, S. L. Non-linear Fourier time series analysis for human brain mapping by functional magnetic resonance imaging. Journal of the Royal Statistical Society - Series C: Applied Statistics, 46:1-29, 1997.

Lavie N. \& Tsal, Y. Perceptual Load As A Major Determinant Of The Locus Of Selection In Visual Attention. Percept.Psychophys. (1994) 56(2): 183-197. 
Lavie N. Perceptual load as a necessary condition for selective attention. J.Exp.Psychol.Hum.Percept.Perform. (1995) 21 (3): 451-468

Lavie, N. \& De Fockert, J. W. Contrasting Effects Of Sensory Limits And Capacity Limits In Visual Selective Attention. Percept.Psychophys. (2003) 65 (2): 202-212.

Lavie, N. Distracted and confused?: Selective attention under load. Trends Cogn Sci. (2005) 9 (2): 75-82.

Lavie, N., Ro, T., \& Russell, C. The role of perceptual load in processing distractor faces. Psychol.Sci. (2003) 14 (5): 510-515.

Lazarus, R. S. \& Alfert, E. Short-Circuiting of threat by experimentally altering cognitive appraisal. J.Abnorm.Psychol. (1964) 69: 195-205.

Lazarus, R. S., Opton, E. M., Jr., Nomikos, M. S., \& Rankin, N. O. The principle of shortcircuiting of threat: further evidence. J.Pers. (1965) 33: 622-635.

Lazarus, R. S. Emotions and interpersonal relationships: toward a person-centered conceptualization of emotions and coping. J.Pers. (2006) 74: 9-46.

Ledoux, J. The Emotional Brain. New York: Simon \& Schuster, 1996.

Ledoux, J.E. Emotion circuits in the brain. Annual Reviews Of Neuroscience (2000) 23: 155-184.

Levenson R.W. Blood, Sweat, and Fears: The Autonomic Architecture of Emotion. Ann. N.Y. Acad. Sci. (2003); 1000: 348-366.

Levesque, J., Eugene, F., Joanette, Y., Paquette, V., Mensour, B., Beaudoin, G. et al. Neural circuitry underlying voluntary suppression of sadness. Biol.Psychiatry (2003) 53: 502-510.

Levesque, J., Joanette, Y., Mensour, B., Beaudoin, G., Leroux, J. M., Bourgouin, P. et al. Neural basis of emotional self-regulation in childhood. Neuroscience(2004) 129: 361-369.

Lewis M.D., Stieben J. Emotion Regulation in the Brain: Conceptual Issues and Directions for Developmental Research CHILD DEVELOPMENT (2004) 75 (2): 371-376

Lieberman, M.D., Berman, E.T., \& Wager, T.D. Correlations in social neuroscience aren't voodoo: Commentary on Vul et al. (2009). Perspectives on Psychological Science (2009) 4(3): 299-307.

Lim SL, Pessoa L. (2008) Affective learning increases sensitivity to graded emotional faces. Emotion 8(1): 96-103. 
Lindquist M.A. \& Gelman A. Correlations and multiple comparisons in functional imaging: A statistical perspective (Commentary on Vul et al. 2009). Perspectives on Psychological Science (2009) 4(3): 299-307.

Liu X., Banich M.T., Jacobson B.L. and Tanabe J.L. Common and distinct neural substrates of attentional control in an integrated Simon and spatial stroop task as assessed by event-related fMRI. NeuroImage 22 (2004) (3), pp. 1097-1106.

Logothetis, N. K. The neural basis of the blood-oxygen-level-dependent functional magnetic resonance imaging signal. Phil. Trans. R. Soc. Lond. B (2002) 357(1424): 1003-1037.

Logothetis, N. K., Guggenberger H., Peled S. \& Pauls J. Functional imaging of the monkey brain Nature Neuroscience (1999) 2: 555 - 562.

Lopes P.N.; Salovey, P.; Cote, S.; Beers, M. Emotion regulation abilities and the quality of social interaction. Emotion (2005) 5(1): 113-118.

Luo Q., Holroyd T., Jones M., Hendler T., Blair R.J.R. Neural dynamics for facial threat processing as revealed by gamma band synchronization using MEG. NeuroImage (2007) 34: 839-847.

MacDonald III A.W., Cohen J.D., Stenger V.A. and Carter C.S. Dissociating the role of the dorsolateral prefrontal and anterior cingulate cortex in cognitive control. Science 288 (2000) pp. 1835-1838.

Malhotra P., Jagar H.R., Parton A., Greenwood R., Playford E.D., Brown M.M., Driver J., Husain M. Spatial working memory capacity in unilateral neglect. Brain (2005) 128: 424435.

Malonek, D. \& Grinvald, A. Interactions between electrical activity and cortical microcirculation revealed by imaging spectroscopy: implications for functional brain mapping. Science (1996) 272: 551-554.

Mauss, I. B., Wilhelm, F. H., \& Gross, J. J. Autonomic Recovery And Habituation In Social Anxiety. Psychophysiology (2003) 40: 648-653.

Maxwell J.S.; Shackman, A.J.; Davidson, R.J. Unattended facial expressions asymmetrically bias the concurrent processing of nonemotional information. Journal Of Cognitive Neuroscience (2005) 17 (9): 1386-1395.

Merikle, P., Smilek, D., and Eastwood, J. D. Perception without awareness: perspectives from cognitive psychology. Cognition (2001) 79: 115-134. 
Mikl, M., Marecek, R., Hlustik, P. et al. Effects of spatial smoothing on fMRI group inferences. Magn. Res. Imaging (2008) 26(4): 490-503.

Milad M.R., Quirk G.J. Neurons in medial prefrontal cortex signal memory for fear extinction. Nature (2002) 420: 70-74.

Milad M.R., Wright C.I., Orr S.P., Pitman R.K., Quirk G.J., Rauch S.L. Recall of fear extinction in humans activates theventromedial prefrontal cortex and hippocampus in concert. Biol Psychiatry (2007) 62: 446-454.

Mitchell D.G.V., Nakic M., Fridberg D., Kamel N., Pine D.S. and Blair R.J.R. Impact of Processing Load on Emotion. NeuroImage 34 (2007) 1299-1309.

Mocaiber, I. ; Erthal, F.S. ; Sanchez, T. A. ; Araujo, D. B. ; Volchan, E. ; Joffily, M. ; Pereira, M.G., Oliveira, L. Ficção atenua o medo: evidências de neuroimagem. In: FESBE, 2009, Águas de Lindóia. XIV FESBE, 2009.

Morgan, M. A. \& Ledoux, J. E. Contribution Of Ventrolateral Prefrontal Cortex To The Acquisition And Extinction Of Conditioned Fear In Rats. Neurobiol.Learn.Mem. (1999) 72: 244-251.

Morris J. S., Öhman, A., Dolan, R. J. Conscious and unconscious emotional learning in the human amygdale. (1998) Nature 393 (4): 467-470.

Morris J.S., Ohman A. and Dolan R. A subcortical pathway to the right amygdala mediating “unseen” fear. PNAS 96 (1999), pp. 1680-1685.

Mourao-Miranda J.; Volchan, E.; Moll, J.; De Oliveira-Souza, R.; Oliveira, L.; Bramati, I.; Gattass, R.; Pessoa, L. Contributions of stimulus valence and arousal to visual activation during emotional perception. Neuroimage (2003) 20(4): 1955-63.

Müller, M.M., Andersen, S.K., Keil, A. Time course of competition for visual processing resources between emotional pictures and foreground task. Cereb. Cortex (2008) 18(8): 1892-9.

Nobre A.C., Coull J.T., Maquet P., Frith C.D., Vandenberghe R. and Mesulam M.M. Orienting attention to locations in perceptual versus mental representations. J. Cogn. Neurosci. 163 (2004), pp. 363-373.

Ochsner, K.N. Current Directions In Social Cognitive Neuroscience. Current Opinion In Neurobiology (2004) 14(2): 254-258. 
Ochsner, K.N.; Bunge, S.A.; Gross, J.J.; Gabrieli, J.D. Rethinking feelings: an fmri study of the cognitive regulation of emotion. Journal of Cognitive Neuroscience (2002) 14(8): 12151229.

Ochsner, K.N.; Gross, J.J. The cognitive control of emotion. Trends in Cognitive Sciences (2005) 9(5): 242-249.

Ochsner, K.N.; Lieberman, M.D. The Emergence of Social Cognitive Neuroscience. American Psychology (2001) 56(9): 7171-734.

Ochsner, K.N.; Ray, R.D.; Cooper, J.C.; Robertson, E.R.; Chopra, S.; Gabrieli, J.D.; \& Gross, J.J. For better or for worse: neural systems supporting the cognitive down- and upregulation of negative emotion. Neuroimage (2004) 23(2): 483-499.

Ogawa, S., Lee, T.-M., Nayak, A. S., \& Glynn, P. Oxigenation-sensitive contrast in magnetic resonance image of rodent brain at highmagnetic fields. Journal Magnetic Resonance in Medicine (1990b) 14: 68-78.

Ogawa, S., Lee, T.M., Kay, A.R., Tank, D.W. Brain magnetic resonance imaging with contrast dependen on blood oxygenation. Proc Natl Acad Sci USA, 1990, vol. 87, p. 98689872.

Ohira H., Nomura M., Ichikawa N., Isowa T., Iidaka T., Sato A. et al. Association of neural and physiological responses during voluntary emotion suppression. Neuroimage (2006) 29: $721-733$.

Öhman A.; Flykt, A.; Esteves, F. Emotion Drives Attention: Detecting The Snake In The Grass. Journal Of Experimental Psychology: General (2001) 130 (3): 466-478.

Oliveira L.A.S., Joffily M., Oliveira L., Lang P., Volchan E. Context modulates skin conductance response to unpleasant visual stimuli. Psychophysiology, v.40, S65, 2003.

Oliveira, L. ; Pereira, M. G. ; Volchan, E. Processamento emocional no cérebro humano. In: Roberto Lent. (Org.). Neurociência da Mente e do Comportamento. $1^{\text {a }}$ ed. Rio de Janeiro: Guanabara Koogan, p. 253-269, 2008.

Oya H., Kawasaki H., Howard III M.A. and Adolphs R. Electrophysiological responses in the human amygdala discriminate emotion categories of complex visual stimuli. J. Neurosci. 22 (2002), pp. 9502-9512.

Padmala, S., Pessoa, L. Affective learning enhances visual detection and responses in primary visual cortex. J. Neurosci. (2008) 28(24): 6202-10. 
Panksepp J. At the interface of the affective, behavioral, and cognitive neurosciences: decoding the emotional feelings of the brain. Brain and Cognition, v.52, n.1, p.4-14, 2003.

Pereira MG, Volchan E, de Souza GG, Oliveira L, Campagnoli RR, Pinheiro WM, Pessoa L (2006) Sustained and transient modulation of performance induced by emotional picture viewing. Emotion 6(4):622-34.

Pessoa L. On the relationship between emotion and cognition. Nature Reviews Neuroscience (2008) 9: 148-158.

Pessoa L. To what extent are emotional visual stimuli processed without attention and awareness? Curr. Opin. Neurobiol. 15 (2005) (2), pp. 188-196.

Pessoa L., Japee S., Sturman D. and Ungerleider L.G. Target visibility and visual awareness modulate amygdala responses to fearful faces. Cereb. Cortex 163 (2006), pp. 366-375.

Pessoa L., McKenna M., Gutierrez E. and Ungerleider L.G. Neural processing of emotional faces requires attention. Proc. Natl. Acad. Sci. U. S. A. 99 (2002) (17), pp. 11458-11463.

Pessoa L., Ungerleider L.G. Neuroimaging studies of attention and the processing of emotion-laden stimuli. Prog. Brain Res. (2004) 144: 171-182.

Pessoa, L., Kastner, S., \& Ungerleider, L. G. (2002). Attentional control of the processing of neural and emotional stimuli. Brain Res.Cogn Brain Res., 15, 31-45.

Pessoa, L., Padmala, S., \& Morland, T. Fate of unattended fearful faces in the amygdala is determined by both attentional resources and cognitive modulation. Neuroimage (2005) 28 : 249-255.

Pezawas, L., Meyer-Lindenberg, A., Drabant, E.M., Verchinski, B.A., Munoz, K.E., Kolachana, B.S., et al., 2005. 5-HT'TLPR polymorphism impacts human cingulate-amygdala interactions: a genetic susceptibility mechanism for depression. Nat. Neurosci. 86, 828-834.

Phan K. L., Fitzgerald, D. A., Nathan, P. J., Moore, G. J., Uhde, T. W., \& Tancer, M. E. Neural substrates for voluntary suppression of negative affect: a functional magnetic resonance imaging study. Biol.Psychiatry (2005) 57: 210-219.

Phan, K. L., Wager, T., Taylor, S. F. and Liberzon, I. Functional Neuroanatomy of Emotion: A Meta-Analysis of Emotion Activation Studies in PET and fMRI. NeuroImage (2002) 16: 331-348.

Phan, K. L., Wager, T., Taylor, S. F. and Liberzon, I. Functional Neuroimaging Studies of Human Emotions. CNS Spectr. (2004) 9(4): 258 - 266. 
Pinsk M. A., Doniger, G. M., \& Kastner, S. Push-pull mechanism of selective attention in human extrastriate cortex. J.Neurophysiol. (2004) 92(1): 622-629.

Poldrack R.A. Region of interst analysis for fMRI. SCAN (2007) 2: 67 - 70.

Poldrack R.A. \& Mumford J. A. Independence in ROI analysis: where is the voodoo? SCAN (2009) 4, 208-213

Poline, J.-B., Kherif, F., e Penny, W. Contrasts and classical inference. In: Human Brain Function (Editores: Frackowiak, R. S. J., Friston, K. J., Frith, C., Dolan, R., Price, C. J., Zeki, S., Ashburner, J., e Penny, W. D), pp. 761-779. Academic Press, 2. edição, 2003.

Porges, S.W. Emotion: An Evolutionary By-Product of the Neural Regulation of the Autonomic Nervous System. Annals of the New York Academy of Sciences: Integrative N (1997) 807(1): 62-77.

Posner, M. I. and Petersen S. The attention system of the human brain. Ann. Rev. Neurosci. (1990) 13: 25-42.

Posner, M. I. Orienting of attention. Quarterly Journal of Experimental Psychology (1980) 32: 3-25.

Quirk, G.J., Gehlert, D.R. Inhibition of the amygdala: key to pathological states? Ann. N. Y. Acad. Sci. (2003) 985: 263-272.

Ray, R. D., Ochsner, K. N., Cooper, J. C., Robertson, E. R., Gabrieli, J. D., \& Gross, J. J. Individual differences in trait rumination and the neural systems supporting cognitive reappraisal. Cognitive, Affective and Beahvioral Neuroscience (2005) 5(2): 156-168.

Rees G., Frith C.D. and Lavie N. Modulating irrelevant motion perception by varying attentional load in an unrelated task. Science (1997) 278: 1616-1619.

Rensink R. A. Change Detection. Annual Review Of Psychology (2002) 53: 245-277.

Rensink, R. A.; O'regan, J. K.; Clark, J. J. To See or not to see: the need for attention to perceive changes in scenes. Psychological Science (1997) 8: 368-373.

Ribas, G. C. As bases neuroanatômicas do comportamento: histórico e contribuições recentes. Rev. Bras. Psiquiatr. (2007) 29(1): 63-71.

Rosen, B. R., Buckner, R. L., e Dale, A. M. Event-related functional MRI: past, present, and future. Proceedings of the National Academy of Sciences of USA, 95:773-780, 1998. 
Schaefer, S. M., Jackson, D. C., Davidson, R. J., Aguirre, G. K., Kimberg, D. Y., \& Thompson-Schill, S. L. Modulation Of Amygdalar Activity By The Conscious Regulation Of Negative Emotion. J.Cogn Neurosci. (2002) 14: 913-921.

Schimmack U. \& Derryberry, D. Attentional Interference Effects Of Emotional Pictures: Threat, Negativity, Or Arousal? Emotion (2005) 5 (1): 55-66.

Schneirla T. C. Behavioral Development and Comparative Psychology. The Quarterly Review of Biology (1966) 41(3): 283-302.

Schupp H.T., Junghöfer M., Weike A.I., Hamm A.O. Attention and emotion: an ERP analysis of facilitated emotional stimulus processing. Neuroreport (2003) 14(8):1107-10.

Schupp HT, Stockburger J, Bublatzky F, Junghöfer M, Weike AI, Hamm AO The selective processing of emotional visual stimuli while detecting auditory targets: an ERP analysis. Brain Res. (2008) 1230: 168-76.

Siegle G. J., Thompson W., Carter C. S., Steinhauer S. R., Thase M.E. Increased Amygdala and Decreased Dorsolateral Prefrontal BOLD Responses in Unipolar Depression: Related and Independent Features Biological Psychiatry (2007) 61(2): 198-209.

Silvert L, Lepsien J, Fragopanagos N, Goolsby B, Kiss M, Taylor JG, Raymond JE, Shapiro KL, Eimer M, Nobre A.C. Influence of attentional demands on the processing of emotional facial expressions in the amygdale Neuroimage (2007) 38(2): 357-66.

Simons D.J. \& Levin D.T. Change Blindness. Trends In Cognitive Sciences (1997) 1(7): 261-267.

Simons D.J. Attentional Capture And Inattentional Blindness. Trends In Cognitive Sciences (2000) 4(4): 147-155.

Slotnick, S. D., Schwarzbach, J., \& Yantis, S. Attentional Inhibition of Visual Processing in Human Striate and Extrastriate Cortex. Neuroimage (2003) 19(4): 1602-1611.

Soares P.P.S., Oliveira L.A.S., Oliveira L., Joffily M., Lang P.J., Nobrega A.C.L. Regulation of heart adrenergic response to mutilated pictures: Influence of dispositional positive affect. Psychophysiology (2004) 41: S33-S33.

Souza A.C.M., Souza G.G.L., Vieira A., Barros E.M., Rujmanek V., Volchan E. Emotional reactions measured in the saliva. Psychophysiology, v.42, S1, 2005.

Stark C.E.L. and Squire L.R. When zero is not zero: The problem of ambiguous baseline conditions in fMRI. PNAS (2001): 98 (22) 12760-12766. 
Swanson, L. W. The amygdala and its place in the cerebral hemisphere. Ann. NY Acad. Sci. 985, 174-184 (2003).

Talairach, J., e Tournoux, P. Co-planar Stereotaxic Atlas of the Human Brain. Thieme, Stuttgart, Alemanha, 1988

Taylor S. F., Phan, K. L., Decker, L. R., \& Liberzon, I. Subjective Rating of Emotionally Salient Stimuli Modulates Neural Activity. Neuroimage., V. 18, N. 3, P. 650-659, Mar. 2003.

Taylor, S. F. \& Liberzon I. Cognitive-emotional interactions: Neural correlates of emotion regulation in psychopathology. TRENDS in Cognitive Sciences (2007) 11(10): 413 - 418.

Thayer, J. F.\& Lane R. D. A model of neurovisceral integration in emotion regulation and dysregulation. Journal of Affective Disorders (2000) 61: 201 - 216.

Thulborn, K. R., Waterton, J. C., Matthews, P. M., e Radda, G. K. Oxygenation dependence of the transverse relaxation time of water protons in whole blood at high field. Biochimica et Biophysica Acta, 714:265-270, 1982.

Tipples J. \& Sharma D. Orienting to Exogenous Cues and Attentional Bias to Affective Pictures Reflect Separate Processes. British Journal of Psychology (2000) 91: 87-97.

Urry H. L., van Reekum, C. M., Johnstone, T., Kalin, N. H., Thurow, M. E., Schaefer, H. S. et al. (2006). Amygdala and ventromedial prefrontal cortex are inversely coupled during regulation of negative affect and predict the diurnal pattern of cortisol secretion among older adults. J.Neurosci., 26, 4415-4425.

Van Zijl, P. C., Eleff, S. M., Ulatowski, J. A., Oja, J. M., Ulug, A. M., Traystman, R. J. \& Kauppinen, R. A. Quantitative assessment of blood flow, blood volume and bloodoxygenation effects in functional magnetic resonanceimaging. Nature Med. (1998) 4: 159_ 167.

Volz, H. P., Nenadic, I., Gaser, C., Rammsayer, T., Hager, F., \& Sauer, H. Time estimation in schizophrenia: An fMRI study at adjustedlevels of dificulty. Neuroreport (2001) 12: 313316.

Vuilleumier P and Huang Y. M. Emotional Attention: Uncovering the Mechanisms of Affective Biases in Perception. Current Directions in Psychological Science. (2009) 18 (3): 148 $-152$. 
Vuilleumier P, Armony JL \& Dolan RJ. Reciprocal Links Between Emotion and Attention. In: R.S.J. Frackowiak et al., editors. Human Brain Function (2 ${ }^{\text {nd }}$ edition), San Diego: Academic Press, 2003, pp. 419-444, Elsevier.

Vuilleumier P, Armony JL, Driver J, Dolan RJ. Effects of attention and emotion on face processing in the human brain: an event-related fMRI study. (2001) Neuron 30, 829-41.

Vuilleumier P, Richardson MP, Armony JL, Driver J, Dolan RJ. Distant influences of amygdala lesion on visual cortical activation during emotional face processing. (2004) Nat Neurosci 7(11):1271-8.

Vuilleumier P. How brains beware: neural mechanisms of emotional attention. (2005) Trends Cogn Sci. 9(12): 585-94.

Vul E., Harris C., Winkielman P., Pashler E. Puzzlingly High Correlations in fMRI Studies of Emotion, Personality, and Social Cognition. Perspectives on Psychological Science (2009) 4 (3): 274-290

Wager, T. D., Davidson, M. L., Hughes, B. L., Lindquist, M. A. and Ochsner, K. N. Prefrontal-subcortical pathways mediating successful emotion regulation. Neuron (2008) 59: 1037-1050.

Whalen P.J.; Rauch, S.L.; Etcoff, N.L.; Mcinerney, S.C.; Lee, M.B.; Jenike, M.A. Masked presentations of emotional facial expressions modulate amygdala activity without explicit knowledge. Journal Of Neuroscience, V.18, P.411-418, 1998.

Willians L., Phillips ML, Brammer M. J., Skerrett D., Lagopoulos J., Rennie C, Bahramali H, Olivieri G., David A.S., Peduto A and Gordon E. M. Arousal dissociates amygdala and hippocampal fear responses: evidence from simultaneous fMRI and skin conductance recording. NeuroImage (2001); 14: 1070-79.

Willians M. A., McGlone F., Abbott D.F. and Mattingley J.B. Differential amygdala responses to happy and fearful facial expressions depend on selective attention. Neuroimage (2005); 242: 417-25.

Winkler A. M. Inferência baseada em Voxel para fMRI. 2007. Dissertação de Mestrado, Universidade Tecnológica Federal do Paraná.

Worsley, K. J. Statistical analysis of activation images. In: Functional MRI: An Introduction to Methods (editors Jezzard, P., Mathews, P. M., e Smith, S. M.), pp. 251-270. Oxford, 2001. 
Young MP, Scannell JW, Burns GA, Blakemore C. Analysis of connectivity: neural systems in the cerebral cortex. Rev Neurosci. 1994 Jul-Sep;5(3):227-50.

Zarahn, E., Aguirre, G. K., e D'Esposito, M. A trial-based experimental design for fMRI. NeuroImage, 6:122-138, 1997b.

Zarahn, E., Aguirre, G. K., e D’Esposito, M. Empirical analyses of BOLD fMRI statistics: I. Spatially unsmoothed data collected under null-hypothesis conditions. NeuroImage, 5:179-197, 1997a. 


\section{ANEXOS}

\section{TERMO DE CONSENTIMENTO LIVRE E ESCLARECIDO}

Você está se propondo a participar como voluntário de um estudo de avaliação da influência dos estímulos afetivos sobre a reatividade cerebral. O estudo será realizado nas dependências do Hospital das Clínicas da Faculdade de Medicina de Ribeirão Preto da Universidade de São Paulo, sob orientação das Profa. Dra. Letícia de Oliveira e Profa. Dra. Mirtes Garcia Pereira e coordenação do Prof. Dr. Draulio Barros de Araújo.

O experimento é composto de uma única sessão experimental com duração de aproximadamente 45 minutos. A sessão experimental será realizada em uma sala especialmente preparada (isolamento acústico relativo, luz indireta, ar condicionado) contendo uma máquina de Ressonância Magnética, não representando nenhum risco potencial para o voluntário. Você deitará em uma cama que será inserida na máquina de Ressonância Magnética Funcional, manterá sua cabeça fixa em um apoiador e usará óculos de realidade virtual, no qual serão apresentadas fotografias de pessoas, bebês, paisagens, objetos, poluições, mutilações, e etc.

A obtenção de imagens através da ressonância magnética é um procedimento que permite aos médicos observar seu organismo inteiramente através de um aparelho que gera um forte campo magnético e ondas de rádio. Este é um procedimento não invasivo usado rotineriamente para exames médicos e é muito seguro para a maioria das pessoas, mas você será monitorado durante todo o procedimento dentro da máquina para caso algum problemas ocorra. Os riscos da ressonância magnética são:

- A máquina de RM contém um magneto muito forte. Desta forma você não poderá entrar na máquina de RM se você possuir algum tipo de metal implantado no seu corpo, por exemplo, marca passo cardíaco, clips cirúrgicos, fragmentos metálicos no corpo ou nos olhos, válvulas cardíacas, próteses metálicas ou de qualquer natureza ou implantes cocleares. Alguém fará essas perguntas a você antes de você entrar na máquina de RM.

- Não existe muito espaço dentro da máquina de RM. Você pode se sentir desconfortável se você não gostar de ficar em lugares fechados (claustrofobia). Durante todo o procedimento, você será capaz de falar com as pessoas que estão controlando a máquina através de um sistema de altofalantes, e no caso de uma emergência, você poderá pedir para parar o exame. Se você tem claustrofobia, você deve avisar ao experimentador.

- A máquina de RM produz um ruído muito alto, que produziu prejuízo auditivo em um pequeno número de pacientes.

- Se você é uma mulher com possibilidade de estar grávida, podem ocorrer prejuízos desconhecidos ao feto. Portanto, antes de participar de um exame em uma máquina de RM, você deverá fazer um teste de gravidez. Você será avisada para fazer um teste em casa antes de inicar a sessão experimental.

A participação na pesquisa é voluntária e você é livre para interromper sua participação a qualquer momento sem nenhuma penalização ou prejuízo. Em qualquer etapa do estudo, você terá acesso aos professores responsáveis, Profa. Dra. Letícia de Oliveira, que pode ser encontrada no Departamento de Fisiologia e Farmacologia da UFF, sala 203 bloco Y, ou pelo telefone (21) 2629-2446 ou Prof. Dr. Draulio Barros de Araujo, que pode ser encontrado no Departamento de Física e Matemática da USP, Avenida Bandeirantes, 3900, Monte Alegre (Ribeirão Preto) ou pelo telefone (16) 3602-3822 para tirar qualquer dúvida ou se manter atualizado com os resultados parciais da pesquisa. Se você tiver alguma consideração ou dúvida sobre a ética da pesquisa, entre em contato com o Comitê de Ética em Pesquisa (CEP) do Hospital Universitário Clementino Fraga Filho - sala 01D-46- $1^{\circ}$ andar, tel: 2562-2480 - e-mail: ccp@,hucff.ufrj.br. Todos os seus dados são confidenciais, as informações obtidas durante a sua sessão experimental serão analisadas em conjunto com as informações dos outros voluntários, portanto você terá 
a sua privacidade garantida. Temos o compromisso de tornar públicos os resultados desta pesquisa, sejam eles positivos ou negativos. Este experimento não é recomendado para pessoas portadoras de distúrbios psiquiátricos, neurológicos, endócrinos e cardiovasculares.

Acredito ter sido suficientemente informado a respeito do estudo acima citado. Ficaram claros para mim quais são os procedimentos a serem realizados, as garantias de confidencialidade e de esclarecimentos permanentes e de que este experimento não é recomendado para pessoas portadoras de distúrbios psiquiátricos, neurológicos, endócrinos e cardiovasculares. Concordo voluntariamente em participar deste estudo e poderei retirar o meu consentimento a qualquer momento, antes ou durante o mesmo, sem penalidades ou prejuízos de qualquer espécie.

Niterói, de de

Assinatura do pesquisador

Assinatura do voluntário 


\section{SRQ (SELF REPORTING QUESTIONNAIRE)}

Responda às perguntas abaixo, com SIM ou NÃO, em relação a como você se sentiu a maior parte do tempo, no último mês.

1. Tem dores de cabeça freqüentes?

SIM NÃO

2. Tem falta de apetite?

3. Dorme mal?

4. Assusta-se com facilidade?

5. Tem tremores na mão?

6. Sente-se nervoso(a),tenso(a) ou preocupado(a)?

7. Tem má digestão?

8. Tem dificuldade de pensar com clareza?

9. Tem se sentido triste ultimamente?

10. Tem chorado mais do que de costume?

11. Encontra dificuldades para realizar c/ satisfação suas atividades diárias?

12. Tem dificuldades para tomar decisões?

13. Tem dificuldades no serviço (seu trabalho é penoso, lhe causa sofrimento)?

14. É incapaz de desempenhar um papel útil em sua vida?

15. Tem perdido o interesse pelas coisas?

16. Você se sente uma pessoa inútil, sem préstimo?

17. Tem tido a idéia de acabar com a vida?

18. Sente-se cansado(a) o tempo todo?

19. Tem sensações desagradáveis no estômago?

20. Você se cansa com facilidade? 


\section{QUESTIONÁRIO DE TRAUMA (TRAUMA HISTORY QUESTIONNAIRE)}

A série de questões a seguir diz respeito a eventos graves ou traumáticos durante a vida. Estes tipos de eventos realmente ocorrem com alguma regularidade, apesar de nós querermos acreditar que eles sejam raros. Após a sua ocorrência, eles afetam a maneira pela qual as pessoas sentem, reagem e/ou pensam a respeito das coisas. $\mathrm{O}$ conhecimento sobre a ocorrência de tais eventos assim como a reação a eles vai nos auxiliar a desenvolver programas de prevenção, educação e outros serviços.

O questionário é dividido em perguntas que abordam experiências relacionadas a crime, perguntas sobre desastre em geral e trauma e perguntas sobre experiências físicas e sexuais. Para cada evento, por favor, indique (com um círculo) se aconteceu e, em caso afirmativo, assinale o quão estressante foi o evento e a sua idade aproximada na época (se não tiver certeza, faça o melhor que puder). Além disso, diga a natureza da relação entre você e a pessoa envolvida e o tipo específico do evento, se for apropriado.

\begin{tabular}{|c|c|c|c|c|}
\hline Eventos relacionados a crime & & & \multicolumn{2}{|c|}{ Em caso afirmativo } \\
\hline & & & $\begin{array}{l}\text { Intensidade } \\
1=\text { nada estressante } \\
5=\text { extremamente } \\
\text { estressante }\end{array}$ & $\begin{array}{l}\text { Idade aproximada } \\
\text { (caso }+ \text { de uma vez } \\
\text { informar o pior) }\end{array}$ \\
\hline $\begin{array}{l}\text { 1. Alguém já tentou tirar alguma coisa diretamente de você } \\
\text { usando força ou ameaça de força, tal como assalto a mão } \\
\text { armada ou furto? }\end{array}$ & Não & Sim & 12345 & \\
\hline $\begin{array}{l}\text { 2. Alguém já tentou roubá-lo (a) ou de fato o (a) roubou } \\
\text { (i.e. furtou seus objetos pessoais)? }\end{array}$ & Não & Sim & 12345 & \\
\hline $\begin{array}{l}\text { 3. Alguém já tentou invadir ou de fato invadiu sua casa } \\
\text { quando você não estava lá? }\end{array}$ & Não & Sim & 12345 & \\
\hline $\begin{array}{l}\text { 4. Alguém já tentou invadir ou de fato invadiu sua casa } \\
\text { enquanto você estava lá? }\end{array}$ & Não & Sim & 12345 & \\
\hline
\end{tabular}

\begin{tabular}{|c|c|c|c|l|}
\hline \multicolumn{1}{|c|}{ Desastre em geral e trauma } & & & & \multicolumn{2}{|c|}{ Em caso afirmativo } \\
\hline & & & $\begin{array}{l}\text { Intensidade } \\
1=\text { nada estressante } 5 \\
\text { extremamente estres- } \\
\text { sante }\end{array}$ & $\begin{array}{l}\text { Idade aproximada } \\
\text { (caso + de uma vez } \\
\text { informar o pior) }\end{array}$ \\
\hline $\begin{array}{l}\text { 5. Você já sofreu algum acidente grave no trabalho, } \\
\text { num carro ou em qualquer outro lugar? } \\
\text { Se responder sim, por favor, especificar. }\end{array}$ & Não & Sim & 12345 & \\
\hline Desastre em geral e trauma & & & & Em caso afirmativo \\
\hline
\end{tabular}




\begin{tabular}{|c|c|c|c|c|}
\hline & & & $\begin{array}{l}\text { Intensidade } \\
1=\text { nada estressante } \\
5=\text { extremamente } \\
\text { estressante }\end{array}$ & $\begin{array}{l}\text { Idade aproximada (caso }+ \text { de } \\
\text { uma vez informar o pior) }\end{array}$ \\
\hline $\begin{array}{l}\text { 6. Você já passou por algum desastre natural, do tipo desli- } \\
\text { zamento de terra, enchente, tempestade, terremoto, etc, } \\
\text { durante o qual você percebeu que você ou pessoas queridas } \\
\text { corriam perigo de vida ou ferimento? }\end{array}$ & Não & Sim & 12345 & \\
\hline $\begin{array}{l}\text { 7. Você já passou por algum desastre causado pelo homem, } \\
\text { tal como choque de um trem, desmoronamento de um pré- } \\
\text { dio, assalto a banco, incêndio, etc, durante o qual você } \\
\text { percebeu que você ou pessoas queridas corriam perigo de } \\
\text { vida ou ferimento? }\end{array}$ & Não & Sim & 12345 & \\
\hline $\begin{array}{l}\text { 8. Você já foi exposto (a) a radioatividade ou a agentes } \\
\text { químicos perigosos que pudessem ameaçar a sua saúde? }\end{array}$ & Não & Sim & 12345 & \\
\hline $\begin{array}{l}\text { 9. Você já esteve em qualquer outra situação na qual você foi } \\
\text { gravemente ferido (a)? } \\
\text { Se responder sim, por favor, especificar. }\end{array}$ & Não & Sim & 12345 & \\
\hline $\begin{array}{l}\text { 10. Você já esteve em qualquer outra situação na qual você } \\
\text { teve medo porque poderia ter sido morto (a) ou gravemente } \\
\text { ferido (a)? } \\
\text { Se responder sim, por favor, especificar. }\end{array}$ & Não & Sim & 12345 & \\
\hline $\begin{array}{l}\text { 11.Você já viu alguém ser gravemente machucado ou morto? } \\
\text { Se responder sim, por favor, especificar quem. }\end{array}$ & Não & Sim & 12345 & \\
\hline $\begin{array}{l}\text { 12. Você já viu cadáveres (excluindo em funerais) ou teve } \\
\text { que tocar em cadáveres por qualquer motivo? } \\
\text { Se responder sim, por favor, especificar. }\end{array}$ & Não & Sim & 12345 & \\
\hline $\begin{array}{l}\text { á teve algum amigo próximo ou membro da sua } \\
\text { assinado ou morto por um motorista bêbado? } \\
\text { der sim, por favor, especificar sua relação com esta } \\
\text { x. mãe, neto, etc). }\end{array}$ & Sim & & 12345 & \\
\hline
\end{tabular}




\begin{tabular}{|l|c|c|c|c|}
\hline $\begin{array}{l}\text { 14. Você já perdeu (por morte) um cônjuge, companheiro (a), } \\
\text { namorado (a) ou filho (a)? } \\
\text { Se responder sim, por favor, especificar sua relação com esta } \\
\text { pessoa. }\end{array}$ & Não & Sim & 12345 & \\
\hline $\begin{array}{l}\text { 15. Você já sofreu de uma doença grave ou que pusesse em risco } \\
\text { sua vida? } \\
\text { Se responder sim, por favor, especificar. }\end{array}$ & Não & Sim & 12345 & \\
\hline $\begin{array}{l}\text { 16.Você já recebeu a notícia de que alguém próximo a você } \\
\text { foi gravemente ferido, teve doença que ameaçou a vida ou } \\
\text { morreu de forma inesperada? } \\
\text { Se responder sim, por favor, indicar. }\end{array}$ & Não & Sim & 12345 & \\
\hline
\end{tabular}

\begin{tabular}{|c|c|c|c|c|c|}
\hline \multirow[t]{2}{*}{ Experiências físicas e sexuais } & & & \multicolumn{3}{|c|}{ Em caso afirmativo } \\
\hline & & & $\begin{array}{l}\text { Intensidade } \\
1 \text { nada estressante } 5 \\
\text { extremamente } \\
\text { estressante }\end{array}$ & $\begin{array}{l}\text { Aproximada mente } \\
\text { quantas vezes esta } \\
\text { experiência se repetiu }\end{array}$ & $\begin{array}{l}\text { Com que ida- } \\
\text { de(s) esses } \\
\text { eventos começa- } \\
\text { ram e termina- } \\
\text { ram }\end{array}$ \\
\hline $\begin{array}{l}\text { 18. Alguém já o (a) obrigou a ter relações sexuais ou sexo anal ou } \\
\text { oral contra a sua vontade? } \\
\text { Se responder sim, por favor, indicar a natureza da relação com a } \\
\text { pessoa (ex., estranho, amigo, parente, pai ou mãe, irmão). }\end{array}$ & Não & Sim & 12345 & & $\begin{array}{l}\text { Início: } \\
\text { Fim: }\end{array}$ \\
\hline $\begin{array}{l}\text { 19. Alguém já tocou em partes íntimas do seu corpo ou o (a) } \\
\text { obrigou a tocar nas dele (a), sob força ou ameaça? } \\
\text { Se responder sim, por favor, indicar a natureza da relação com a } \\
\text { pessoa (ex., estranho, amigo, parente, pai ou mãe, irmão). }\end{array}$ & Não & Sim & 12345 & & $\begin{array}{l}\text { Início: } \\
\text { Fim: }\end{array}$ \\
\hline
\end{tabular}




\begin{tabular}{|c|c|c|c|c|}
\hline $\begin{array}{l}\text { 20. Além dos incidentes mencionados nas questões } 18 \text { e } 19 \text {, } \\
\text { já houve outras situações nas quais outra pessoa tentou } \\
\text { forçá-lo (a) a ter contato sexual contra a sua vontade? }\end{array}$ & Nâo & Sim & 12345 & $\begin{array}{l}\text { Início: } \\
\text { Fim }\end{array}$ \\
\hline $\begin{array}{l}\text { 21. Alguém da sua família já lhe bateu, espancou ou } \\
\text { empurrou de modo a causar intensa humilhação ou } \\
\text { pavor? }\end{array}$ & Não & Sim & 12345 & $\begin{array}{l}\text { Início: } \\
\text { Fim }\end{array}$ \\
\hline $\begin{array}{l}\text { 22. Alguém da sua família ou pessoa próxima persistente- } \\
\text { mente já lhe ridicularizou, humilhou ou ignorou causando } \\
\text { intenso sofrimento? }\end{array}$ & Não & Sim & 12345 & $\begin{array}{l}\text { Início: } \\
\text { Fim }\end{array}$ \\
\hline $\begin{array}{l}\text { 23. Alguém, incluindo membros da sua família ou amigos, já } \\
\text { o (a) atacou usando um revólver, uma faca ou qualquer outra } \\
\text { arma? }\end{array}$ & Não & Sim & 12345 & $\begin{array}{l}\text { Início: } \\
\text { Fim }\end{array}$ \\
\hline $\begin{array}{l}\text { 24. Alguém, incluindo membros da sua família ou amigos, já } \\
\text { o (a) atacou desarmado e o (a) feriu gravemente? }\end{array}$ & Não & Sim & 12345 & $\begin{array}{l}\text { Início: } \\
\text { Fim: }\end{array}$ \\
\hline $\begin{array}{l}\text { 25. Alguém da sua família já lhe bateu, espancou ou } \\
\text { empurrou com força suficiente para causar ferimento? }\end{array}$ & Não & Sim & 12345 & $\begin{array}{l}\text { Início: } \\
\text { Fim: }\end{array}$ \\
\hline
\end{tabular}

\begin{tabular}{|l|l|l|l|l|}
\hline Outros eventos & & & \multicolumn{2}{|c|}{ Em caso afirmativo } \\
\hline & & & $\begin{array}{l}\text { INTENSIDADE } \\
1 \text { nada estressante } 5 \\
\text { extremamente estressante }\end{array}$ & $\begin{array}{l}\text { Idade aproximada (caso + de } \\
\text { uma vez informar o pior) }\end{array}$ \\
\hline $\begin{array}{l}\text { 26. Você já passou por alguma outra situação ou evento } \\
\text { extraordinariamente traumáticos que não foram abordados } \\
\text { nas questões acima? } \\
\text { Se responder sim, por favor, especificar. }\end{array}$ & Não & Sim & & \\
\hline
\end{tabular}

ATENÇÃO : Identifique na lista acima, pelo número, o evento que você considere que tenha sido o mais estressante em sua experiência de vida: 


\section{PANAS (POSITIVE AND NEGATIVE AFFECTIVE SCALE)}

Essa escala consiste de palavras que descrevem diferentes sentimentos e emoções. Leia cada item e então marque a resposta apropriada no espaço ao lado da palavra. Indique o quanto você se sente assim em geral, em média/no momento.

\begin{tabular}{|c|c|c|c|c|c|}
\hline & $\begin{array}{l}\text { Muito pouco ou } \\
\text { nada }\end{array}$ & Um роисо & Moderadamente & Muito & Excessivamente \\
\hline Interessado & $\bigcirc$ & O & 0 & 0 & 0 \\
\hline Aflito & O & 0 & 0 & 0 & 0 \\
\hline Empolgado & O & 0 & 0 & 0 & 0 \\
\hline Chateado & O & 0 & 0 & 0 & 0 \\
\hline Forte & 0 & 0 & 0 & 0 & D \\
\hline Culpado & 0 & 0 & 0 & 0 & 0 \\
\hline Com medo & 0 & 0 & 0 & 0 & 0 \\
\hline Hostil & 0 & 0 & 0 & 0 & 0 \\
\hline Entusiasmado & 0 & 0 & 0 & $\bigcirc$ & O \\
\hline Orgulhoso & 0 & 0 & 0 & 0 & 0 \\
\hline Irritável & 0 & O & 0 & O & O \\
\hline Alerta & O & 0 & 0 & 0 & 0 \\
\hline Envergonhado & $\bigcirc$ & 0 & $\bigcirc$ & 0 & 0 \\
\hline Inspirado & 0 & O & 0 & 0 & 0 \\
\hline Nervoso & 0 & 0 & 0 & 0 & 0 \\
\hline Determinado & 0 & 0 & 0 & 0 & $\bigcirc$ \\
\hline Atento & 0 & O & 0 & 0 & O \\
\hline Agitado & 0 & 0 & 0 & 0 & 0 \\
\hline Ativo & 0 & 0 & 0 & 0 & 0 \\
\hline Apavorado & 0 & 0 & 0 & $\bigcirc$ & 0 \\
\hline
\end{tabular}




\section{STAIT TRAIT ANXIETY INVENTORY - TRAIT (IDATE-T)}

Leia cada pergunta e faça um círculo ao redor do número à direita que melhor indicar como você geralmente se sente. Não gaste muito tempo numa única afirmação, mas tente dar a resposta que mais se aproximar de como você se sente geralmente.

\section{Avaliação}

Quase sempre.........4 Às vezes......2

Freqüentemente.....3 Quase nunca....1

\begin{tabular}{|c|c|c|c|c|c|}
\hline Item & Descrição & & & & \\
\hline 1 & Sinto-me bem & 1 & 2 & 3 & 4 \\
\hline 2 & Canso-me facilmente & 1 & 2 & 3 & 4 \\
\hline 3 & Tenho vontade de chorar & 1 & 2 & 3 & 4 \\
\hline 4 & Gostaria de ser tão feliz quanto os outros parecem ser & 1 & 2 & 3 & 4 \\
\hline 5 & Perco oportunidades porque não consigo tomar decisões rápidas & 1 & 2 & 3 & 4 \\
\hline 6 & Sinto-me descansado & 1 & 2 & 3 & 4 \\
\hline 7 & Sinto-me calmo, ponderado e senhor de mim mesmo & 1 & 2 & 3 & 4 \\
\hline 8 & $\begin{array}{l}\text { Sinto que as dificuldades estão se acumulando de tal forma que } \\
\text { não as consigo resolver }\end{array}$ & 1 & 2 & 3 & 4 \\
\hline 9 & Preocupo-me demais com as coisas sem importância & 1 & 2 & 3 & 4 \\
\hline 10 & Sou feliz & 1 & 2 & 3 & 4 \\
\hline 11 & Deixo-me afetar muito pelas coisas & 1 & 2 & 3 & 4 \\
\hline 12 & Não tenho confiança em mim mesmo & 1 & 2 & 3 & 4 \\
\hline 13 & Sinto-me seguro & 1 & 2 & 3 & 4 \\
\hline 14 & Evito ter que enfrentar crises e problemas & 1 & 2 & 3 & 4 \\
\hline 15 & Sinto-me deprimido & 1 & 2 & 3 & 4 \\
\hline 16 & Estou satisfeito & 1 & 2 & 3 & 4 \\
\hline 17 & $\begin{array}{l}\text { Às vezes idéias sem importância me entram na cabeça e ficam me } \\
\text { preocupando }\end{array}$ & 1 & 2 & 3 & 4 \\
\hline 18 & $\begin{array}{l}\text { Levo os desapontamentos tão a sério que não consigo tirá-los da } \\
\text { cabeça }\end{array}$ & 1 & & 3 & 4 \\
\hline 19 & Sou uma pessoa estável & 1 & 2 & 3 & 4 \\
\hline 20 & $\begin{array}{l}\text { Fico tenso e perturbado quando penso em meus problemas do } \\
\text { momento }\end{array}$ & 1 & 2 & 3 & 4 \\
\hline
\end{tabular}




\section{QUESTIONÁRIO MUTILADOS (MQ - MUTILATION QUESTIONNAIRE)}

Este instrumento é composto de 30 itens referentes a seus sentimentos a respeito decorrentes da visualização de ferimentos ou lesões. Cada alternativa pode ser "VERDADEIRA" ou "FALSA". Tente decidir se "VERDADEIRO" ou "FALSO" representa a maior parte dos seus sentimentos quando associados com os seus pensamentos ou experiências mais recentes, depois circule a letra apropriada (V= VERDADEIRO; F= FALSO). Lembre-se que esta informação é completamente confidencial. Responda rapidamente e não gaste muito tempo em nenhum dos item. Neste questionário queremos a sua primeira impressão. Vá em frente, responda rápido, e lembre-se de responder a todos os itens.

1- Eu não consegui remover um anzol de um peixe que foi pescado. (V) (F)

2- Eu sentiria repugnância ao olhar um cérebro preservado em uma garrafa. (V)

3- Se uma pessoa severamente machucada aparece na televisão, eu desvio o olhar. (V)

4- Eu tenho aversão a olhar figuras de acidentes ou ferimentos em revistas. (V) (F)

5- Eu não me importo em visitar um hospital e ver pessoas doentes ou feridas. (V)

6- Odores médicos me fazem sentir tenso e desconfortável. (V) (F)

7- Eu não sairia para caçar porque eu não suportaria olhar um animal morto. (V)

- Observar um açougueiro trabalhando me deixaria ansioso. (V)

9- A carreira de médico ou enfermeiro é muito atraente para mim. (V)

10- Eu me sentiria desfalecendo se eu visse alguém com um ferimento no olho. (V)

11- Observar pessoas usando ferramentas afiadas me deixa nervoso. (V)

12- A perspectiva de tomar ou ver alguém tomando uma injeção me incomoda bastante. (V)

13- Eu me sinto enjoado ou desfalecente ao ver sangue. (V) (F)

14- Eu aprecio ler artigos sobre técnicas modernas da medicina. (V) (F)

15- Ferimentos, acidentes, sangue, etc., me incomodam mais que qualquer coisa. (V)

16- Sob nenhuma circunstância eu aceitaria um convite para assistir uma cirurgia. (V)

17- Quando eu vejo um acidente eu me sinto tenso. (V)

18- Eu não me incomodaria de ver um corte desde que ele estivesse limpo e suturado. (V)

19- Usar facas muito afiadas me deixa nervoso. (V)

20- Não são apenas cortes e feridas que me perturbam, a visualização de pessoas com membros amputados, cicatrizes grandes ou cirurgia plástica também me incomodam. (V)

21- Se houvesse meios disponíveis, seria interessante ver a ação dos órgãos internos em um organismo vivo. (V) (F)

22- Eu fico aterrorizado com a idéia de alguém retirar uma amostra de sangue de mim. (V)

23- Eu não acredito que alguém seria capaz de ajudar uma pessoa com um ferimento sangrando sem se sentir pelo menos um pouco perturbado. (V)

24- Eu fico apavorado com a idéia de fazer uma cirurgia. (V)

25- Eu fico aterrorizado pelo pensamento de que um dia eu posso ter que ajudar uma pessoa muito machucada em um acidente de carro. (V) (F)

26- Eu estremeço quando eu penso na possibilidade de me cortar acidentalmente. (V)

27- A visão de sangue seco é repulsivo. (V) (F)

28- Sangue e sangue coagulado não me perturbam mais que a média das pessoas. (V)

29- A visão de uma ferida aberta me deixa nauseado. (V)

(F)

30- Eu nunca poderia limpar uma ferida. (V)

(F) 